\title{
Enhancing Collaboration in Design Groups: \\ Lessons from Music Improvisation towards Product Innovation
}

by

Lucas Lacerda

A thesis submitted to

the Faculty of Graduate and Postdoctoral Affairs

in partial fulfillment of the requirements for the degree of

Master of Design

in

Industrial Design

Carleton University

Ottawa, Ontario

(C) 2012, Lucas Lacerda 
Library and Archives

Canada

Published Heritage

Branch

395 Wellington Street

Ottawa ON K1A ON4

Canada
Bibliothèque et

Archives Canada

Direction du

Patrimoine de l'édition

395 , rue Wellington

Ottawa ON K1A ON4

Canada
Your file Votre référence

ISBN: 978-0-494-87843-9

Our file Notre référence

ISBN: $978-0-494-87843-9$

\section{NOTICE:}

The author has granted a nonexclusive license allowing Library and Archives Canada to reproduce, publish, archive, preserve, conserve, communicate to the public by telecommunication or on the Internet, loan, distrbute and sell theses worldwide, for commercial or noncommercial purposes, in microform, paper, electronic and/or any other formats.

The author retains copyright ownership and moral rights in this thesis. Neither the thesis nor substantial extracts from it may be printed or otherwise reproduced without the author's permission.
AVIS:

L'auteur a accordé une licence non exclusive permettant à la Bibliothèque et Archives Canada de reproduire, publier, archiver, sauvegarder, conserver, transmettre au public par télécommunication ou par l'Internet, prêter, distribuer et vendre des thèses partout dans le monde, à des fins commerciales ou autres, sur support microforme, papier, électronique et/ou autres formats.

L'auteur conserve la propriété du droit d'auteur et des droits moraux qui protege cette thèse. $\mathrm{Ni}$ la thèse ni des extraits substantiels de celle-ci ne doivent être imprimés ou autrement reproduits sans son autorisation.
In compliance with the Canadian Privacy Act some supporting forms may have been removed from this thesis.

While these forms may be included in the document page count, their removal does not represent any loss of content from the thesis.
Conformément à la loi canadienne sur la protection de la vie privée, quelques formulaires secondaires ont été enlevés de cette thèse.

Bien que ces formulaires aient inclus dans la pagination, il n'y aura aucun contenu manquant. 


\begin{abstract}
In turbulent and uncertain environments within design groups, conflict represents one of the most prominent threats to collaborative work towards innovation. In attempting to tackle the persisting trouble of friction in team collaboration, researchers and practitioners turn their attention to the phenomenon of improvisation extensively performed by jazz musicians. The fascination with music comes from the fact that improvisers keep an intricate and serendipitous process of high creativity and inventiveness. This research considers music improvisation a real paradigm of group effectiveness and regards design as a spontaneous and serendipitous activity. In this context, this interdisciplinary study investigates an ensemble of musicians performing music extemporaneously and three design teams creating design solutions. The groups are put under scrutiny with the same improvisational criteria. It is found that verbal communication, task definition, and validation are crucial aspects in improvised performance in the management of conflict towards effective collaboration and innovation.
\end{abstract}

Keywords: music improvisation, conflict, innovation, design groups, collaboration. 


\section{ACKNOWLEDGMENTS}

Design and music had already been merged before in different situations in my academic and professional life. However, I had never faced the challenge of exploring such intense topic as improvisation. It is a passionate subject that I intend to keep on exploring.

For that reason, I would like to express my immense gratitude to my advisor Professor WonJoon Chung for the vision in making this thesis project possible and for the long and productive conversations in his office. I appreciate his availability and his eagerness for this study as well as the opportunity to experience a cross-cultural journey in South Korea.

I would also like to thank my co-advisor Professor Jesse Stewart, who lent me his improvisational expertise to find inspiration and explore different research possibilities. I thank him for having believed in this project and helped me to develop research in such an original theme for the design field.

I would like to especially thank my school and life partner Maria Gabriela Sanches for embarking with me on that journey and supporting me in every step during this process. Thanks for being my greatest inspiration. I also thank my family for the visits, the vacations back home, and all the support to achieve a high level of commitment.

I send a big thanks to my Master's friends for the good moments inside and outside school, and my fellows at Rostov Metro for the good jamming times.

Finally, I would like to thank my dear Professors Lorenzo Imbesi and Lois Frankel for sharing their knowledge and kindness during this entire journey, and show my gratitude to graduate administrator Valerie Daley for her cheerful humour, helpfulness, and musicianship. 


\section{TABLE OF CONTENTS}

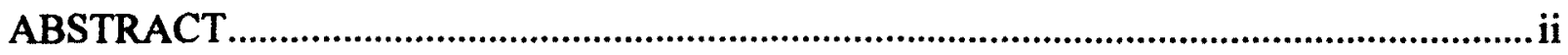

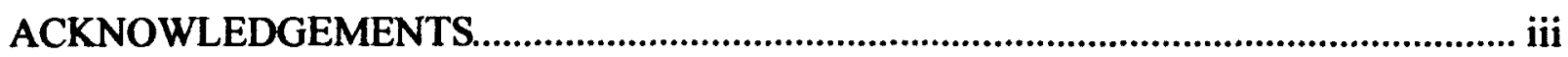

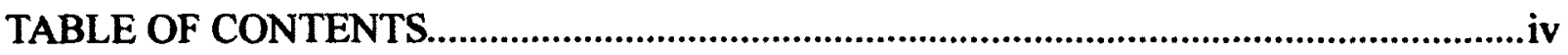

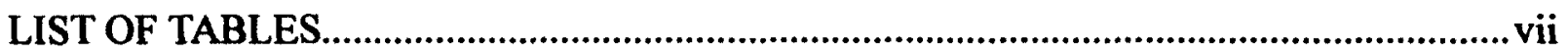

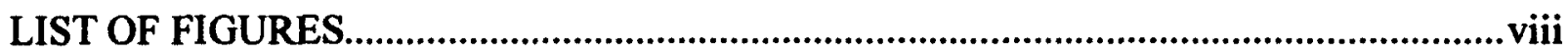

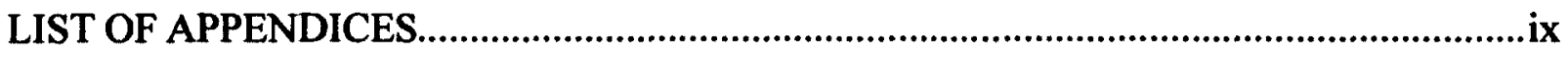

CHAPTER 1

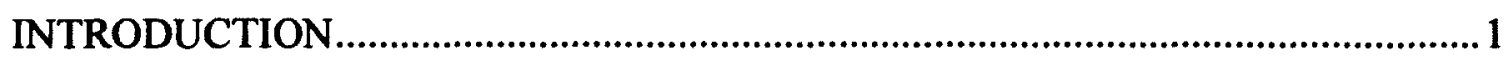

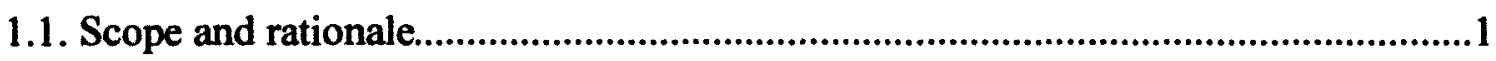

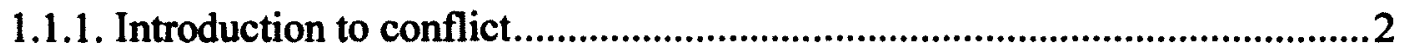

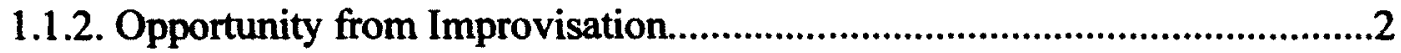

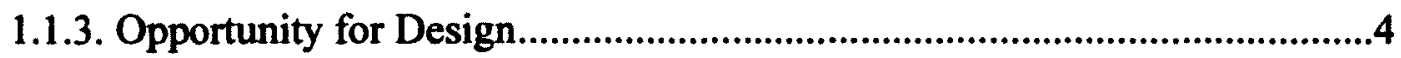

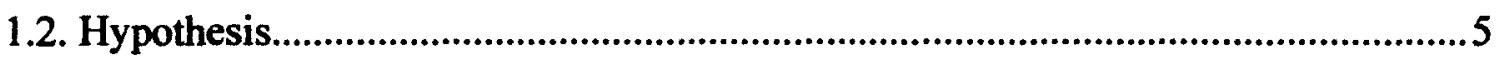

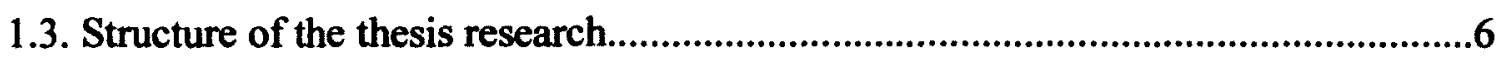

CHAPTER $2+8$

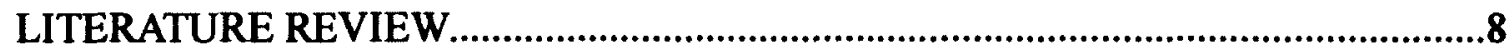

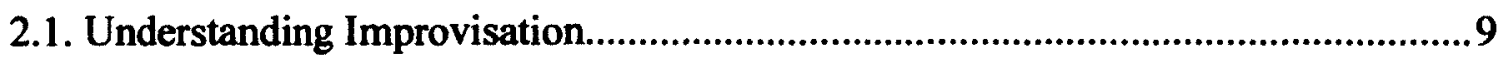

2.2. Improvisation and its collective aspects.................................................13

2.2.1. Music improvisation as conversation.............................................. 15

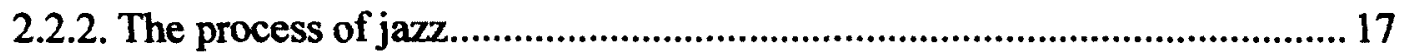

2.2.3. Jazz, collaboration and the emergence of conflictual events...................21 
2.2.4. Group effectiveness and types of conflict................................................... 26

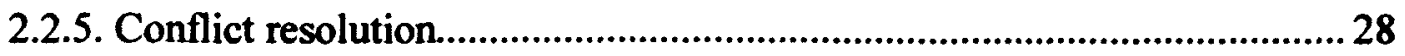

2.2.6. The "rules" of conduct in improvisation...................................................33

2.3. Improvisation in Collaborative Design Process........................................................41

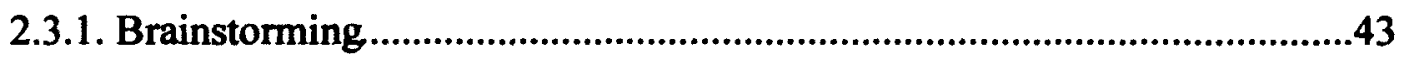

2.3.2. Collaborative design prototyping, sketching, and storytelling................... 46

2.4. Reflections on the Literature Review...............................................................53

CHAPTER 3

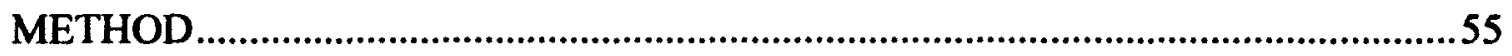

3.1. Setting and Participants..........................................................................................56

3.2. Procedure

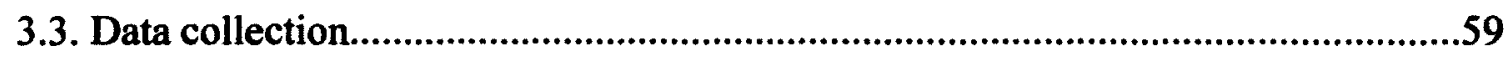

3.3.1. Interview with musicians................................................................................61

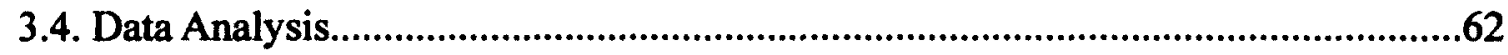

3.4.1. Emergence of conflictual events..............................................................63

3.4.2. Use of collaborative components..................................................................64

3.4.3. Alternation of roles......................................................................................6

3.4.4. Process of evaluation....................................................................................66

CHAPTER 4 _ 68

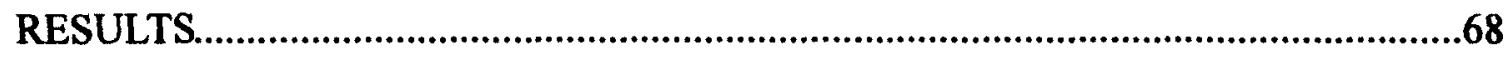

4.1. Observation of the musical ensemble........................................................................68

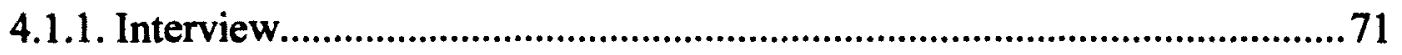

4.2. Observation of the design teams............................................................................ 72

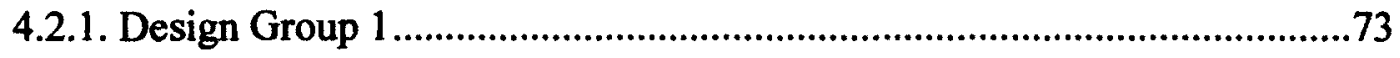




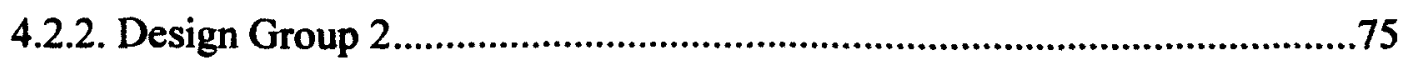

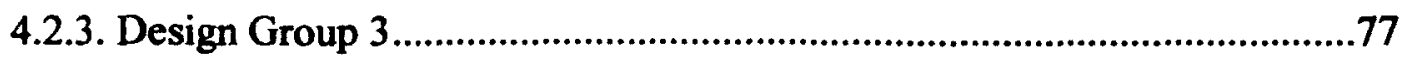

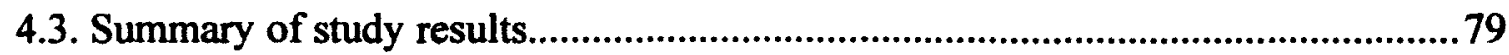

CHAPTER $5+81$

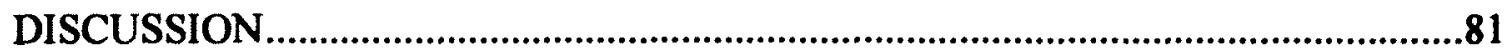

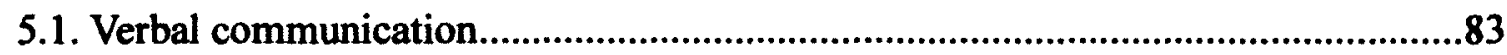

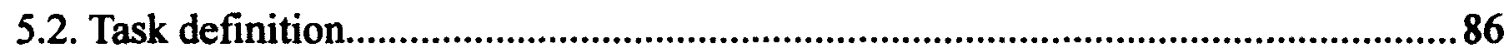

5.3. Validation of individual performance.......................................................88

5.4. Summary of research discussion..........................................................92

CHAPTER 6

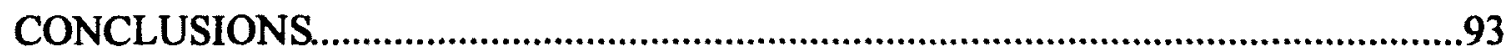

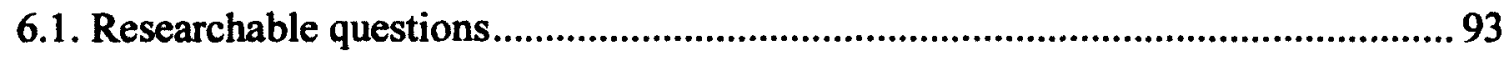

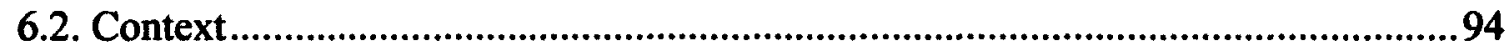

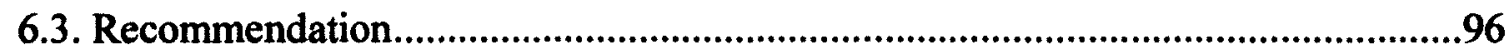

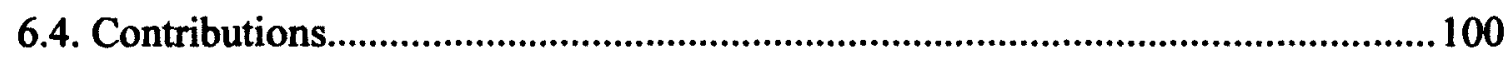

6.5. Direction for further studies............................................................... 100

BIBLIOGRAPHY 102

GLOSSARY _ 107

APPENDICES 109 


\section{LIST OF TABLES}

Tables

1. Groups distribution scheme.

2. Example of interview questions related to the research criteria. 62

3. Example of conflictual events in group performance. 63

4. Collaborative components in music and design practices...................................... 65

5. Following and leading behaviours in music and design sessions...............................66

6. Process of evaluation in music and design groups................................................67

7. Results for the musical ensemble observation...................................................69

8. Interview answers according to the improvisational criteria................................. 71

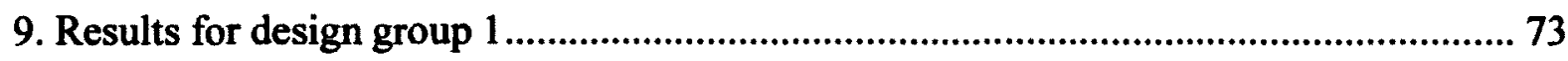

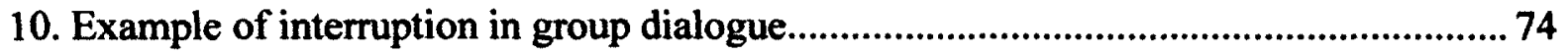

11. Example of tension and frustration in group dialogue.......................................... 74

12. Example of confirmation in the dialogue between members.....................................75

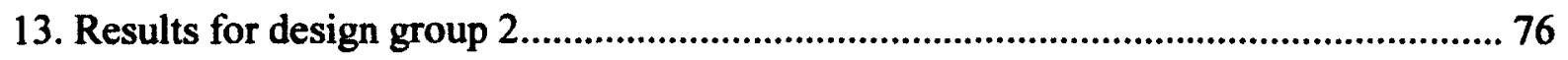

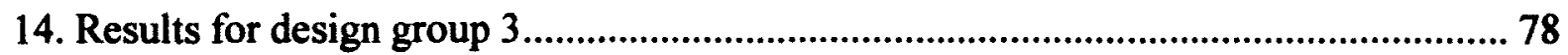

15. Example of stuck idea in group dialogue............................................................. 79

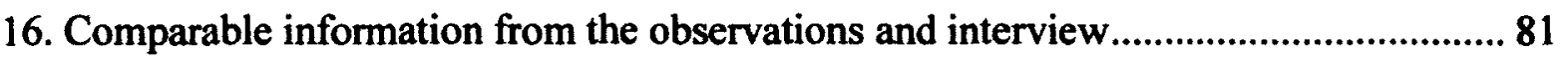




\section{LIST OF FIGURES}

Figures

Pages

1. Improvisation as the convergence of intuition and spontaneity ................................11

2. Lower and higher-level structures of improvisational performance............................. 19

3. The collaborative emergence frame in improvised dialogue..................................... 20

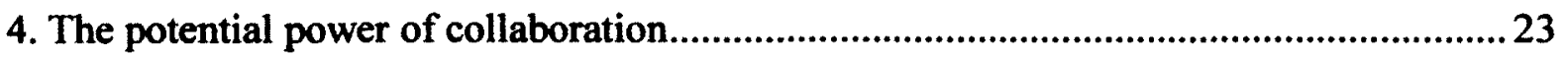

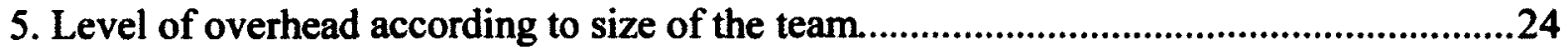

6. Design as a trajectory of goal-definitions..............................................................50

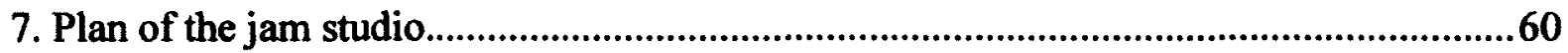

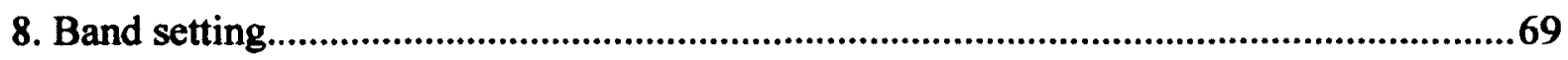

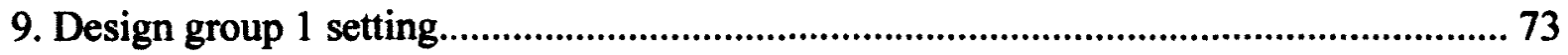

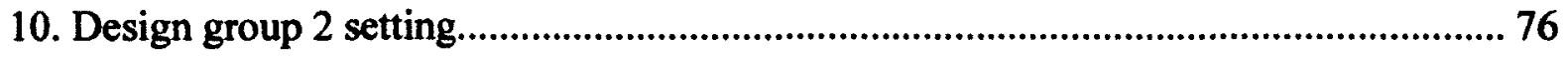

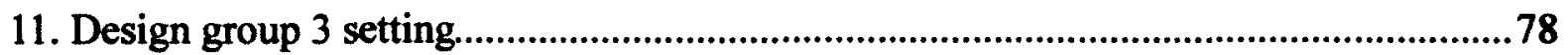

12. The communicative channel for verbalization in the design groups........................ 84

13. The communicative channels combined in the design groups..................................85

14. Instruments/roles/channels of communication in musical groups............................91 


\section{LIST OF APPENDICES}

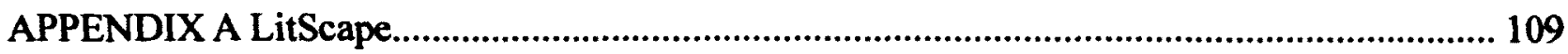

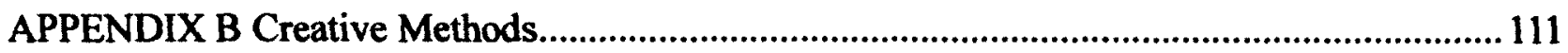

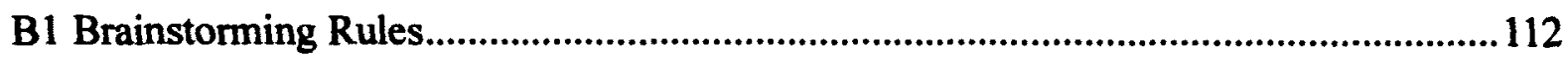

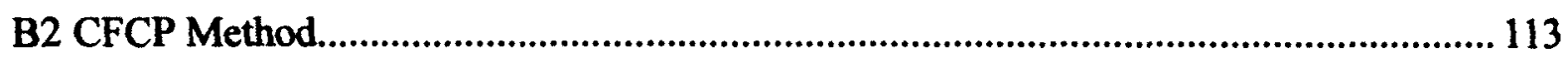

APPENDIX C Ethics documentation......................................................................................114

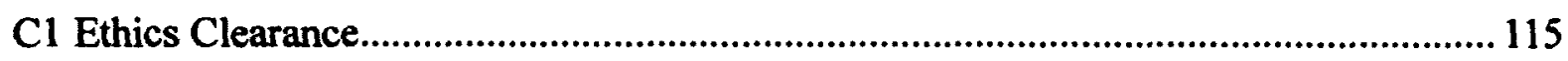

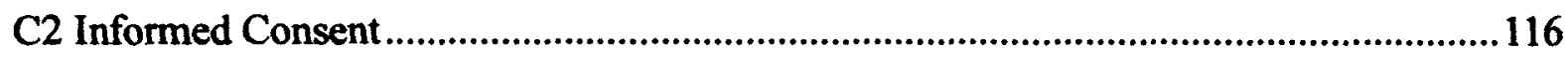

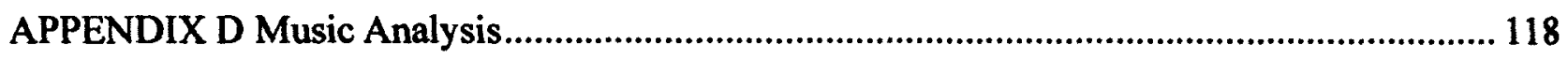

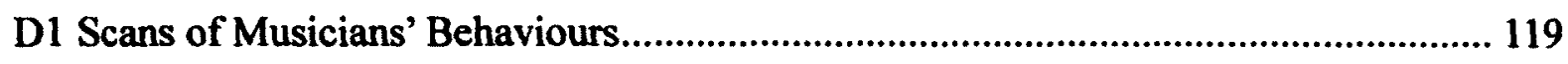

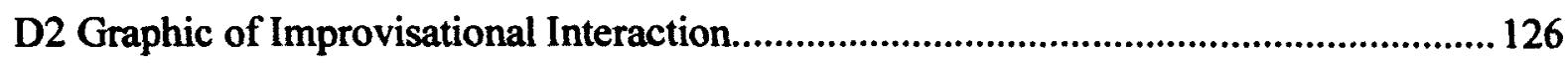

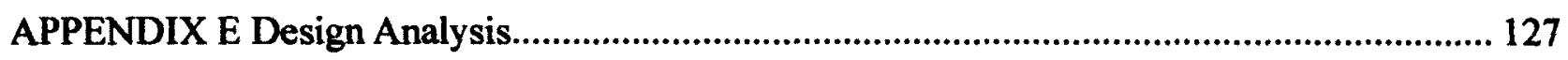

E1 Scans of Participants'Alternation of Roles..............................................................128 


\section{CHAPTER 1}

\section{INTRODUCTION}

The purpose of this study is to investigate the phenomenon of improvisation in collaborative design groups. Collaboration inputs clear advantages to tackle design challenges, yet conflict remains indefinite in creative settings where different backgrounds clash. As a result, this exploratory research aims to look into the practice of jazz improvisation as a model of effective group interaction towards innovation. Improvising musicians bring up the notion of spontaneous performance and serendipitous idea creation to collaborative work. Music improvisation is synergetic, creating a great opportunity to researchers, who seek solutions to the perennial problem of conflict in design teams.

\subsection{Scope and rationale}

The present-day frenetic search for innovation leads to the need for frequent, relentless and epidemic change (Brown \& Eisenhardt, 2002). However, transformation imposes challenging tasks for many organizations. Change can be risky and episodic (Brown \& Eisenhardt, 2002), hindering groups from excelling at their performance. In fact, organizational leaders often rely on rigid structures of labour that eventually stop smooth communication and foster individualistic activities. Nevertheless, innovation requires more flexible structures and collaborative endeavours. On the other hand, the employment of collaboration can trigger conflictual events in workgroups that may block creativity, minimize productivity, and clog the achievement of new ideas. 


\subsubsection{Introduction to conflict}

Conflict is inevitable in teams that follow a list of norms and activity frameworks. Many studies suggest that conflict can be either negative or positive depending on the way a task is performed. An activity based on strict routines is more likely to create animosities in workgroups whereas a flexible organization of labour confers an increasing synergetic environment among individuals (Jehn, 1995).

Improvisational interaction may promote group cohesion and behavioural integration in performance (Magni, Proserpioa, Hoegl \& Provera, 2008). As a social phenomenon, improvisation holds the concept of communitas by carrying a sense of unity between fellow performers (Fortier, 2008). In this scope, conflict is existent, yet it possesses a positive bearing that potentializes group creativity and innovation.

In this research, jazz improvisation serves as foundation for an exploratory method of collaborative creativity for design groups towards product innovation.

\subsubsection{Opportunity from Improvisation}

In order to decode collaborative issues of workgroups, organizational studies have recently turned their attention to different collective contexts of performing arts. Music has been an inspiration for numerous businesses seeking to improve their skills of leadership, teamwork, innovation, and communication (Cho, 2010; Hough, 2011). This recent tendency in organizations relies on the fact that musicians improvise. 
Improvisation is probably the oldest and most widespread mode of music making in the world (Bailey, 1980). Over the past century, improvisation has attained a particular high level of refinement and sophistication in the musical genre known as 'jazz.' Jazz musicians and audiences alike place great emphasis on improvisation. In many ways, successful jazz ensembles provide a model for effective collaboration towards inventiveness (Yudkin, 2008). As a matter of fact, a jazz band epitomizes the ideal type of collaborative organization (Weick, 2002). It is highly creative, spontaneous, committed, and innovative.

Improvisation and innovation are not the same thing, but jazz ensembles can achieve both. Adrian Cho, a Canadian musician and business scholar, claims that to innovate is to create something new or genuine, while improvising is to develop a solution to a problem with whatever time and resources are available (2010). In the same vein, creativity does not necessarily involve improvisation, unless there is a short time frame for finding novel solutions to an emergent need (Magni e al., 2008). The creative aspect of improvisation refers to the search for new and useful ideas in performing spontaneous behaviours (Magni et al., 2008).

In reality, every performance involves elements of improvisation. Improvising takes place in much of what we do on our day-to-day activities ranging from casual conversations to fairly important decisions that have a fundamental bearing on our very existence (Kamoche, Cunha \& Cunha, 2002). Improvisation can take place within a collective creative phenomenon, an individual skilled performance, within a rooted practice, or it can serve as a set of generative techniques (Santi \& Illetterati, 2010). In any organizational context, musical or otherwise, improvisation involves spontaneous and creative behaviours in response to unexpected events and emergent issues (Magni et al. 2008). Consequently, improvisation is particularly useful in 
collaborative projects which do not rely on the application of routines, and require flexibility and extemporaneous reactions (Moorman \& Miner, 2002; Kamoche \& Cunha, 2001).

This research aims to build a metaphor between musical ensembles and design groups in improvised situations. Using jazz as a model of improvisation, the study looks for creating opportunities to the design practice, methods and tools.

\subsubsection{Opportunity for Design}

The implications of an improvisational approach to the design field might bring positive outcomes leveraging designers as real performers in the creation of new product solutions. Sports, military, and information technology have benefited from the study of improvisation (Cho, 2010; Gladwell, 2005). Likewise, some researchers envision a patent contribution to the design of new products, which is also unpredictable, creative and spontaneous.

Today, design practice is in transition from a traditional approach to emerging disciplines concerning the usage and experience of products and services (Sanders \& Stappers, 2008). The traditional design disciplines focus on the 'designing of products,' while the emerging design disciplines focus on 'designing for a purpose' (Sanders \& Stappers, 2008). For instance, graphic design, web design, and product design become design for experiencing, for emotion, and for transforming. This new approach requires that designers collaborate or co-design using new creative tools for ideation. Collaboration poses a fresh opportunity for the utilization of methods and techniques such as brainstorming, sketches and prototypes. However, co-design may prompt unexpected occurrences among collaborators, when different backgrounds overlap and 
conflicting opinions emerge in interaction. It is then quite opportune to investigate a way to optimize interactive friction in workgroups towards high productivity and innovation.

This study proposes a careful look into creative design environments where groups, besides bolstering a certain degree of improvisational performance, present both positive and negative friction in interaction. The intention is to provide an initial view of the phenomenon of improvisation in design groups.

\subsection{Hypothesis}

The core problem in organizational groups is that there is a centrality in individual and collective outcomes, such as innovation effectiveness, whilst less prominence has been placed on team interaction processes that may affect individual performance (Magni et al., 2008). Improvisation regards the process as the product retaining performers' attention in the ongoing procedure of creativity rather than focusing on future results.

In order to address the latent conflictual issues that design ensembles face, researchers and practitioners should look at the ongoing practice of those in the development of new solutions. Design as a creative and innovative activity holds a high level of spontaneity and serendipity within its practice. In this scope, design is improvisational, especially considering its fuzzy front end phase (Sanders \& Stappers, 2008), where individuals participate in a rather turbulent and unpredictable performance.

This research offers an investigation of how musicians improvise, the characteristics that have made improvisation so attractive to collaborative studies, and how musicians perform in tune rather than in conflict. Considering that conflictual events can become a major obstacle 
preventing innovative work, why have organizations increasingly adopted a collaborative work, and why do they claim that improvising jazz ensembles hold the formula for effective collaboration? In this sense, how can improvisational practice manage conflict within collaborative design teams in idea generation processes? It is vital to assess how conflict emerges in design performance, what kinds of individual behaviours take place in improvisational interaction, and specify how collaboration is built within group improvisation. Since conflict is inherent in any collaborative work, both design and musical groups are scrutinized in this research considering their collective aspects.

Taking jazz ensembles as a paradigm of collaborative work, this study attempts to (1) present a detailed review of literary works concerning the phenomenon of improvisation, the perils and benefits of collaboration, and improvised creativity in design teams, and (2) provide a set of criteria to measure improvisational performance in musical ensembles and design teams according to the emergence of conflictual events, use of collaborative components, alternation of individual roles, and process of evaluation of ideas. These four criteria are rooted aspects of collaboration and improvisation.

\subsection{Structure of the thesis research}

This study is divided in six chapters dedicated to the exploration of improvisation in both music and design improvisational practices.

This chapter introduced the opportunities in improvisational studies and their contribution to the design field towards effective collaboration and rapid innovation. The second chapter is devoted to a literature review regarding improvisation, jazz process, collaboration studies, and 
the evidences of improvisation within design practices. In this chapter, jazz improvisation is distilled to its essentials in a way to unveil musicians' set of rules for interaction that are claimed to be a paradigm of collaborative and innovative work.

The third chapter examines, through an exploratory method, the intricacies of both music and design performances when individuals are improvising ideas for songs and products. A musical ensemble and three groups of master of design students are put under scrutiny in a detailed process of observation and interview. The method was performed according to a set of criteria based on the emergence of conflictual events, the use of collaborative environment components, the alternation of individual roles, and continuous process of evaluation in group performance.

Chapter four presents the results of the data collection and analysis. From a video recording, several issues are assessed concerning the criteria proposed in the previous chapter. Chapter five aims to develop a detailed discussion of the findings showed in the fourth chapter. The intention is to make connections that can lead to new insights, which might boost collaboration, optimize group friction, and provide a framework to improvising design groups.

The last chapter provides a conclusion with some general thoughts about the research including connections between the literature review, the results and the discussion chapters. Also, this chapter presents opportunities for future research in improvisational design groups. 


\section{CHAPTER 2}

\section{LITERATURE REVIEW}

As a music genre, a cultural discourse or an organizational process, jazz foregrounds improvisational practice notorious in complex and collective environments. In this chapter, jazz practice is analyzed to reveal the dynamics of musicians who play songs and deal with various conflicting situations.

The literature review is then divided in three main sections in order to cover the key aspects proposed in this research. First, improvisation is conceptualized according to its main characteristics. Second, the collective aspects of improvisation are displayed by exploring the jazz process, musicians' interplay, collaboration, conflict resolution and the rules and behaviours of group improvisation. Finally, improvisation is explored in creative design practices such as brainstorming, storytelling, sketching and prototyping. There are some important manifestations of an improvisational approach in the design field, which strives for unceasing innovation and more flexible frameworks (Danzico, 2010a).

Jazz, collaboration, conflict, and design are interrelated by some aspects of improvisation. As this research focuses on both improvisation and collaboration, Chapter 2 offers a review of group interaction by discussing important aspects in the literature. Because improvisation and conflict are notions connected with several issues in group interaction, the current analysis also covers general concepts related to collaboration and creativity. The concepts here presented disclose a set of criteria for a study in Chapter 3 involving musical ensembles and design groups in improvisatory interaction. 


\subsection{Understanding Improvisation}

So "improvisation" is one of those words of which we can say that everyone who knows what it means knows what it means, but no one who uses it can define it in a way that will satisfy even the definer, and certainly not the rest of the interested community.

(Faulkner \& Becker, 2009:28)

It seems that improvisation is too evanescent to be enshrined by a definition, too vast to be captured by a description, too unpredictable to be clarified by explanation. At the same time, when speaking of improvisation, we appear to be dealing with something whose features, examples and roles are well known as they appear in the different fields of life-experience.

(Santi \& Illetterati, 2010:1)

Improvisus. This is the Latin word for 'not seen ahead of time' (Barrett, 2002; Akgün \& Lynn, 2002). By its very evanescent nature, as Barry Kernfeld once claimed, improvisation is one of the least amenable subjects to historical research (Faulkner \& Becker, 2009). Even though too complex to define, many experts agree that improvisation is the convergence of performance and composition (Bailey, 1980; Bastien \& Hostager, 2002; Barrett, 2002; Moorman \& Miner, 2002; Magni et al., 2008). It can also be referred to as "responding to unforseen challenges" (Blum, 1998) in performing arts, "thinking in the midst of action" in education, occurring when "acts of composing and performing are inseparable" in communication, "reading and reacting in parallel" in sports psychology, "real-time composition" and "making decisions affecting the composition of music during its performance" in music, and representing "no split between design and production" in organizational studies (Moorman \& Miner, 2002). Improvisation entails exploring, continual experimenting, tinkering with possibilities without knowing where one's queries will lead or how action will unfold (Akgün \& Lynn, 2002; Barrett, 2002). 
Performing and composing simultaneously involves practitioners making very sophisticated decisions on the spur of the moment, without the benefit of any kind of script or plot (Gladwell, 2005). Improvisation is therefore a retrospective method rather than a blueprint method (Gioia, 1988). Blueprint method is associated with a planned action, scripted activities, and highly structured organization. It is a top down process in which a performer first creates and structures, and then acts according to the plan. In contrast, a retrospective method does not predict future outcomes so that it is not previously planned. It focuses on the ongoing process of action being structured as the performer goes.

Improvisation is indeed a structure, which is tied to the notions of process and event (Dean, 1992). Within this structure, freedom and constraint are in accurate balance. As loose as improv can be, its very constraints liberate participants (Danzico, 2010a). As representatives of freedom, (a) serendipity, (b) intuition and (c) spontaneity are factors chiefly responsible for the success of improvisation (Coker, 1964; Danzico, 2010a).

a. Serendipity is a term coined in 1754 by English writer and politician Horace Wadpole, who derived the word from a fairy tale, "The Three Princes of Serendip" (Danzico, 2010b). Falling somewhere between accidental and sagacity, serendipity is synonymous with neither one nor the other, perhaps closest only to "chance encounters" with positive outcomes (Danzico, 2010b:16). In Serendip, the three princes were always making unpredictable discoveries of things they were not in quest of (Danzico, 2010b).

"Serendipity is often cited as a key factor in the success of the new" (Danzico, 2010b:16). New behaviours, new structures and new ideas are often products of chance encounters. 
b. Intuition involves the subconscious processing of ideas and rapid responses to a stimulus (Crossan \& Sorrenti, 2002). In Dane and Pratt (2007), several definitions of intuition are culled from works in psychology, philosophy, and management. Intuition is often referred to as a process of perceiving or sorting data, an outcome that one apprehends or recognizes, or a process and outcome at the same time (Dane \& Pratt, 2007). Intuition is largely examined at the individual-level and it is often related to spontaneous reactions (Crossan \& Sorrenti, 2002).

c. Spontaneity is an important value in improvisation (Lewis, 2004). According to Lewis (2004), spontaneity involves uniqueness in the activity being performed. In reality, spontaneous reactions permeate every activity, as does improvisation. According to Crossan and Sorrenti (2002), improvisation is "intuition guiding action in a spontaneous way" (pp. 27). In this context, improvisation is highly spontaneous and intuitive (Figure 1).

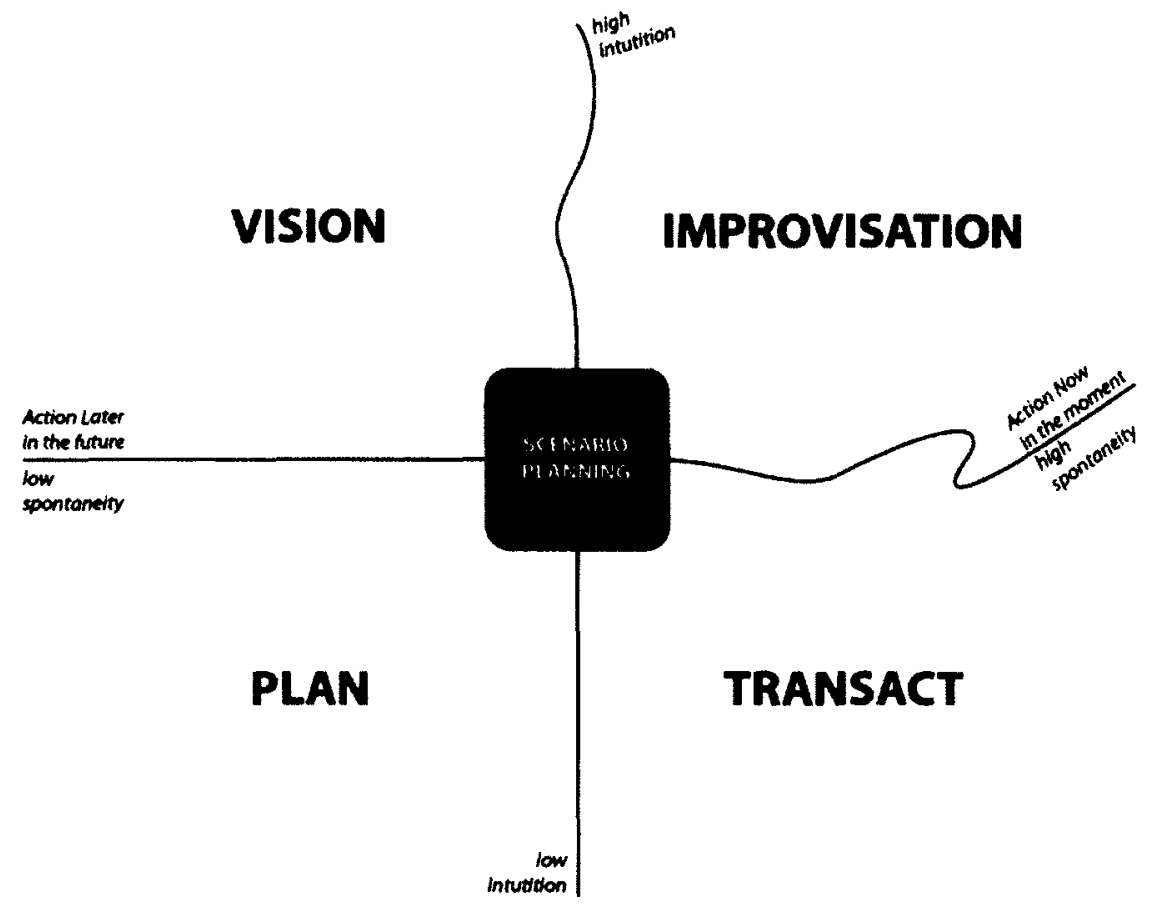

Figure 1. Improvisation as the convergence of intuition and spontaneity. 
However, serendipity, intuition and spontaneity are not entirely unplanned phenomena in improvisation. Danzico (2010b) suggests that serendipity can be a coordinate chance, which is somewhat planned in improvisation. Intuition is part of some improvisation, but improvisation can occur without using intuition, especially in collective situations (Crossan \& Sorrenti, 2002). Spontaneity and uniqueness are somewhat ad hoc, being rather constructed phenomena during improvisative action (Crossan \& Sorrenti, 2002; Gladwell, 2005). Improvisation is shaped by several constraints such as the environmental factors, audience responses (Danzico, 2010a), and people's life experiences (musical and otherwise), as well as personality including intellect, emotion and habit (Cocker, 1964; Miner, Bassof \& Moorman, 2010).

In other words, improvisation involves "responses commensurate to a situation" (Blum, 1998:28). Everything extant in the performance environment can influence the improvisatory process. Therefore, the relationship between performer and instruments/artefacts, and the performer and listeners is paramount in improvisation. The dynamics of performers/artefacts/ listeners constitutes the organization of improv practices.

In this case, design groups have much to learn from improvisation "that accents conversational energy and inventive flexibility, from art forms that disrupt orthodox standards of coherence, judgment, and value with a spirit of exploration and restless innovation" (Fischlin \& Heble, 2004:35). Improvisation includes acting from inner intelligence and/or impulse without premeditation from the whole field of available possibilities, as well as acting with [a particular] vocabulary within more prescribed forms (Oliveros, 2004:50). In this scenario, serendipity, 
intuition and spontaneity are, to a certain degree, coordinated and "based on [a] distilled experience" (Crossan \& Sorrenti, 2002:28).

This research aims to investigate group improvisation. Collective situations impose different interrelations that shape performance. The improvisational conversation among performers and audiences may create unexpected scenarios including conflicting actions. In this sense, how do musicians balance freedom and constraint in their performance in a way to achieve effective group outcomes? How do they organize their improvisation towards maximum creativity and assertive innovation? How do musicians develop their process of performing and composing at the same time in collaboration, coordinating unexpectedness and dealing with conflict? In the next section, a review of the collective aspects of improvisation is introduced.

\subsection{Improvisation and its collective aspects}

Blum (1998) claims that the practice of improvisation is an innate social interactive phenomenon, in which place, time, and people are involved and influential. Improvisation is a process of give and take constituting a conversational process in which performers contribute with different vocabularies (Berliner, 1994).

Even though improvisation has had a significant socio-cultural impact, its practice has received little recognition (Bailey, 1980). For many years, improv practices had been considered a vulgar habit within Western music, and were largely ignored by dominant discourses surrounding cultural production (Bailey, 1980). With the advent of new technologies in the late $19^{\text {th }}$ century, notably phonographic recording and playback technologies, improvisation started to 
become more popular in the music industry (Gioia, 1988). The improvisatory music that came to be known as 'jazz' was among the earliest beneficiaries of the new technology.

Gioia (1988) stresses that improvisation is as essential as it is problematic to jazz. As an art form, improv jazz has become a second-rate movement with particular aesthetics. Aesthetics, in principle, focus our attention on those attributes of a work of art which reveal the craftsmanship and careful planning of the artist (Gioia, 1988). Form, symmetry, and balance are elements of the artistic methodology that are related to jazz improvisation (Gioia, 1988). Jazz improvisation speaks a language and involves a high degree of communication (Bailey, 1980). The musician works in the vernacular and translates experience at a particular node in a network of cultural relations (Soules, 2004). This node "marks both a particular instance of local expression - the vernacular - and a point with no fixed address, something of a cultural universe ruled by archetypes and protocols" (Soules, 2004:277).

In the next sub-sections, many collective aspects of jazz improvisation are examined in order to understand the collaborative model of improvising music and how jazz musicians cope with conflict. First, the conversational aspect of improvisation is explored. Second, the jazz process is analyzed considering musicians' interrelation. Following is an investigation of collaboration in jazz and non-jazz organizations in an attempt to highlight the specific ways that groups manage personal friction and collaborate within performance. And finally, the behaviour of musicians in improvisation is investigated displaying the main "rules" of improvisational interaction. 


\subsubsection{Music improvisation as conversation}

Musicians often use the metaphor of conversation to describe improvisation (Monson, 1996). In interviews with musicians, Ingrid Monson compiled several materials in which music and language are considered inseparable aspects of improv practices (1996). "Jazz as a musical language, improvisation as musical conversation, and good improvisation as talking or 'saying something"' (Monson, 1996:73) are some of the descriptions musicians attribute to jazz interaction. Berliner (1994) suggests that the language of jazz is learned in much the same way that children learn to speak by imitating older speakers. Music improvisation in addition is learned from several influential and conventional streams (Sawyer, 2003b).

In light of these thoughts, ethnomusicologist Aaron Berkowitz likens the process of learning to improvise to that of learning a second language (Martinez, 2010). "It's all about memorizing vocabulary words, useful phrases and verb conjugation tables," he says. Musicians, for instance, learn the structure of the blues; "they learn basic chords and get the form down, but they're still very limited in what they can do" in the beginning (Martinez, 2010).

Berkowitz suggests that musicians, when in the initial learning phase, must think about how to put the next note in the song they are playing and how it relates to the chordal structure. It is just like a student who is watching a foreign movie and, in order to understand the sense of the scene, he needs to first understand the verb in the right tense. An important part of most students' learning process is the imitation of accomplished improvisers (Martinez, 2010). Robert Levin, a classical pianist, recalls that improvisation is a long process of apprenticeship and memory acquisition. By obtaining experience and knowledge, a musician achieves fluency. Eventually, improvising musicians are able to play without thinking about each note in a 
conscious, left-brained way. The human brain begins exerting control at a higher level, directing bigger chunks of information that can be expressed as whole ideas (Martinez, 2010).

Studies performed by Berkowitz and fellow scientists reveal that when musicians improvise, certain regions in the brain shut down and others are very active. Interestingly, the region in constant activity is the one responsible for self-expression and autobiography. One area of the brain that tends to dim is the area that governs self-consciousness and inhibition (Martinez, 2010). Within musical idioms such as jazz that involve highly codified sets of rules governing musical syntax, successful improvisation is generally only possible through practice. If one does not possess enough experience, the improvised action will not be as successful since the musician will not have enough vocabulary to communicate properly.

At this level of musical cognition, the improviser often achieves a seamless trade-off between his conscious and subconscious knowledge. He knows he's creating the music and feels very much in control, yet he also feels as if he's watching himself play, a paradox that Berkowitz calls the creator/witness phenomenon. "They'll be playing and something happens that they didn't quite expect," Berkowitz said. "Then they react to that and it kind of starts this dialogue where the improviser is steering the ship, but is also being steered by the ship."

(Martinez, 2010:3)

In jazz improvisation, new musical ideas are invented, adopted, and implemented through rules for musical grammar, much as our everyday discourse is generated through grammatical conversational rules (Bastien \& Hostager, 2002; Sawyer, 2003b). A song constitutes a cognitive rule itself holding much of what is necessary for a musician to properly play. Time signature, chords and chordal progressions, phrasing, chorus length, and levels of embellishment are musical details performed by musicians functioning as a sort of backup when they improvise. These musical structures dictate most of what an expert musician should know and do when playing along with an ensemble, as well as the communicative codes and behavioural norms required to shape the performance (Bastien \& Hostager, 2002). 
The conversational process of jazz provides a clear understanding of improvisation as a sort of negotiation. Musicians learn to speak a language as they grow up by acquiring experience, skills, and repertoire (Faulkner \& Becker, 2009; Monson, 1996). The repertoire represents the musician's vocabulary, including a diverse library of artist albums and written scores in the form of "lead sheets." This repertory serves the improviser's practice. The more vocabulary a musician has, the more successful his/her musical statements are going to be.

\subsubsection{The process of jazz}

Successful group improvisation is a negotiation between performers (Barrett, 2002). Conversation - the exchange of musical vocabulary - is how jazz musicians develop their improvisational process (Berliner, 2004). When jazz musicians perform, they create a unique style of music while confronting an equally unique set of challenges (Cho, 2010:6). Besides delivering a ready product, they continuously create that product in the moment (Cho, 2010).

Jazz as we tend to look at it is a style, but I feel that jazz is not so much a style as a process of making music. It's the process of making one minute's music in one minute's time, whereas when you compose, you can make one minute's music and take three months to compose one minute's music.

(Bill Evans, cited in Cho, 2010:6-7)

Hodson (2007:20) suggests that "improvising musicians engage in a dynamic, interactive process of deciding what to play, playing it, hearing what the other musicians are playing, and adapting what they play to take into account the other musicians' improvisations." In the dynamic process of jazz improvisation, "anything played by any member of the ensemble can potentially have an effect on any other member of the ensemble, increasing the range of possibilities for potential interactions" Hodson (2007:22). On that note, improvising can be an 
infinite practice considering its influential power in collective environments (Bailey, 1980; Berliner, 1994).

According to Sawyer (1997), the social exchange of musical structures in improvisation proceeds from lower structural levels to higher ones. In some systems, complex and differentiated higher-level structures emerge from the organization and interaction of simpler, lower-level component parts (Sawyer, 2003a). "The music progresses from 'simple' to complex'...from collective improvisation to solo improvisation" (Monson, 1996:133). Within this "collaborative structure" (Figure 2), musical instruments, amplifiers, and acoustics are part of lower-level components. They are the mediums played and manipulated by musicians, who create new sounds, define and modify the musical conversation using harmony, chordal phrases, sequence of notes, which are the complex components from the higher-level structures. 


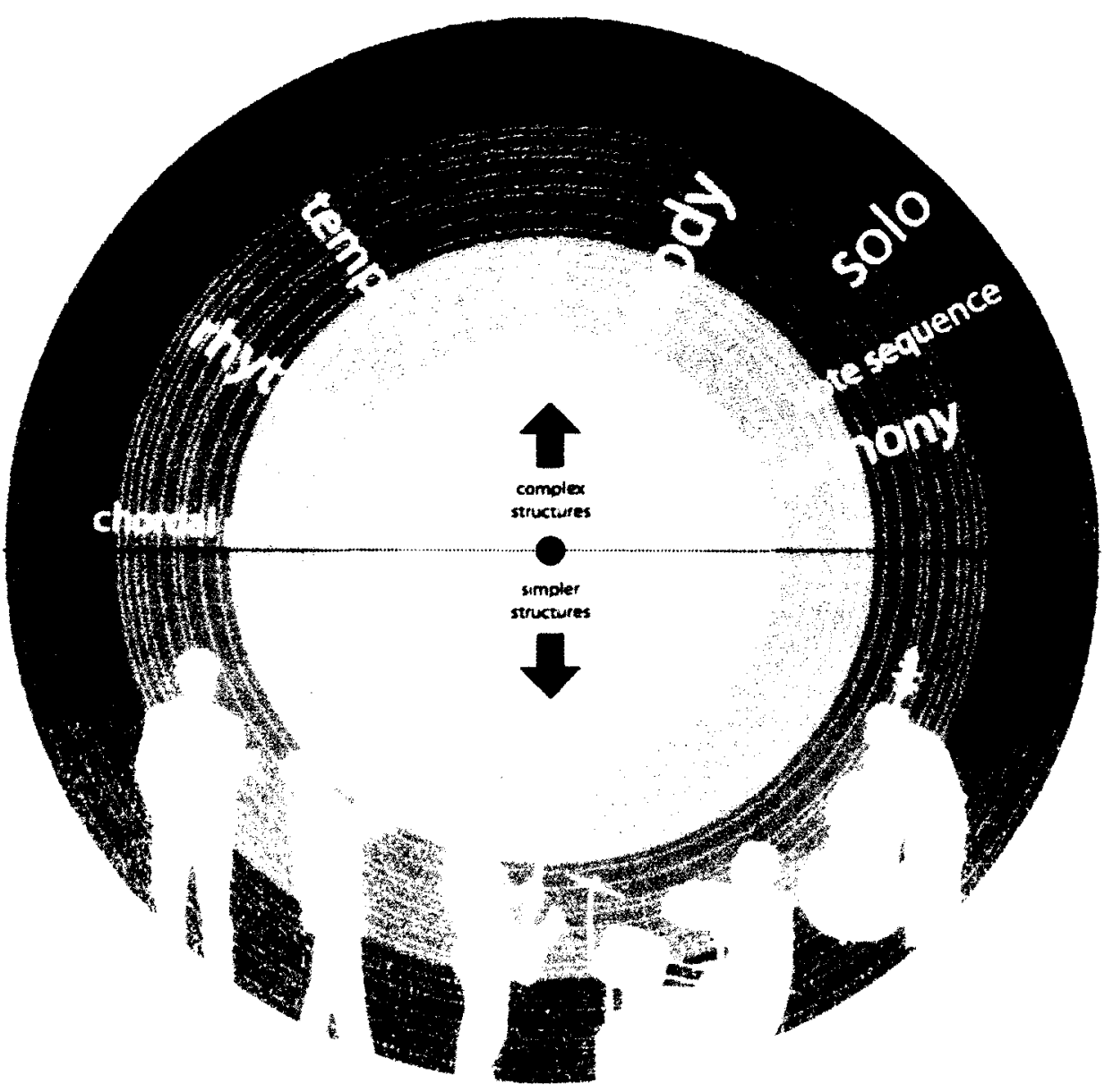

Figure 2. Lower and higher-level structures of improvisational performance.

Improvisation for the master drummer...lies not so much in the genesis of new rhythms as in the organization and form given to the already existing rhythms, and a musician's style of organizing his playing will indicate the way he approaches from his own mind the responsibility of his role toward making the occasion a success.

(John Miller Chernoff, quoted in Soules, 2004:276)

Focusing on idea generation, Sawyer (1997) argues that a collaborative emergence frame (Figure 3) is created collectively rather than individually in social interaction. Participants are constrained to operate within the genre of play (Sawyer, 1997). They are expected to contribute something in order to conserve the continuous play. 


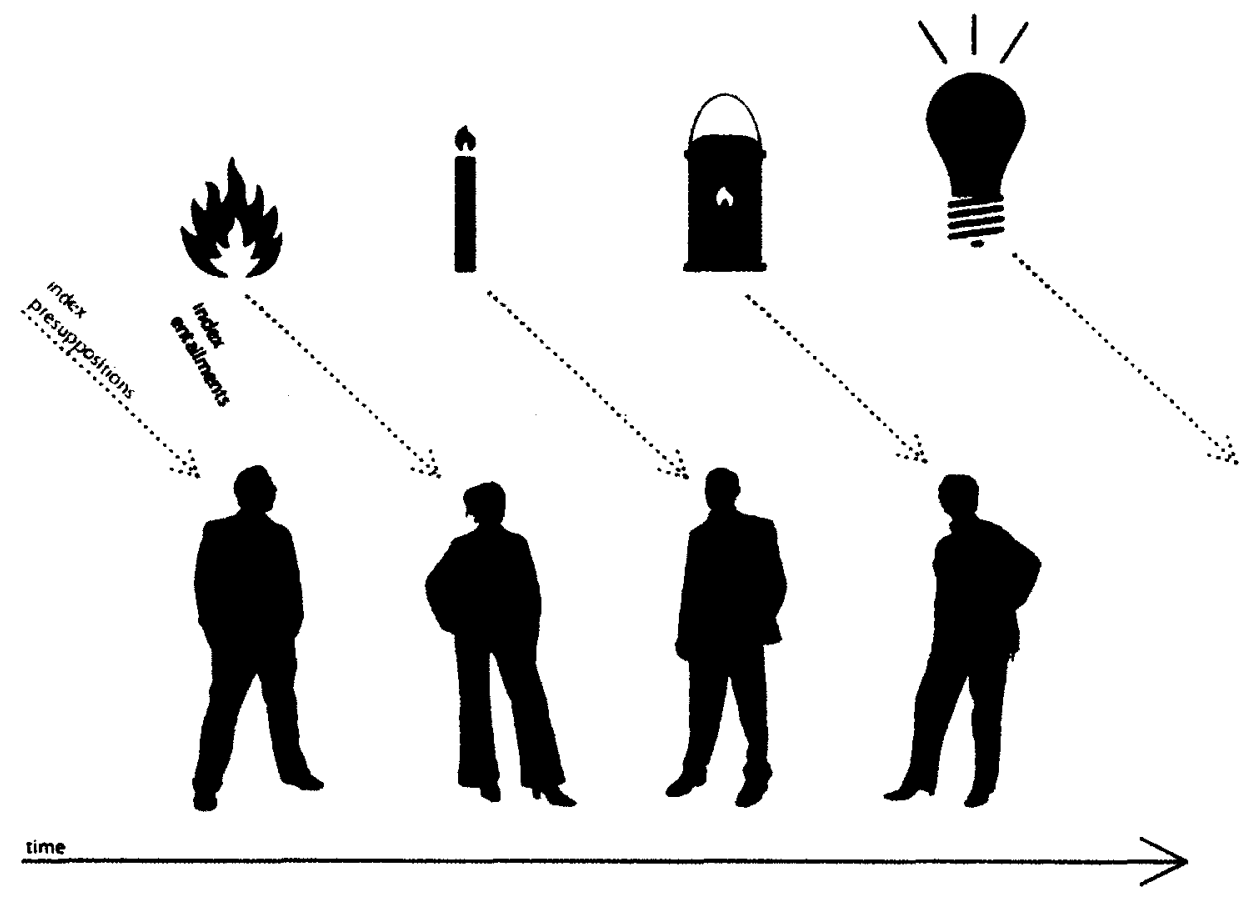

Figure 3. The collaborative emergence frame in improvised dialogue (Sawyer, 1997).

The emergent represents ephemeral inputs that are transformed into social entities as the group refines ideas through a process of indexical entailment (Sawyer, 1997). In indexical entailment, for instance, a musician creates a musical phrase, keeping a certain rhythm according to a specific genre. The other performers interpret this influential emergent idea through a process of indexical presupposition, in which improvisers build a conventional sequence of action (Sawyer, 1997). In this case, musicians interpret and evaluate one idea before building a new one.

According to Monson (1996), the jazz process progresses in some inexorable way from simpler and crude ideas to more complex and refined ones. Musicians start playing eclectic 
musical forms that are transformed into clearly bounded structures. The logic of the collaborative frame constrains the unpredictable aspect of improvisation. Jazz musicians negotiate musical ideas through a careful process of elaboration and refinement. So, how does it relate to conflict in organizational groups? According to Berliner (1994), Magni et al. (2008), and Coutu (2009) the organizational principles of improvisation have provided jazz musicians with the capacity to deal with conflict. Next, a careful look at the collaborative and conflictual aspects of jazz and organizational groups attempts to unveil what makes jazz improvisation so effective in collaborative environments.

\subsubsection{Jazz, collaboration and the emergence of conflictual events}

Today you build different teams. Sounds beautiful. Yet nobody has really found a way to do it.

(Schwartz \& Kelley, 1996)

There are many different ways to create the conditions for effectiveness, sustain them, and help teams take full advantage of them. The best team leaders are like jazz players, improvising constantly as they go along.

(J. Richard Hackman, quoted in Coutu, 2009:103)

In 1959, Miles Davis assembled a group of musicians in a studio in Manhattan for a recording session that came to be recognized as one of the most successful jazz albums in music history (Yudkin, 2008). Kind of Blue was the result of a single-day of collaboration between the musicians (Danzico, 2010a). Considering that some of them had never met before, Davis' Kind of Blue is all the more remarkable in the history of jazz, improvisation and effective collaboration.

Collaboration, the act of working together, is very valuable in today's economy (Cho, 2010). Being a team player has become almost a sacrosanct trend (Coutu, 2009). However, there is considerable controversy in collaboration studies around the necessity of having workgroups 
tackle project problems (Coutu, 2009). On one hand, collaboration is powerful, and highly beneficial to a work process (Sawyer, 2007). On the other hand, it can be disastrous, leading to the emergence of conflictual events and a lack of productivity (Coutu, 2009).

In theory, if an individual with ten ideas teams up with a second person with ten ideas, the interaction of those ideas can produce a hundred ideas (Figure 4). That's the potential power of collaboration in jazz ensembles, which is combinatory and exponential (Sawyer, 2007). According to Sawyer (2007), if four musicians are put in different rooms to play the same song without listening to each other, the recording that would result if we put each of the separate tracks together will sound horrible. However, if the same group of musicians are put together in the same room, they will excel because they will all be able to listen to one another and respond accordingly, putting the collective sound of the group before their own individual contributions. 


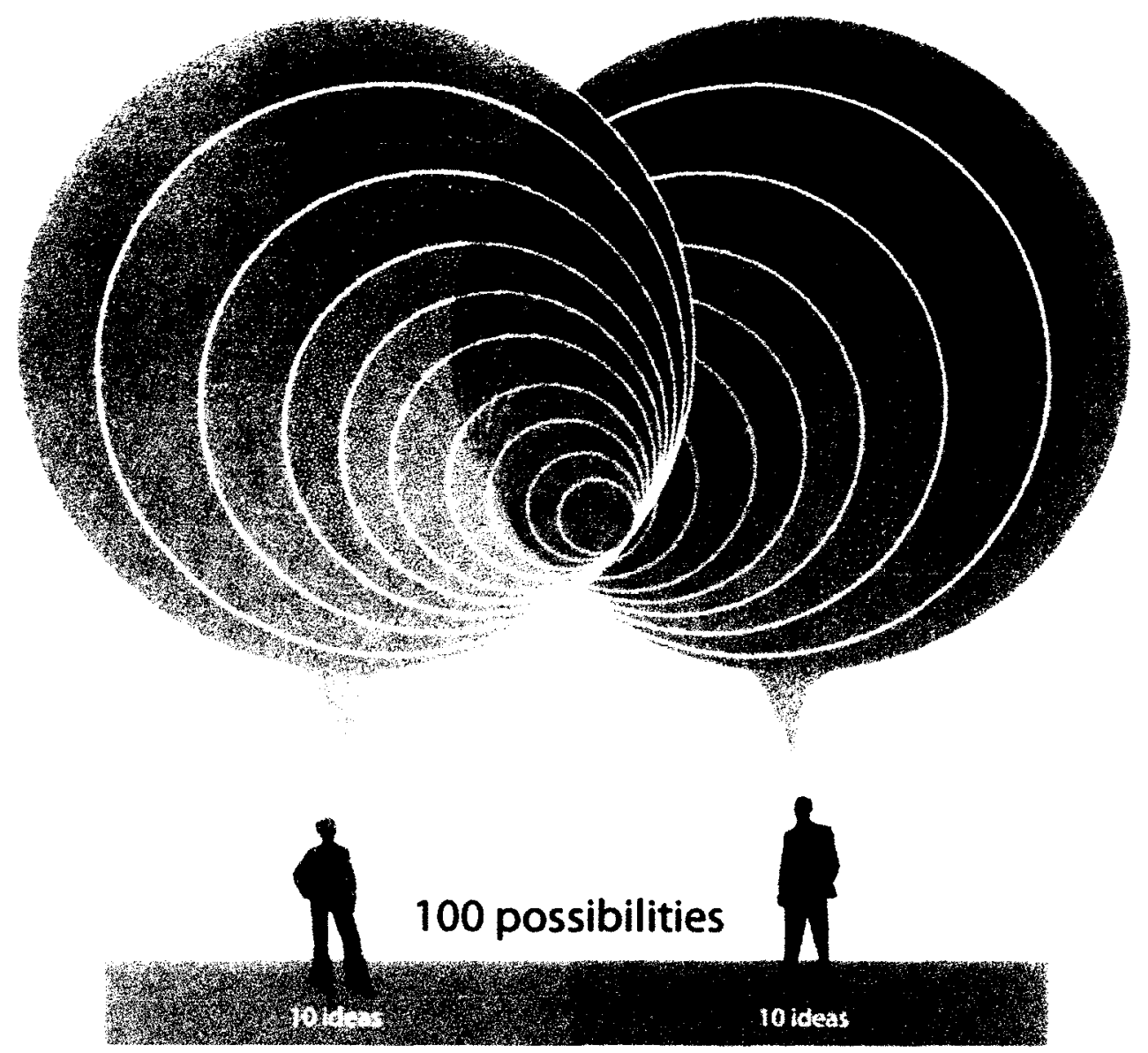

Figure 4. The potential power of collaboration (Sawyer, 1997)

Many people think that collaboration is a requirement for success. However, according to Hansen (2009) and Sawyer (2007), this is not always the case as only few groups benefit from its real power. Research consistently shows that teams often underperform their full potential (Coutu, 2009). In creative teams, such as design groups, idea generation is often better performed individually. Sawyer (2007) suggests that work team performance might be additive rather than exponential. In this case, two individuals with ten ideas each will produce no more than twenty ideas together. 
According to Cho (2010), collaborative efforts involve overhead that results in less work than is expected being produced (Figure 5). The interaction of individuals in a team environment can create problems including conflicts between group members (Cross, 1995). So what makes jazz ensembles proficient in collaboration and why do many organizational teams have difficulties in collective endeavours?

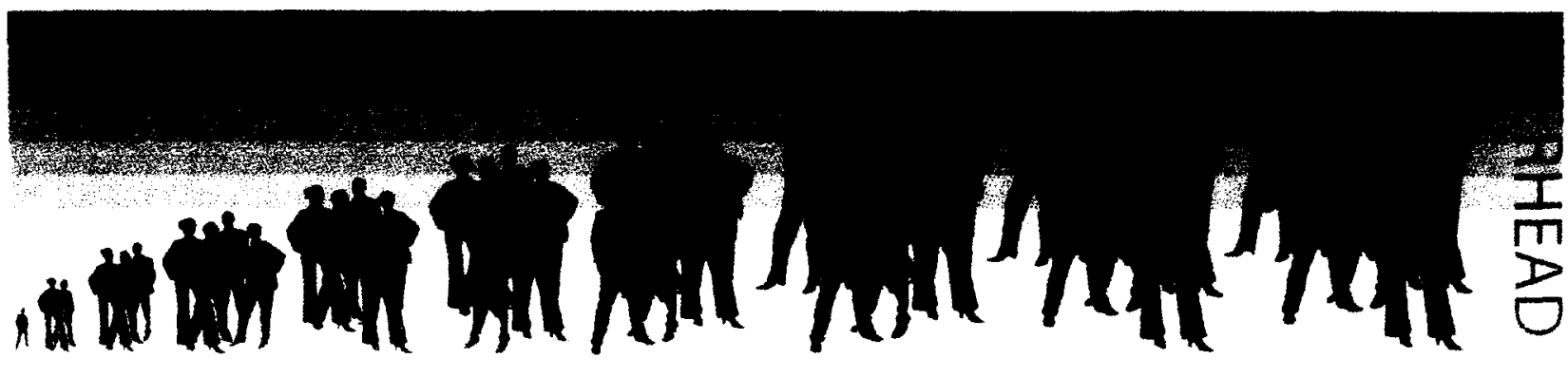

SIZE OF THE TEAM

Figure 5 Level of overhead according to size of the team (Cho, 2010)

In new product development, for instance, the design process includes professionals from various streams constituting a mix of disciplines, organizations and cultures since the creation of new products requires differentiated specialists to tackle project puzzles (Sonnenwald, 1996). In this interdisciplinary milieu, conflict often arises and design participants need to know how to integrate and manage differences. Communication becomes a significant issue in this process given the fact that different professionals come to the group with different pre-existent behaviours and disciplinary vocabularies. Yet conflict in teams seems not to be only associated with the difference of opinions and personality. Hackman claims that effective collaboration does not mean group homogeneity (Coutu, 2009). Homogenous teams can stifle creativity and learning in organizational groups. 
Similar to interdisciplinary groups, jazz ensembles also deal with different personalities (Berliner, 1994). Jazz musicians often experience conflicting situations with fellow musicians on and off stage, including clash of egos, intense discussions, and some serious confrontations. For instance, young musicians have been known to get in the way of more experienced musicians, who may have wanted the "new guys" to perform according to a certain routine. Standing against this authoritarian regimen was a common reaction in jazz bands, which sometimes, depending on the flexibility of the leader, created an interesting dissonance (Berliner, 1994).

Dissonance is probably the best term to describe this music style as a cultural discourse and a social phenomenon. When Jelly Roll Morton declared the creation of jazz in 1902, musicians threw away their written scores and started to spontaneously play songs (Gioia, 1988). This historical rebellion marked the struggle of African-Americans against the dominant European class in the United States at that time (Heble, 2000). Jazz is a representation of a community endeavour to achieve an identity (Heble, 2000). Duke Ellington, commenting on the condition of African Americans, once turned to his piano and played a dissonant chord. "That's the Negro's life. (...) That's us. Dissonance is our way of life in America. We are something apart, yet an integral part" (Heble, 2000).

Friction enables jazz improvisation. According to Berliner (1994), jazz groups often include musicians with opposing tastes and incompatible skills. This a propitious scenario for conflict, but it can also create interesting interactions if friction is well balanced in performance. In design teams, a similar set of circumstances permeates participants' activity. Besides the unpredictability of outcomes, different skills and personalities are put together, just like in jazz 
ensembles. It is imperative to understand how to govern the different kinds of dissonance in collaborative design groups towards effectiveness.

\subsubsection{Group effectiveness and types of conflict}

In many organizations, there is the illusion of group effectiveness (Sawyer, 2007).

Managers, as Hackman suggests, sometimes think that groups always help individuals to perform better (Coutu, 2009). However, groups are not necessarily productive (Sawyer, 2007). In 1972, Irving Janis coined the term "groupthink" to describe common situations where teams of smart people end up creating dumber ideas than they would have created if they had worked on their own (Sawyer, 2007). Groupthink is dangerous because it runs the risk of abandoning individual creativity and critical thinking (Cho, 2010). Hackman (Coutu, 2009) and Cho (2010) agree that when group cohesiveness is too high and people are getting along, the group begins to share too much tacit knowledge, which can inhibit the potential for what can be thought of as positive conflict in groups.

In organizations, conflict can be classified in two main streams: relationship and taskoriented conflict (Jehn, 1995). Relationship conflict is often associated with negative friction, which slows down group productivity and efficiency (Jehn \& Mannix, 2001; De Dreu \& Weingart, 2003). Task-oriented conflict constrains the group towards performance rather than interpersonal issues enhancing positive reactions among individuals (Jehn \& Mannix, 2001).

Jehn (1995) maintains that disagreements, confrontation and frustration can be among the main types of negative conflict within groups. Yet what would be the positive conflicts in group interaction? In different studies with design teams, Cross and Cross (1995) raise important 
queries around the participants' behaviour during idea generation. In the dialogues analyzed, besides showing frustration and disagreements, participants also displayed positive reactions such as laughing and affirmative statements (Cross \& Cross, 1995). Cross and Cross (1995) add that design groups can benefit from specific analysis of individual behaviour, which bears different reactions, verbal or non-verbal, that might affect group performance.

In studies performed with one hundred and fifty groups, Jehn (1995) found that negative conflict is normally connected to organizational routines, whereas positive conflicts are more likely to happen when groups perform according to flexible frameworks, similar to organizational dynamics within jazz ensembles. In jazz, for instance, rhythmic tension is generated by off-beat rhythms that are often performed by the drummer. Sometimes, the syncopation might be highly complex, making it difficult for even accomplished musicians to follow (Cho, 2010). Still, positive conflict generates negotiation and conversation.

Berliner (1994) relates jazz performance to a cyclical process of conflict resolution. Once negativity arises in interaction, experienced jazz musicians find a way to contour the situation and take advantage of awkward moments. Improvisation within jazz can be a democratic process (Berliner, 1994). Although this is not always the case in jazz ensembles, individual improvisers within a jazz ensemble generally have a voice in determining the collective direction of the group. In the following sub-section, conflict resolution is investigated in jazz ensembles and organizational groups. 


\subsubsection{Conflict resolution}

Researchers have been striving to find ways to reduce friction with so-called "social lubrication" (Cho, 2010), which involves relaxing the tone of business meetings in the hopes of avoiding any confrontation during the process. Morris, Nadler, Kurtzberg \& Thompson. (2002) list some of these social lubricants:

1. Background conversation or "schmoozing" about personal or unrelated issues to "break the ice" at the beginning of a negotiation or to relieve tension during a negotiation;

2. Responsive expression to create a feedback loop that compensates for the difficulty of conveying non-verbal nuances;

3. Explicit statements that affirm the value of the relationship;

4. Clarification to avoid and repair misunderstandings;

5. Apologizing for or accepting blame for a mistake;

6. Acknowledging facts;

7. Making substantial change that demonstrates a willingness to immediately address a problem;

8. Giving credit where it is due;

9. Downplaying mistakes others make.

Theoretically, this etiquette of group organization creates harmony and helps to avoid friction. Nonetheless, Havard's J. Richard Hackman, a specialist in organizational teams, states that even harmonious groups can fail to produce successful outcomes (Coutu, 2009). Many think that teams in which the individuals get along will be the best and most productive ones. Yet, studies have shown the opposite. Sometimes conflict can be productive. It provides challenging situations that nourish the creative process.

In the same vein, jazz musicians do not try to avoid friction. Instead, they often work around the optimization of conflictual events (Cho, 2010) such as dissonance, melodic chromaticism and rhythm syncopation. Musicians manage musical friction by striving to find a balance between consonant and dissonant elements, creating enough tension to maintain musical interest and creativity, but not so much tension that the music becomes unlistenable. Listening to 
music with too much tension can be tedious. On the other hand, if there is too little tension, the music lacks interest.

What's interesting about friction is that although it generally creates difficulties when present in large quantities, eliminating it entirely can create a whole different set of problems. (...) If there's too little friction, an action can fall into a mode of hunting, which can cause delays or damage to an activity. As it turns out, friction is a necessary evil. Too much friction is bad, but too little is also a problem.

(Cho, 2010:192).

Magni et al. (2008) claim that improvisation is emergent and efficient when team members exchange information openly and fluidly. Groups lose control when they lack integration and do not present good cohesion in performing tasks. "Put the team first" is one of the commandments of team management in an endeavour to teach individuals selflessness (Cho, 2010). Once again, a useful parallel can be drawn with the way that jazz musicians build their performance. They are aware of what is going on in the performance and act towards the group accomplishments (Barrett, 2002).

Band leaders as Miles Davis, Charlie Parker, Thelonious Monk, and Art Blakey used to know who they hired and what each musician was capable of (Berliner, 1994). In jazz, there is a sense of community as if it was an educational system for musicians. Jamming becomes much more than just playing; it turns into a common place where musicians share their experiences and learn from different and more experienced improvisers how to behave, and deal with different situations on the stage (Berliner, 1994).

In fact, jazz musicians collaborate radically - their level of trust and the intensity of their work are far above and beyond normal teamwork (Hough, 2011). Building trust is a distinguished characteristic in improv troupes, but a rare behaviour in non-performing arts activities (Cho, 2010). Musicians must trust in their co-performers' abilities, especially when they take risks (Monson, 1996). Inventiveness and efficacy in this sense are products of a 
trustworthy environment achieved by a synergetic interrelation between individuals (Hough, 2011).

According to Cho (2010), overhead decreases and productivity increases when synergy is established by the group. "Synergy is a natural outcome when each member of these teams plays to his or her strengths and successfully combines talents with those of the other ensemble members" (Cho, 2010:4). Synergy occurs when the combined efforts of individuals can be collectively higher than the individual contributions of the members in a group (Cho, 2010).

In order to keep individuals in sync, it is important to limit the number of members in a group. There is considerable evidence to suggest that teams consisting of more than seven or eight people struggle to maintain a productive workflow and the chances of negative conflict go up considerably (Cho, 2010). One of the main reasons for this is that large groups spend too much time listening to others' thoughts. Group members are more prone to be distracted with the flurry of ideas around them, which leaves individual members with little mental energy to provide new ideas (Sawyer, 2007). Interestingly, most modern jazz ensembles keep their groups as a quintet or sextet.

As a collective approach to the process of innovation, jazz specifies a turbulent task environment for individual musicians, a complex field for interaction in which individuals are simultaneously required to invent new musical ideas and to adapt their playing to that of the collectivity. Turbulence in this environment not only results from the dynamic process of individual invention; turbulence also arises from the dynamic process of coordinating invention. Moreover, these dynamic processes are not independent of one another. The invention of musical ideas affects and is affected by the adoption and implementation of musical ideas. The inherent musician cannot fully predict the behaviour of the other musicians or, for that matter, the behaviour of the collectivity.

(Cho, 2010)

Synergy in small jazz ensembles is recognizable when musicians "jam". They extemporaneously gather with the purpose of improvising together (Sawyer, 2003b). Requiring 
creativity and extreme concentration, jamming is how jazz musicians organize their improvisational practice (Sawyer, 2003b).

Jam sessions include more than just a rational process of negotiation between musicians, as previously displayed in the collaborative emergence frame. In improvisatory interaction, jazz musicians enter a zone where they often create (a) fantasia (Blum, 1998) and establish (b) the groove (Barrett, 2002). Whereas one is related to a transcendental aspect of individual actions, the other stands for the optimal moment in the group improvisation.

a. Fantasia recalls the elusive aspect of jazz improvisation. Improvisers excel by fantasizing worlds out of nowhere (Sawyer, 1997). The fantastic characteristic of improvisation regards jazz as a spiritual process, free of reign involving a mix of feelings, and empowerment of musicians' capabilities (Sawyer, 2003b; Barrett, 2002).

For instance, musician Steve Lacey said:

It is something to do with the "edge." Always being on the brink of the unknown and being prepared for the leap. And when you go out there you have all your years of preparation and all your sensibilities and your prepared means but it is a leap into the unknown.

(Bailey, 1980: 74)

Lacey expressed improvisation as a transcendental activity, a dramatic process.

Likewise, clarinetist Ken Peplowski pronounced:

When we play at our best, I find many times that I'm not actually thinking about anything and you can actually have a strange experience of going outside of yourself and observing yourself while you're performing. It's very strange. And you can actually listen as you're playing and listen to the rest of the group and you can be completely objective and relaxed. And come to think of it, completely subjective also, because you are reacting to everything else around you.

(Barrett, 2002:150)

Peplowski recounts his jamming experience as an out of body experience to explain how musicians feel when they achieve an optimal level of performance and exceed their own expectations. 
b. The Groove or feeling is the optimal level in improvisation, which represents one of the main goals of any improvising jazz ensemble (Barrett, 2002, Monson, 1996). The groove is "something that unites the improvisational roles...into a satisfying musical whole" (Monson, 1996:26).

When you get into that groove, you ride right on down that groove with no strain and no pain -you can't lay back or go forward. That's why they call it a groove. It's where the beat is, and we're always trying to find that.

(Drummer Charlie Persip, quoted in Berliner 1994:349)

Every musician wants to be locked in that groove where you can't escape the tempo. You're locked in so comfortably that there's no way you can break outside of it, and everyone's locked in there together. It doesn't happen to groups every single night, even though they may be swinging on every single tune. But at some point when the band is playing and everyone gets locked in together, it's special for the musicians and for the aware, conscientious listener. There are the magical moments, the best moments in jazz.

(Franklin Gordon, quoted in Berliner 1994:388)

The groove is the node that holds structural constraints and transcendental freedom in improvisation. In this simultaneous network of actions, improvisation is governed by rules, protocols or etiquette that shape, evolve and enable the fantastic, impulsive and spiritual process of improvising music.

The possibility of fantasizing and grooving, gives the musician the opportunity to acquire and show off his/her skills. As an expression of freedom (Berliner, 1994), jazz often relies on individual identity in search of authentic musical statements. The musician is limited in a zone of performance where fellow performers cannot predict what the others are playing. But at the same time, they need to keep the rhythm.

Thus, conflict resolution in collaborative environments is not just about avoiding friction or creating harmony among individuals. In order to resolve conflict, jazz musicians, for instance, often turn friction into positive musical outcomes. A diversified group can provide more opportunities for inventiveness than homogenous groups whose personalities are similar and 
non-frictional (Cho, 2010). For jazz leaders, dissonance drives the creative process of spontaneous music. "Among the factors that determine the outcome of [successful] negotiation are the individual's sense of artistic identity, and the values he or she attaches to collective improvisation as a form of social and musical interaction" (Berliner, 1994:417). In the social form of musical interaction, Hodson (2007) suggests that improvisation includes musical roles and behaviours which guide performance to its paragon.

\subsubsection{The "rules" of conduct in improvisation}

Many people relate improvisation to a chaotic, erratic and random phenomenon. On the contrary, improvisation is a true "art form governed by a series of rules towards specific goals" (Gladwell, 2005:113). Cho (2010) stresses that improvisation is a manifestation of a creative freedom; that is, too many rules might be dangerous when performance is improvisatory. Yet history tells us that the most successful jazz ensembles have always followed a particular set of codes, a protocol, and a system of musical logic (Barrett, 2002; Fischlin \& Heble, 2004). The "rules" do not limit the performance of a group, but rather provide a set of parameters through which improvisers articulate a sense of freedom and achieve something new.

Rules provide a framework for general understanding. Imagine a newcomer in a product development team. He/she would have to learn the way things work in the organization to be fully comfortable within the group. According to Cho (2010), improvisation teaches that the rules must be learned and they must be enough to provide both stability and the necessary freedom to allow for creative innovation. 
Four interdependent rules for interactive behaviours within improvisation can be summarized as: (a) alternation between leading and following roles (Barrett, 2002; Cho, 2010), (b) Johnstone's rule of agreement (Gladwell, 2005), (c) provocative competence (Barrett, 2002), and (d) embracing errors (Barrett, 2002). They are examined in this research in order to clarify the ways in which jazz musicians constrain and liberate their improvisational performance considering the emergence of conflictual aspects.

\section{a. Alternation between leading and following roles}

The alternation between leading and following roles constitutes one of the most widespread, yet overlooked, structures in jazz (Barrett, 2002). Cho (2010) defends that the alternation of roles in performance provides individual empowerment and group integration. Jazz bands take turns, soloing and supporting other soloists by providing rhythmic and harmonic background. Such an egalitarian model assures that each player will get an opportunity to develop a musical idea while others create space for this development to occur.

The dynamism of a jazz ensemble consists in balancing the constraining factors of the structural and syntactical aspects of the composition they are performing with the dynamic, inventive, and interactive processes that take place between the members of the ensemble (Hodson, 2007). According to Hodson (2007), there are several common interactions in jazz improvisation:

1. Call and response: musical dialogue between equals; 
2. Fills: a musician briefly emerges from the background of the performance to respond to the foreground soloist's improvisation;

3. Accenting the end of formal units: co-ordination between the soloist and rhythm section to mark structural boundaries;

4. Common motive: exact repetition of a phrase;

5. Responding to the peaks of the soloist: rhythm section's support of the overall level of intensity of a soloist improvisation.

According to Barrett (2002) and Cho (2010) leading behaviours in jazz improvisation can be related to soloing, disruption, and initiation. Whenever a musician initiates, solos, or disrupts a song, he or she is taking the lead of the performance.

On the other hand, a follower is the one who accepts, supports, accompanies, embraces, and sustains the performance for the leader. The role of accompaniment, or "comping" is a very active and influential one: it provides a framework which facilitates and constrains the soloist. In written arrangements, the scored passages often precede the soloist's improvisation and channel, sustain, and embellish it (Barrett, 2002).

In a sense the background accompaniment conditions the soloist, organizes the course of the solo through passing chords, leading tones and thythmic accents. It is not enough to be an individual virtuoso, one must also be able to surrender one's virtuosity and enable others to excel. In order to "comp" or accompany soloists effectively, jazz musicians need to be very good listeners. They need to interpret others' playing, anticipate likely future directions, make instantaneous decisions in regard to harmonic and hythmic progressions.

(Barrett, 2002:154)

Comping introduces a model of fellowship in jazz improvisation (Barrett, 2002; Cho, 2010). Taking place primarily in the rhythm section in most jazz ensembles, comping involves accompanying, supporting and complementing the front line roles, as soloing in particular (Monson, 1996; Hodson, 2007). 
Following roles provide harmonic and rhythmic support. According to Hodson (2007), the three instrumental roles of the rhythm section - bass, drums, and piano (or guitar) - cooperate and collaborate in defining harmony, keeping time (pulse and meter) and using non-regular rhythmic events.

Of course, following roles can contribute to melodic chromaticism, and leading roles can keep time and define rhythm. Still, the clear division of labour in jazz groups (even though this division is not absolute) "serves a useful purpose: it symbolizes the group aesthetic of jazz, an aesthetic that values...the sharing of responsibilities" (Hodson, 2007:26).

None of this responsiveness can happen unless players are receptive and taking in one anothers' gestures. If everyone tries to be a star and does not engage in supporting the evolution of the soloist's ideas, the result is bad jazz. When they listen well to others' soloing, they help the soloist reach new heights. Usually we think that great performances create attentive listeners. This notion suggests a reversal: attentive listening enables exceptional performance.

(Barrett, 2002:154)

Both roles - leading and following - are interdependent and when performed together create a friction in which musicians meet with error, interruptions, redundancy and repetition, absence and confrontation. Even so, taking turns in musical performance fosters a sense of community, a sense of collective investment in the music being created, thereby contributing to successful improvised dialogue. When one musical participant assumes a leadership role, he/she provides opportunities for other participants to play supporting roles. 


\section{b. The rule of agreement}

Playing with musicians is like a conversation. If when I speak, you say 'Yes,' or you look at me and blink your eyes or interject some comment of your own, that keeps me going.

(Bassist Chuck Israels, quoted in Sawyer, 2003b:)

Gladwell (2005) identifies Johnstone's "rule of agreement" as the main principle of improv theatre. This rule states that every offer made to the performance must be accepted by the group. In theatre, one actor might make a comment, to which a second will respond with an association between the comment and another topic, and then a third actor might link these issues to a third, inclusive topic (Moorman \& Miner, 2002). The excerpt below, taken from an improv theatre exchange between two actors, exemplifies this type of exchange (Gladwell, 2005).
A: Augh!
B: Whatever is it, man?
A: It's my leg, Doctor.
B: This looks nasty. I shall have to amputate.
A: It's the one you amputated last time, Doctor.
B: You mean you've got a pain in your wooden leg?
A: Yes, Doctor.
B: You know what this means?
A: Not woodworm, Doctor!
B: Yes. We'll have to remove it before it spreads to the rest of you.
(A's chair collapses.)
B: My God! It's spreading to the furniture.

In the example, the actors accepted all offers made. Breaking this rule might ruin the entire procedure of improvisation. Here is another example from the same performance, but now without the sense of agreement.
A: I'm having trouble with my leg.
B: I'm afraid I'll have to amputate.
A: You can't do that, Doctor.
B: Why not?
A: Because I'm rather attached to it.
B: (Losing Heart) Come on, man.
A: I've got this growth on my arm too, Doctor. 
Keith Johnstone, celebrated theatre director, claims that when actor A disagreed with B, the dialogue did not develop (Gladwell, 2005). Actor A turned down a suggestion made by B. B tried to back up with more inputs, but "you can't do that" in the dialogue blocked out the innovative element, which can be seen in the first extract, "My God! It's spreading to the furniture."

Even though, the rule of agreement is most commonly associated with improvisatory theatre, one may argue that it is a common practice in jazz improvisation as well. Musician Chuck Israels, in the epigraph at the outset of this section, recalls a scene that is familiar to many jazz practitioners. Performers need confirmation of what they are doing, and when someone initiates a performance, the others simply accept it to keep it going (Sawyer, 2007).

\section{c. Provocative Competence}

Provocative competence is an improvisative tactic, in which improvisers are forced to exceed their own abilities, to breakthrough in unexpected occasions, and interrupt habitual patterns in performance (Barrett, 2002). Even highly specialized musicians are tied to what they do well and might not expand their limits, something that happened in the second Johnstone's excerpt (and often happens in performance). Barrett (2002) refers to this as the "competency trap," yet good improvisers know how to come up with fresh solutions to musical provocations. 
The idea behind the provocation is to create incremental disruptions to the performance, bringing fresh material to the ongoing process. It represents deliberate efforts to interrupt habitual patterns. For instance, Miles Davis routinely performed provocative competence by demanding musicians to try new challenges (Barrett, 2002).

When we went in to do recording sessions for Kind of Blue, I brought in musical sketches. I did not write out the music because I wanted spontaneity.

(Davis, 1989)

When in a jazz band a drummer decides to double the tempo as a cue for change, the musicians are compelled to follow the drummer's lead. In this situation, a tension is created to push the group in a new direction. Disruptions are beneficial when musicians have sufficient experience and competency to respond to the provocation without relying on stock phrases or clichéd musical ideas (Barrett, 2002).

Musical provocation in improvisation is probably one of the most differentiated rules in performance. Although it can spark creativity, it can create too much tension. Disruptions interrupt the continuous process of jazz improvisation, but good jazz improvisers are able to respond in a way that enlivens the musical performance.

\section{d. Embracing Errors}

A significant issue in organizations is management of error (Barrett, 2002). Indeed, errors are an important source of learning. As individuals learn through error correction procedures, they come closer to the eventual goal of error-free performance (Barrett. 2002). Jazz bands see errors as inevitable and something to be assimilated and incorporated into the performance. Sometimes musicians misinterpret each others' cues or simply play the wrong notes. Jazz players are often able to turn these unexpected 
problems into musical opportunities. Although some critics and historians criticized Miles Davis' soloing technique, the trumpeter's missed notes, slips, and cracks in his performance actually represented a very unique way to play the instrument (Walser, 1993). Davis could use his flaws "to his advantage, building a style out of his weaknesses, forging his mistakes into a positive result" (Walser, 1993:344). ...a thoroughly original style built on the acknowledgment of technical limitations. (...) By the time of 'My Funny Valentine,' which contains one of the most notorious fluffs ever released, one got the feeling that his every crackle and splutter was to be embraced as evidence of his spontaneous soul.

(Gary Giddins's words about Miles Davis's style, cited in Walser, 1993:344)

Barrett (2002) adds that mistakes can be seeds for activating and arousing the imagination. Any event or sound, including an error, becomes a possible springboard to prime creativity, an opportunity to re-define the context so that what might have appeared initially to be an error becomes integrated into a new pattern of activity.

Musicians often take risks in search of that transcendental and grooving moment. If one musician misses a note the others can take over and fix it. This notion of accountability enforces the synergetic nature of improvising groups. There are great innovative cases, especially in jazz, in which musicians build new ideas from a fellow member by fixing the performance to the mistaken tone (Barrett, 2002). Improvisation, of course, so fundamental to the very idea of jazz, is nothing more than repetition and revision. In this sort of revision, again where meaning is fixed, it is the realignment of the signifier that is the signal trait of expressive genius.

(Henry Louis Gates Jr., cited in Soules, 2004:279).

The rules of improvisation - alternation of roles, rule of agreement, provocative competence, and embracing errors - function as behavioural codes in performance. They 
encourage the individual musician to perform at his or her highest level while not overwhelming his/her co-performers' playing. In improvisation, performance must be balanced considering individual freedom and the collaborative structure. In this case, conflict is negotiated through a sort of politics of improvisation following not only the rules of musical syntax, but also musical behaviour. Improvisation is a democratic process allowing individuals to have a voice in the negotiation of ideas.

Based on the organizational aspects of improvisation, how is design organized when participants face unexpected situations and spontaneous reactions in creative processes? If every performance is to a certain extent improvisational, what makes design ideation processes improvisatory? In the section that follows, I examine the ways that improvisation is connected to collaborative design process.

\subsection{Improvisation in Collaborative Design Process}

As in improvisatory jazz, design is often vaguely defined, but at the same time overly specified. Definitions of design vary according to different disciplines (Lawson, 1997). A graphic designer would say something different than a mechanical engineer, whose ideas would contrast with those of an architect and so forth. Many forms of design deal with both precise and vague ideas, calling for systematic and chaotic thinking, and requiring both imaginative thought and mechanical calculation (Lawson, 1997:4). Similar to improvisation and jazz, design thinking copes with various dichotomies. The binary that most designers grapple with lies between the notions of problem and solution (Lawson, 1997). 
Design thinking is an iterative process involving analysis of a problem, synthesis of ideas and evaluation of solutions (Lawson, 1997). Although the design process aims to create an "endproduct," Cross and Cross (1995) suggest that the investigation of planning and action in new product development is essential to understand how designers face unplanned and opportunistic activities. In this sense, Sanders and Stappers (2008) agree that the current transitional phase design is experiencing calls for more attention in the ongoing process of product/service creation.

That said, design thinking has been increasingly adopting a collaborative, interdisciplinary approach in recent years (Frankel \& Tsuji, 2005). Designers need to consider different perspectives seeing as their own viewpoints and methodologies might clash with those of other participants in the design process. In this view, several creative methods brainstorming, prototyping and sketching - have been adapted to facilitate negotiation within contemporary, design groups. And because designing includes a turbulent and unpredictable task, improvisation offers a fruitful approach to collaborative design groups towards product innovation (Danzico, 2010b).

In fact, there have been attempts to introduce improvisation into some creative design processes, which are inherently improvisational. Brainstorming, for instance, has been a method widely used by many successful companies (Sawyer, 2007). IDEO, an acclaimed American design company is not only one of the greatest proponents of the creative method in contemporary design, but also a pioneer in the use of 3D models, sketches and storytelling as real facilitators towards innovation (Brown, 2009). These three activities entail spontaneous individual and group accomplishments that are ripe for an improvisational design approach. 
This research intends to look into each of these mentioned design interactions. The plan is to examine connections between current design creativity approaches and improvisation when it comes to collaborative environments that are likely to result in conflictual issues within design ensembles. Collaborative design teams provide unprecedented problems such as the struggle to enhance collaboration when "designers work in conflict, rather than in concert" (Gerber, 2007:1070). Brainstorming, prototyping, sketching and storytelling are some of the design methods highlighted in this research as prominent improvisational undertakings.

As in jazz improvisation, the creative design methods - brainstorming, prototyping, sketching and storytelling - include conversational aspects among performers. In these activities, conversation - exchange or negotiation of ideas - creates a dialogical process that builds larger units of talk called "participant frameworks" (Monson, 1996). "Arguments, storytelling, instigating, and a gossip dispute process called 'he-said-she-said' are among the types of participant framework" (Monson, 1996:82). It is crucial then to investigate how negotiation in creative design methods lead to negative or positive reactions in groups when improvising design solutions.

\subsubsection{Brainstorming}

Brainstorming is a generative method of ideas still largely practised by many corporations. The term "brainstorming" was coined in the 1950s by Alex Osborn, a founding partner of the legendary advertising firm BBDO (Sawyer, 2007). In his book, says Sawyer, Osborn laid out the basic principles of a brainstorming session. First, no criticism: do not evaluate any ideas until you have finished generating them; second, "freewheeling" is welcomed: 
the wilder the idea, the better; third, quantity is the goal: the more ideas you think up, the more likely you are to find the best ideas; fourth, look for combinations of previous ideas, and for improvements on previous ideas.

IDEO has carried the banner of brainstorming more than any other company in the design industry in recent years (Sawyer, 2007). Brainstorming sessions last between forty-five minutes and one and a half hour, and have between three to ten participants (Kelley, 2001). IDEO has special conference rooms designed for brainstorming sessions; the brainstorming rules are displayed on signs around the room. Everyone gets butcher paper and pens. During the brainstorm, the facilitator enforces the rules and writes everyone's suggestions on the white board. Using a trained facilitator can be very helpful; research shows that groups led by a trained facilitator are twice as creative (Sawyer, 2007).

There's just one problem: brainstorming "can fail in at least as many ways it can succeed" (Gerber, 2009:97). For every success story like IDEO's, you can find another company for which brainstorming has failed to deliver on its potential (Sawyer, 2007). This isn't surprising to psychologists; decades of research have consistently shown that brainstorming groups proportionally think of far fewer ideas than the same number of people who work alone and later pool their ideas (Sawyer, 2007).

Although collective and creative, brainstorming has a very structured script to which it can be difficult for groups to adhere (Gerber, 2009). Elizabeth Gerber (2009) suggests that group brainstorming can be improved with theatre techniques, based on Keith Johnstone's principles of improvisation. She encourages students to create design solutions by building scenarios in which they would act according to a given problem/scene. She named this process "bodystorming" 
because it relies on the interaction between designers when translating observational data to a simulated environment.

In the same way, IDEO's brainstorming sessions encourage designers to act on different experiences. Kelley (2001) also speaks about a process of "bodystorming" in which designers not only think an idea, but also act it out. Perhaps the reason why IDEO's brainstorming sessions have triumphed over the years is the fact that the company has adapted this method. Stay focused on the topic, stick to one conversation at a time, be visual, be physical, and use the space are some additions that designers perform at IDEO that enforce visual communication (Sawyer, 2007; Kelley, 2001). Just recently, researchers have found that visual creativity is a powerful tool in groups compared to solo performers (Sawyer, 2007).

At IDEO, creative activity is indeed replete with visual representations. Sketches and prototypes are major vehicles for communicating ideas within the company (Kelley, 2001; Brown, 2009). Research shows that prototyping is key in the resolution of conflictual events within teams (Chung, 2009) and sketches are a powerful way to allow for efficient communication and further examination. In the case of the design firm IDEO, their brainstorming sessions go through a critical process of thorough evaluation as in an improvisational collaborative frame. This is somewhat paradoxical given that the first and most important rule of brainstorming is to withhold judgement. Presumably, critiques are thought to brake the creative process and the production of numerous ideas; nevertheless, at IDEO, it is believed that critiques help to evaluate the creative procedure and select the best ideas (Sawyer, 2007). 


\subsubsection{Collaborative design prototyping, sketching, and storytelling}

Prototypes, sketches and storytelling have been increasingly used in design teams. They permeate the interaction of design groups looking for inventiveness (Kelley, 2001; Brown, 2009). From an improvisational perspective, prototyping and sketching constitute the binary of simultaneous planning and implementation when individuals think an idea at the same time they build a tangible medium or draw a visual representation, which is manipulated, tested, and modified. In current design approaches, (a) prototyping and sketching are means to tell a story about a situation (often related to the user experience). (b) Storytelling is a common and ancient practice in many communities to learn and share knowledge as well as negotiate power within the group (Lawrence \& Thomas, 1988).

\section{a. Prototyping and sketching}

Barrett (2002) suggests that a counterpart to the improvised song in design process would be rapid prototyping, with regular updating and changing of design prototypes (often controlled by engineers in the end of the process). Traditionally, prototypes are a common activity employed in the middle of the design process to only test and evaluate design concepts or specifications (Chung, 2009). However, some major design companies have employed the use of prototypes in the beginning of the design process (Chung, 2009). For instance, IDEO has adopted a collaborative culture of prototyping early in the life of a project as a way of creating "just enough" ideas to allow the team to learn something and move on (Brown, 2009). 
In Tom Kelley's book "Art of Innovation" (2005), there is an appropriate quote to define the power of early prototyping in product development:

In engineering, if you have more variables than equations, you normally have an unsolvable situation. But on the other hand, if you just take some good guesses and fill in the blanks on some of them you'll get some answers.

(Dennis Boyle, IDEO studio head)

As in improvisatory jam sessions in which performers collectively grapple with new musical ideas, prototypes can precipitate serendipitous ideas (Chung, 2009). Prototyping earns good answers for unpredictable problems by experimenting with different possibilities. Gasson (2010) makes an interesting point on the serendipitous and experimental character of design process. She compares the tinkering nature of prototyping and even sketching to the process of bricolage. It involves repeated "trying out" and experimentation until a pattern is discerned that is useful (Gasson, 2010). Claudio Ciborra (2002) describes bricolage as "the constant re-ordering of people and resources that is the true hallmark of organizational change." But bricolage is not random experimentation. It is based on leveraging the world "as defined by the situation" (Ciborra, 2002). It can now be seen as an ordering of situational elements until they make sense according to previously encountered patterns. Here, bricolage is an activity that leverages prototyping as an actual improvisational performance. How does it work in design groups?

Chung (2009) discusses the implications of Cross-Functional Collaborative Prototyping (CFCP). The CFCP is a design method that brings the construction of prototyping to the beginning of the process as a way to boost collaborative creativity in design teams (Chung, 2009). It is clear that different disciplinary backgrounds and 
competencies can create conflictual events in group creativity. CFCP can alleviate some negative tension in groups by transforming conflict into positive energy in collaborative interaction. Although just a few attempts have been made to investigate its benefits, this CFCP method provides some evidence of effectiveness in design groups since it physically represents individuals' ideas, facilitates knowledge sharing and learning, and increases productive friction between group members.

To better understand how early prototyping functions as a powerful tool for innovation, Chung (2009) puts forward an intricate view on the activity of CFCP. Ideation, embodiment and critique are three fundamental behaviours in prototyping activity that keep the flow of the creative design process (Chung, 2009). Ideation is about generating new ideas, which creates new queries that supposedly drive the group creativity, just like jazz musicians negotiate musical structures in jam sessions. Chung suggests that questions are integral to CFCP since they are mediated and responded to by playing with tangible objects. Embodiment is a process of externalization of individual internal thoughts through tangible models. When prototypes are shared in the group, members can then see, touch, judge, and evaluate new ideas. This process is called critique and it is crucial to the design process because it can create positive debate that leads to the refinement of ideas and the narrowing down of possibilities to specific solutions. "Prototypes give everyone an opportunity to recognize and trust others' ideas" (Chung, 2009:4). This is similar to jazz improvisation, in which musicians build trust on others' abilities. 
These three behaviours in collaborative prototyping - ideation, embodiment, and critique - elucidate what designers perform everyday at work. For example, American director Sydney Pollack filmed a documentary about the life and work of famous architect Frank O. Gehry (2005). Sketches of Frank Gehry exhibits the architect's dayto-day business in his studio designing buildings, brainstorming ideas and constructing different scaled models. Gehry is one of the most innovative architects in the world and, perhaps not coincidentally, one of the most improvisational designers in terms of his creative methods. He is always tinkering with materials, trying new shapes, spoiling entire models, going back and forth from sketching, notes, and prototypes.

Gehry's method is reactive and spontaneous. In one scene, Gehry and his design partner are working around a building model, trying to solve the appearance of one of the sides of the construction. It was a quite sophisticated piece, and Gehry could not hide his frustration with its specific shape. He suddenly got a piece of paper, kneaded it and spontaneously created a new form. Then, he gladly states, "This is incredibly stupid!" Smiling, Gehry expressed his wry satisfaction, which was sparked by the combination of prototyping and sketching.

Drawing is another medium that designers utilize to create and demonstrate ideas. As Lawson (1997) remarks, drawing represents a vehicle for designers to freeze ideas and hold productive discussion within groups. As observed by Cross and Cross (1995), sketches facilitate critiques and help designers to evaluate idea generation. In the same vein, Lawson (1997) enforces the importance of drawing and talking as the main actions in a design studio. Designers are always talking and sketching ideas. Cross (1996) 
identifies plenty of situations in which groups are compelled by new statements spoken by various team members when analyzing different drawings. This process of give and take constitutes what Gasson (2009) refers to "breakdowns in individual buy-in to the group consensus definition of the design vision" (Figure 6). The design trajectory changes while ideas are evaluated and tested in the group.

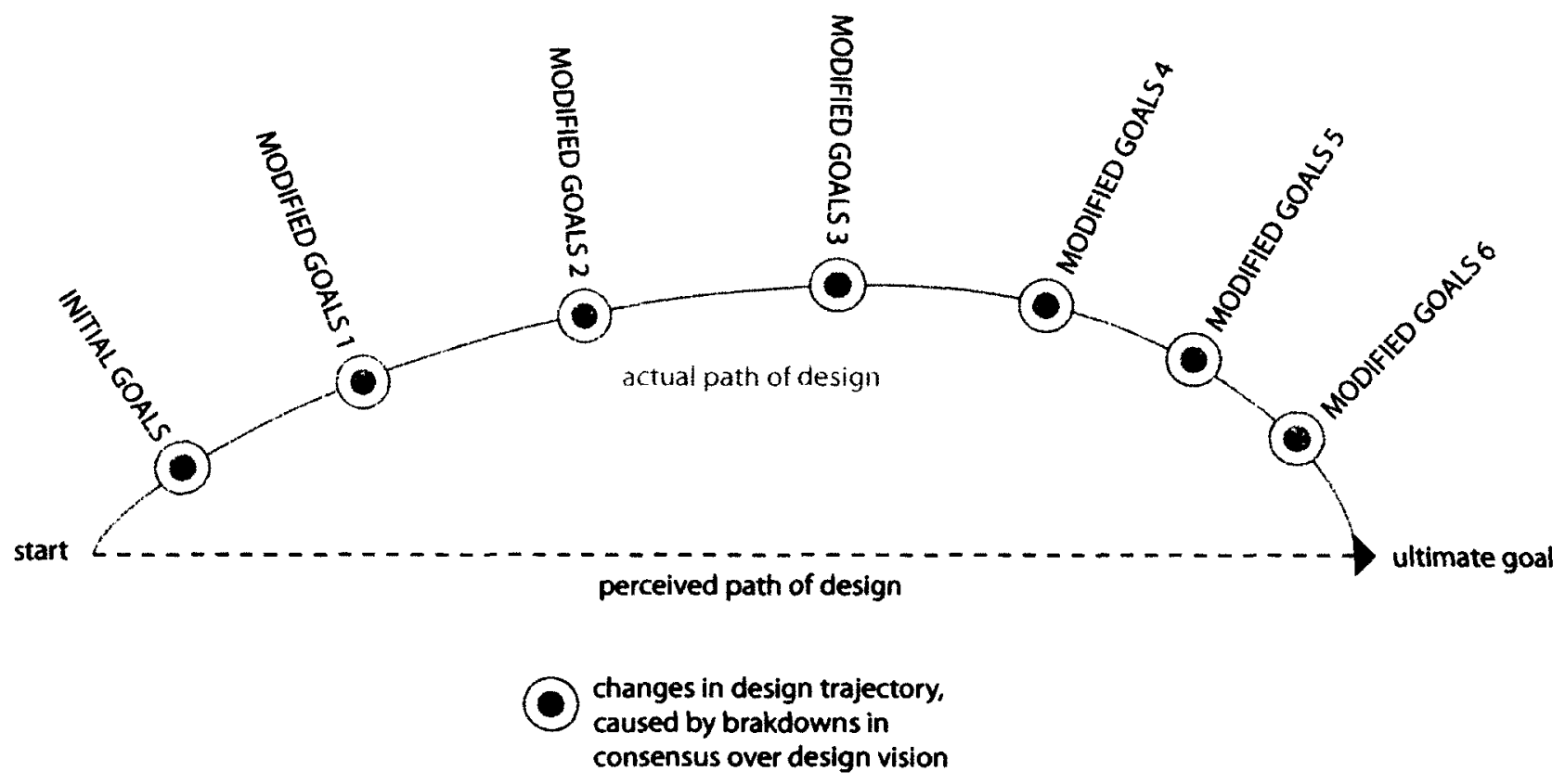

Figure 6. Design as a trajectory of goal-definitions (Gasson, 2009)

CFCP and sketching fit the notion of improvisational performance. Early prototyping involves simultaneous action; prototypes are built with whatever materials are available at the time. Prototyping can be a medium for communicating and guiding discussions, or a means of encouraging playfulness among group members. It is quite interesting as well that both activities - prototyping and sketching - involve a language 
based in visual representation. As jazz improvisers use sound to convey musical ideas, designers use visuals as a channel of communication.

\section{b. Storytelling}

The combination of sketching and prototyping is, in many ways, the vernacular of design groups, just as music represents the vernacular of jazz ensembles. The existence of a design language denotes a patent improvisational characteristic of the creative design process in building narratives on the spur of the moment. Brown (2009) claims that the creation of human-centred experiences is a process of storytelling based on different contexts. He points out that consciousness, language, and society have developed our capacity to tell stories from different technologies. The designer's ability to put his or her ideas on a paper or communicate them through building materials give the ideas meaning. Telling stories through visual representations implies that the reproduction of past experiences and transformation of them into new events are intricate actions of design ideation.

Storytelling involves framing events of a collective making strong statements about stories, and exercising power (Lawrence \& Thomas, 1988). Collaborative storytelling requires "various individuals contributing their own recollections and interpretations" (Lawrence \& Thomas, 1988:1989). In a collective, storytelling becomes a process of taking turns, in which questions, comments, and suggestions are among the main reactions. Again, the collective aspects of improvisation can be likened to 
processes of telling stories individually taking turns (soloing) within a larger group context.

Tim Brown suggests that an idea is developed and visualized as it unfolds overtime; the design thinker must consider both the actions of designing in space and designing with time (2009), just like in improvisatory performance and storytelling. They are different, but moving along these two axes of performance is crucial to achieve innovation (Brown, 2009).

In a way, the design process, according to the CFCP method, is a three-staged activity including first storytelling, second sketching and third prototyping. Prior to the construction of models, participants are recruited and broken into small teams. Then the design challenge is presented to the groups. After, participants are asked to introduce themselves and talk about their background. It is often shown that verbal conversations about personal experiences, anecdotes, and interesting stories related to the project usually arise first, which in turn creates a warm atmosphere (Chung, 2009). Following, several emergent ideas are discussed through conversations, note-taking, diagramming, and sketching. Then, there is the prototyping session, subdivided in two phases: the preliminary and final prototyping, in which participants can share ideas and feelings about the process and then test and evaluate the group's ideas. During the prototype session, storytelling and sketches are still produced, but, as previously stated, individuals are generally more comfortable in first discussing issues related to the process and then visually representing their ideas. (See Appendix B2 for more detail). 
It is obvious that designers design through improvisation, spontaneously creating ideas by sketching and prototyping visual representation, which facilitates communication between individuals. What seems to be missing in this process is improvisation for design; that is, the contribution of an improvisational plan to design methods. Improvisation, as discussed in Chapter 2 is a processual activity, unique in its capacity to resolve conflict, enhance productivity and innovate rapidly in group settings. No clear improvisational framework has yet been developed for cross-functional design teams. In order to contribute to this "new design method," this research first attempts to create a conceptual foundation of improvisational interaction and its benefits to effective team collaboration in design

\subsection{Reflections on the Literature Review}

Like jazz, the practice of design is both a discourse and a social interactive phenomenon. As social interaction, collaborative design teams often bring together people from various streams who debate ideas and raise important queries about the experience of a product or service. In this context, how can participants interaction manage conflict during idea generation processes?

In jazz improvisation, conflict is balanced by keeping fresh dialogues in performance that respect the musical vocabularies of the participants and the musical structures that are collectively brought into existence and navigated. In this context, trust is crucial to provide a synergetic environment and achieve the groove. In order to reach the optimal level of performance, jazz musicians respect a series of rules of conduct, which lead the interaction to new heights of expressive achievement and innovation. 
The rules of improvisation are based on the rotation of roles, in which individuals are empowered through an evaluative process of ideas. Design groups have somewhat equivalent parameters in performance. By using prototypes, sketches and stories in collaboration they go through a process of ideation, embodiment and critique of ideas. Assumedly, this process assures the continuous dialogue of design thoughts integrating individuals' participation.

Chung (2009) suggests that the issue of negative conflict in cross-functional design teams and processes is not entirely clarified and needs to be further addressed. On that note, Cross \& Cross (1995) reflect on the necessity of a deeper investigation of individuals' behaviour when they are performing design ideas. Communicative modes, verbal or non-verbal, such as body and facial expressions, gestures, and laughs can denote different meanings and affect a collaborative performance in many ways. It is important to define the emergent conflicts in group improvisation, the use of simpler and complex structures of performance, the alternation of roles in interaction and the process of evaluation of ideas. These four definitions serve as criteria for the examination of a musical ensemble and three design teams in the following chapters. 


\section{CHAPTER 3}

\section{METHOD}

The research method was qualitative, and attempted to explore and compare groups of musicians and designers. At first, musicians were observed during a rehearsal while they improvised some songs. The performance was mapped out considering the criteria extracted from the literature review - emergence of conflictual events, use of simple and complex structures, alternation of roles and process of evaluation. In addition, the participants were interviewed with informal questions concerning these four criteria of analysis. The enquiry aimed to validate these four aspects according to the musicians' perspectives. The intention was to see what and how conflict, collaborative components, roles, and evaluation emerge in improvised performance.

Based on the observation and interview with the musicians, a careful investigation of a creative session in design groups was performed. The same criteria that were applied to the musical jam session were used as a way to understand how design teams can effectively collaborate through improvisation. The idea then was to investigate and explore how designers "achieve the groove" in collaborative design ideation when errors, disagreements, and boredom become sources of conflictual events in teamwork that obstruct the path to inventiveness.

In order to investigate the improvised interaction of the design and musical groups this chapter is arranged in four main sections. First, the setting and participants of both groups are identified and described according to the activity environment and performers' métier. Second, the procedure is presented by describing the activities participants performed. Third, the data 
collection was specified. Finally, the data analysis was scrutinized according to the four main criteria of the research - emergence of conflictual events, use of collaborative components, alternation of roles, and process of evaluation. This qualitative method attempted to analyze how groups can be productive and why music improvisation - when successfully performed - is so effective in collective settings.

\subsection{Setting and Participants}

a. Musical ensemble

The band selected for this study consisted of five musicians: a drummer, a singer, two guitarists and a bassist. The band set up in the bassist's home basement (Figure 7). The drums were positioned in a central part of the room. On its left side, a table and the bass amplifier stood. On the other side, an old sound system stood by the wall with cables running to microphones distributed throughout the room. The guitar gear was set in the corner of the room, facing the bass gear and beside the piano set.

These five experienced musicians were ready to play an impromptu performance with no intent other than to generate new musical ideas. The band was selected based on its improvisational skills and the fact that they were acquaintances of the researcher. They were used to jamming before and after rehearsals for gigs. During the observation, the musicians would improvise naturally without any interference. 


\section{b. Design Teams}

During a day-long design workshop at Carleton University, a group of ten graduate students gathered in the Master of Design studio space. They were supposed to participate in a creative process to develop interactive products for healthcare systems. The workshop was part of a lecture in interdisciplinary design studio and ministered by a professor and a guest designer from the healthcare design industry.

The students' profiles were provided by the professor (Table 1). Some students had more experience in the market than others having worked in studios, colleges, and companies. The students were divided into three groups (Table 1): two groups of three and one group of four. This was an important variable in this research. The number of participants in a group could not surpass seven individuals.

Table 1. Groups distribution scheme

$\begin{array}{ll}\text { GROUP } 1 & \text { (A) Industrial design } \\ & \text { (B) interior designeducation } \\ \text { (C) graphic design } & \\ \text { GROUP } 2 & \text { (D) Industrial design/Psychology } \\ & \text { (E) industrial design } \\ \text { (F) interior design } \\ \text { (G) fine arts (illustration) } \\ \text { GROUP 3 } & \text { (H) Graphic design } \\ & \text { (I) fine art } \\ & \text { (J) architecture }\end{array}$

The students were asked to bring different materials for sketching and prototyping. They also brought in data from initial research, including information provided by the project stakeholders. For the purpose of this research, the participants were identified by the letters A, B, C, D, E, F, G, H, I, and J, as it is shown in Table 1 . 
The studio room was full of tables, shelves, and boards which could serve as support for interaction and the development of ideas. They were also provided with a projector and a printer.

\subsection{Procedure}

\section{a. Musical Ensemble}

The musicians jammed with no intervention by the researcher. They would improvise songs for a certain period of time and then rehearse some known songs from their repertoire. They explored a variety of musical styles including classic rock, funk, and blues.

Performance details such as who would initiate the playing and the duration of each song were not predetermined in the jam session. The process was entirely extemporaneous. During some breaks and after the jam session, the researcher questioned the musicians according to the set of criteria proposed for analysis related to conflict resolution, the use of musical equipment and generation of song ideas, the musical roles in performance, and negotiation and exchange of individual ideas.

\section{b. Design Teams}

The professor designed the workshop in collaboration with his guest, who advised each group in their design solution process. The design charrette was divided into three stages. First, each group presented their initial research data and project information followed by discussions. This stage developed as a meeting at a table where the students could use the projector and the boards to convey the project briefings. Second, each group arranged a space in the room where students could brainstorm and develop some ideas (that was the stage analyzed by the 
researcher). All groups chose tables to initiate the discussions. Third, all groups and advisors got together to show out their new ideas and directions in a more formal reunion at the end of the session with some discussions.

The participants had at their disposal notebooks, craft materials, drawing materials, laptops, research documents, and samples of an apartment plan. There was no interference by the researcher. The intention, as with the musical ensemble, was to see designers interacting spontaneously and naturally.

\subsection{Data collection}

a. Musical Ensemble

The jam session was video recorded to capture as many details of the communicative interaction - both musical and visual - as possible. A camcorder was placed near the staircase of the studio in such a way as to film every participant (Figure 7). It was essential to differentiate each instrument in the jam session. The intention was to examine how each musician contributed to the group dynamic, assuming leadership and/or supporting roles and creating disruptions or errors to be negotiated by the group. 


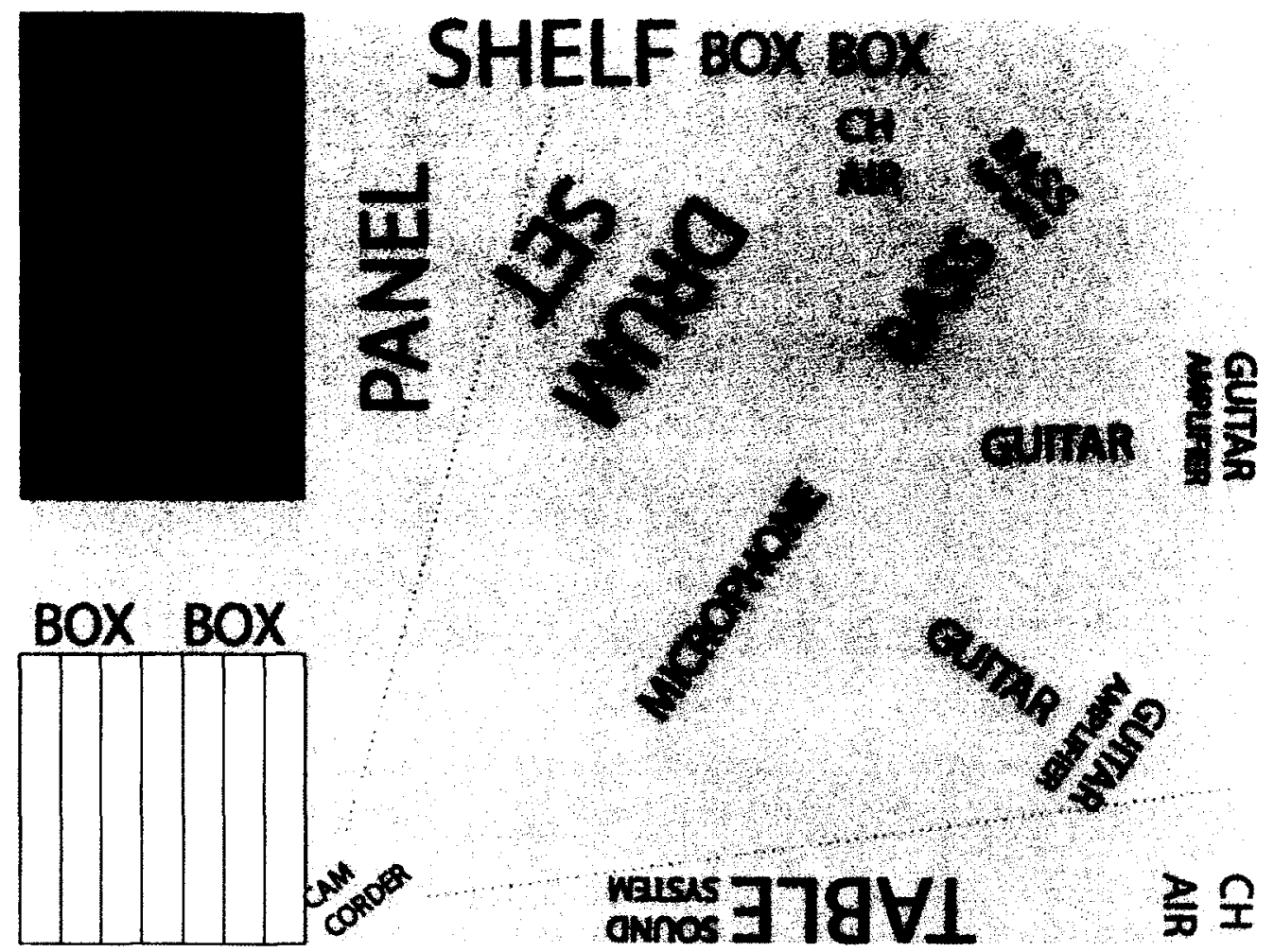

Figure 7. Plan of the jam studio

Along with the observational data, the musicians were interviewed at different moments of the performance. Four open ended questions - one for each research criteria (emergence of conflict, use of collaborative components, alternation of roles, and evaluation process) - were informally asked. The interview portion was designed to help validate the criteria used in the data analysis. This validation was also important to provide a consistent analysis of design teams according to an improvisational approach. 


\section{b. Design teams}

For each group, a camera was positioned in order to record as many interaction as possible. The groups were simultaneously featured for $\mathbf{4 5}$ minutes to one hour. This time frame is roughly comparable to that of the musical jam session. As one could expect from a qualitative approach, observation became more efficient by channelling all the variables (Creswell, 2003).

The camera was the main tool for data collection. It allowed the researcher to go back and forth between each collaborative session, distilling each performance to its essentials. The device was set so that it could catch communicative forms and emerging interaction. The camera position was important in capturing audio-visual data that would later be analyzed according to specific criteria involving the improvisational rules of performance and conflictual events. The intention was to guarantee the clear screening of warm ups, errors, tensions, agreements, provocations, turn taking, dialogue, and use of lower level components and construction of higher level components.

\subsubsection{Interview with musicians}

The interview with the musicians was informal in tone. The musicians elaborated on the research topics without specific questions. The intention was to cross the observational data with additional information from the musicians' opinions about their jamming process in order to acquire more insightful data. Table 2 displays some examples of open-ended questions. 
Table 2. Example of interview questions related to the research criteria.

\begin{tabular}{|c|c|}
\hline Emergence of conflictual event & $\begin{array}{l}\text { Whenever you improvise, how often does the jam work } \\
\text { out? } \\
\text { What does make it successful or unsuccessful? }\end{array}$ \\
\hline Use of collaborative components & $\begin{array}{l}\text { How do you describe your relation with your } \\
\text { instrument and the other musicians' performance? }\end{array}$ \\
\hline Alternation of roles & $\begin{array}{l}\text { When do you know you can start a song, make a solo, } \\
\text { or modify the melody/rhythm in improvisation? }\end{array}$ \\
\hline Process of evaluation & $\begin{array}{l}\text { How do you develop your musical ideas during } \\
\text { performance? }\end{array}$ \\
\hline
\end{tabular}

\subsection{Data Analysis}

The collected data was analyzed in a way to respond to and evaluate the research questions and hypotheses. Based on the information gathered in Chapter 2, the factors leading to the emergence of conflictual events in creative design teams remain inconclusive. For this reason, the method outlined here provided an opportunity to examine what types of friction positive and negative - are more likely to happen in performance among individuals, what mediums (simpler components) can provide different ideas, thoughts and opinions (complex components), what roles or behaviours individuals assume during interaction, and what processes participants used to evaluate ideas in improvised interaction.

The emergence of conflictual events, use of collaborative components, alternation of roles and process of evaluation were scrutinized through different observational sessions in an attempt to point the main aspects of interaction. In other words, each group's video recording was analyzed four times, according to the four improvised criteria. By using notes and computer programs for video reproduction and sound editing, the researcher pinpointed what characterizes 
each criteria in the groups. Furthermore, the study attempted to analyze how these criteria were enacted during improvisatory performance.

\subsubsection{Emergence of conflictual events}

Conflict is a major obstacle to collaboration. Nonetheless, it can be managed if the focus remains on the performance rather than on the relationships between members. In this analysis, the major conflictual events in both music and design performances were investigated to verify how improvisational attitudes help to develop a positive environment.

Table 3 lists some examples of conflict. They are divided in relationship conflict and task-oriented conflict for a more specific analysis.

Table 3. Example of conflictual events in group performance

\begin{tabular}{|c|c|}
\hline $\begin{array}{c}\text { RELATIONSHIP } \\
\text { Disagreement }\end{array}$ & $\begin{array}{l}\text { TASK-ORIDNTDD } \\
\text { Error, failure, mistakes }\end{array}$ \\
\hline Frustration & Interruption, disruption, deviance \\
\hline Boredom, Absence, Lack of interest & Excitement, intensity (voice or instrument) \\
\hline Misunderstanding & \\
\hline Stuck ideas, Uncertainty & \\
\hline
\end{tabular}

These are examples of the types of conflicts encountered in collective sessions.

Disagreement can be enacted by negative expressions such as ' $\mathrm{No}$ ', which may create a certain tension in performance. Disagreements can trigger frustration and boredom in participants. Facial expressions of indifference can be an instance of frustration. Boredom can be characterized by a lack of interest or absence of action in the performance. For instance, a bored 
participant would do something separate from the group or would be distracted with a different doodle.

Misunderstanding is another possible friction in performance, when one's ideas cannot be absorbed or learned by another member who would probe for more explanation. Misunderstanding can lead to frustrations, absence and stuck ideas in which individuals can be trapped in one specific discussion that may block productivity.

According to Barrett (2002), error is a sort of friction. For instance, musicians might make mistakes by hitting notes that sound odd in the performance. Interruption can also be a risky behaviour as it can interrupt another person's train of thought. However, it might denote a high degree of engagement from the participants, who show commitment and interest in developing the activity. Indeed, interruption may indicate a level of excitement. Other indicators of excitement include intensification in the volume of the voice or instrument or laughter.

\subsubsection{Use of collaborative components}

To analyze the footage, attention needs to be focused on the use of tools and objects in music and design environments. In the case of music, musicians played instruments to produce and modify sound. In the design groups, participants used different materials and tools to sketch ideas and build 3D models. The intention was to discover if the negotiation process of creating complex components was mediated by the use of mediums (simpler components).

Table 4 exposes the instruments that the groups used to negotiate ideas in music and design practices. Here, the design is separated from music because of the nature of both activities. Whereas the former can use craft materials, the latter can use musical instruments. 
Table 4. Collaborative components in music and design practices

\begin{tabular}{c|c} 
MUSIC & DXSIGN \\
\hline $\begin{array}{c}\text { Musical Instruments (drums, guitars, } \\
\text { microphone, bass guitar). }\end{array}$ & $\begin{array}{c}\text { Craft materials and tools (papers, markers, } \\
\text { pens, card boards, Styrofoam) }\end{array}$ \\
\hline Acoustics & Furniture, boards
\end{tabular}

In a jam session, the band plays musical instruments in order to produce and modify musical structures such as rhythm, chordal progressions and solos. In creative design sessions, craft materials and tools are common mediums used to produce sketches and 3D models. The environment itself, including the acoustics and furniture in the space, are also part of the collaborative frame.

\subsubsection{Alternation of roles}

As reviewed in chapter 2 , improvisation often involves the rotation of leading and following roles. Within this rotation, different behaviours take place to maintain the alternation. In improv practice, leading and following are equally important roles performed by participants. Rule of agreement and embracing errors are examples of following roles while provocative competence can be a case of leading action.

Table 5 shows a list of supposed roles performed by the participants. They are organized in leading and following to better elucidate the main aspects of the alternation of roles. 
Table 5. Following and leading behaviours in music and design sessions

\begin{tabular}{c|c} 
Listening, eye contact & Initiation \\
\hline Agreement, acceptance & Soloing, speech \\
Sustaining, support, embracement & Disruptions
\end{tabular}

Accompaniment, or "comping" is a very significant role in improvisational interaction. Listening is one of the most obvious behaviours in conversational activities. It can be characterized by a variety of cues including eye contact, nods, or vocal utterances such as 'mhmm' that offer positive reinforcement to the interaction. In the case of music, body movement according to the song can indicate that performers are listening attentively.

Agreement in design interaction can be represented by different verbal expressions such as "Ok", “I agree...", and "Yeah!”, which might indicate positive responses in performance. In music, the acceptance of different participant's musical suggestions can be evident through such supportive behaviours as the repetition or development of another musician's suggestion or idea.

\subsubsection{Process of evaluation}

According to the collaborative emergence frame, the improvised activity of playing music and conversing evolves through an evaluative process, in which performers test, experiment, elaborate, and refine ideas. Table 6 displays the possible phases of idea evaluation in improvisative performance. 
Table 6. Process of evaluation in music and design groups.

\begin{tabular}{c|c} 
Test, evaluation, confusion & Refinement, Embellishment \\
\hline Fixing errors & Confirmation, approval
\end{tabular}

The probation phase in improvisational interaction may indicate intensive test and evaluation of ideas being suggested in the performance. Probation can be marked by a certain disorder as the entire ensemble tries to offer different ideas. There might be an abundance of errors and it is important that the group fixes them by treating them as opportunities, as talented jazz ensembles do. By fixing errors, performers can refine, and embellish ideas until they strike a groove by confirming or approving the group's efforts. 


\section{CHAPTER 4}

\section{RESULTS}

In this chapter, the results of the observation of the groups and interview with the musicians are presented. Firstly, the aspects related to each improvisational criteria - emergence of conflictual events, use of collaborative components, alternation of roles, and process of evaluation - are defined. Then, the compilation of data extracted from the video observation sums up musicians' and design groups' actions. The findings are distributed in a table with three columns. The first column refers to the proposed criteria or measurements of the analysis. The second is 'aspects', which represents the types of conflict, mediums, behaviours and structures of improvisation. They are the expected occurrences in improvised performance and are represented by 'what.' The last column is 'action,' which relates to the performance of the 'aspects;' that is, 'how' the aspects were variably enacted by performers.

\subsection{Observation of the musical ensemble}

The musical ensemble was formed by five musicians who played the drums, the bass, the vocals and the guitars (Figure 8). 


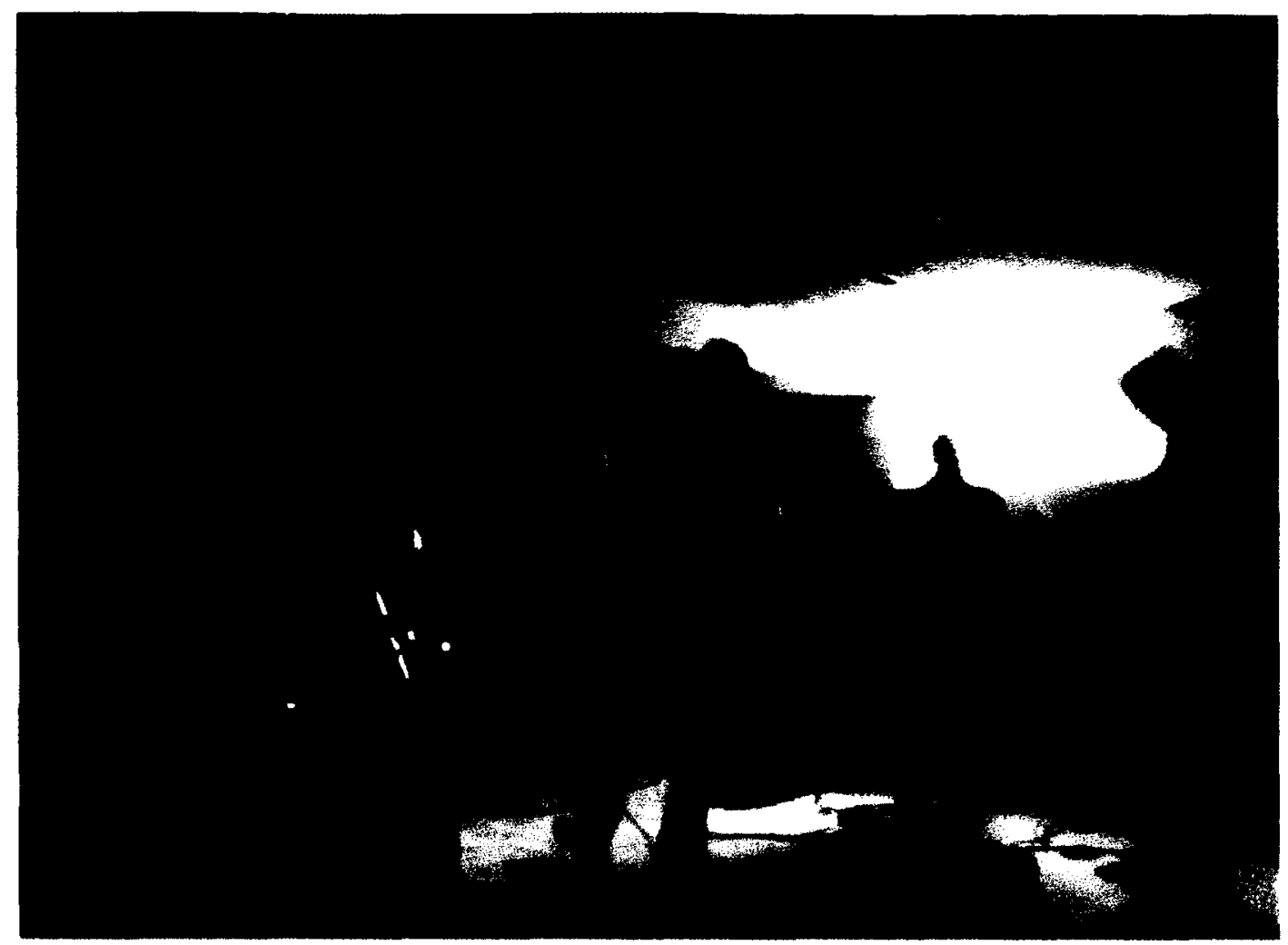

Figure 8. Band setting

Table 7 showcases the results of the analysis of the musical ensemble.

Table 7. Results for the musical ensemble observation

\begin{tabular}{|c|c|c|}
\hline VIEASI REMIITIS & ANPCOT & $10110)$ \\
\hline \multirow[t]{2}{*}{ Emergence of conflictual events } & Errors, dissonance & $\begin{array}{c}\text { Missed notes } \\
\text { Harmonic inaccuracy } \\
\text { Syncopation }\end{array}$ \\
\hline & Disagreements & Verbal discussion \\
\hline Use of collaborative components & $\begin{array}{c}\text { Musical Instruments, peripherals } \\
\text { Musical structure: rhythm, tempo, } \\
\text { notes }\end{array}$ & $\begin{array}{c}\text { Ploy instruments } \\
\text { Modify musical structures }\end{array}$ \\
\hline \multirow{2}{*}{ Alternation of roles } & $\begin{array}{c}\text { Leading: Disruptions, Initiation, } \\
\text { Addition }\end{array}$ & $\begin{array}{c}\text { Solo, Intensification, chordal } \\
\text { phrases, turns, tempo modification }\end{array}$ \\
\hline & Following: Sustaining, Listening & $\begin{array}{l}\text { Eye contact, playing, turns, riffs, } \\
\text { chordal phrases }\end{array}$ \\
\hline
\end{tabular}


Probation

Process of evaluation
Elaboration

Refinement

Confirmation
Production and fix of errors Eye contact

Solos and turns to embellish the song

Repetition of musical ideas Body movement and nod Smile of enjoyment

Emergence of conflictual events. Errors were the main source of conflict in the musical ensembles. They were mostly produced by missed notes and some harmonic inaccuracy. These task-oriented conflicts resulted in awkward sonic manifestations that often did not make sense to the musicians. Disagreements came to light in a specific moment of the performance when musicians started to discuss an idea for a song that one of the guitarists had created.

Use of collaborative components. Musicians played musical instruments during the entire session to create and negotiate ideas. They also utilized amplifiers, sound systems, computers, and effect pedals to intensify, modify, and record the improvised songs. Furniture such as chairs, and tables were part of the collaborative frame to support the performance, as the musicians could sit down to play.

Alternation of roles. There was a clear definition of roles in performance depending on the instruments used. The guitarists and vocalist were the predetermined leaders and the bassist and drummer were natural followers. Disruptions were mostly performed by the drummer, who occasionally changed the song tempo. Solos were dominated by guitarists. Initiation and supportive attitudes such as listening and acceptance were equally performed by all members of the group. 
Process of Evaluation. Musicians went through a probationary period in the beginning of every song. By producing errors, they elaborated on a song by fixing mistakes, adapting it to a new direction, and then refining the structure of the improvised songs. Probing involved the production of errors frequently characterized by misleading attempts to follow the song tune or by missing notes in a chordal phrase or solo. To fix these errors, the musicians often elaborated on the misleading attempts by undertaking a solo or shifting the rhythm. The musicians then refined the different ideas by repeating and adapting the note sequence. Confirmation could be perceived when musicians were moving their bodies according to the song, keeping eye contact, nodding or giving a smile.

\subsubsection{Interview}

Table 8 lists some notes on the conversation with musicians during the jam session intervals in the performance.

Table 8. Interview answers according to the improvisational criteria

Guitarist:
"We all get along and everything, but I've known [the other guitarist] for a
longer time than the others. Somehow these differences in our relationship is
reflected in the way we play. You can see that [the other guitarist] and I are
always musically dialoguing, while the drummer and the bassist are closer, and
the vocalist is on its own. He is the newer one."
"When we are playing, our styles always clash; we know that, especially because
we have totally different ways to play. But in a way this discrepancy between us
often is beneficial. If our jamming is not working we simply terminate the song
and keep on to the next. Well, you saw that in one of the songs."


Guitarist:

"It is nice to have the contrast between the electric string instruments against the acoustic traditional drums."

Use of collaborative components

Alternation of roles
"The use of technology (provided by the electronic amplifiers and effect pedals) influences a lot our decisions. If an effect doesn't work you can see right away their faces (laughter), but when it works is really nice. It is a great advantage to change in one song from a clean sound to a distorted noise. It intensifies my performance and influence the others to change accordingly."

Drummer:

"Sometimes I get tired of playing the same beat all the time. So I syncopate or double the tempo as I said, 'Hey, let's change, guys!' In the end, the recording is really nice with all those tums."

Bassist:

"I don't really like to solo or to develop complex fancy things. My style is simple, more with the grooving part, and following the band. Sometimes I can increment with a new line, but that is it. I like to groove."

Guitarists:

"We are a group with sub-groups, and they are defined (in our case) by the instruments we play, the level of our acquaintance, and external factors such as profession. The drummer and the bassist studied together; they do the same thing."

"If you look at us, you will see that [the other guitarist] like to play with his guitar down to the waist. He likes to hit big noisy chords sometimes, even when he's following my solos. Myself, I prefer more precise and fast paced notes when I'm soloing. So, I keep the guitar height closer to my chest."

Bassist:

"We always jam to create new ideas. What you saw, us discussing a song, is rare, but [the guitarist] had that idea for a while and wanted to show to us."

Guitarist:

"We always record the jam sessions. Improvising is the best way to create ideas, but they are too ephemeral. We need a recorder. We already had great ideas today and they are safe in your movie (smile)."

Drummer:

Process of evaluation wrong note, or the vocalist struggle to find the right melody, we usually laugh and keep on. I think we cannot stop playing."

Vocalist:

"When $I$ like something you played in a jam session, I ask you to repeat that because what I developed on top of your line was pretty good... and because, obviously, what you did was nice too. Repetition of nice passages in a song is a nice way to confirm an idea. Then I will listen to it a lot, and in the next session, I will ask to jam that again (laughter)."

\subsection{Observation of the design teams}

Three design groups were investigated. They were presented through the same criteria as

the musical ensembles. 


\subsubsection{Design Group 1}

This group consisted of three members. A, B, and C sat around a small table where they distributed their belongings (Figure 9). They were designing a system device that could monitor seniors' activities in their living space. As it follows, Table 9 exhibits the results of this exploratory analysis.

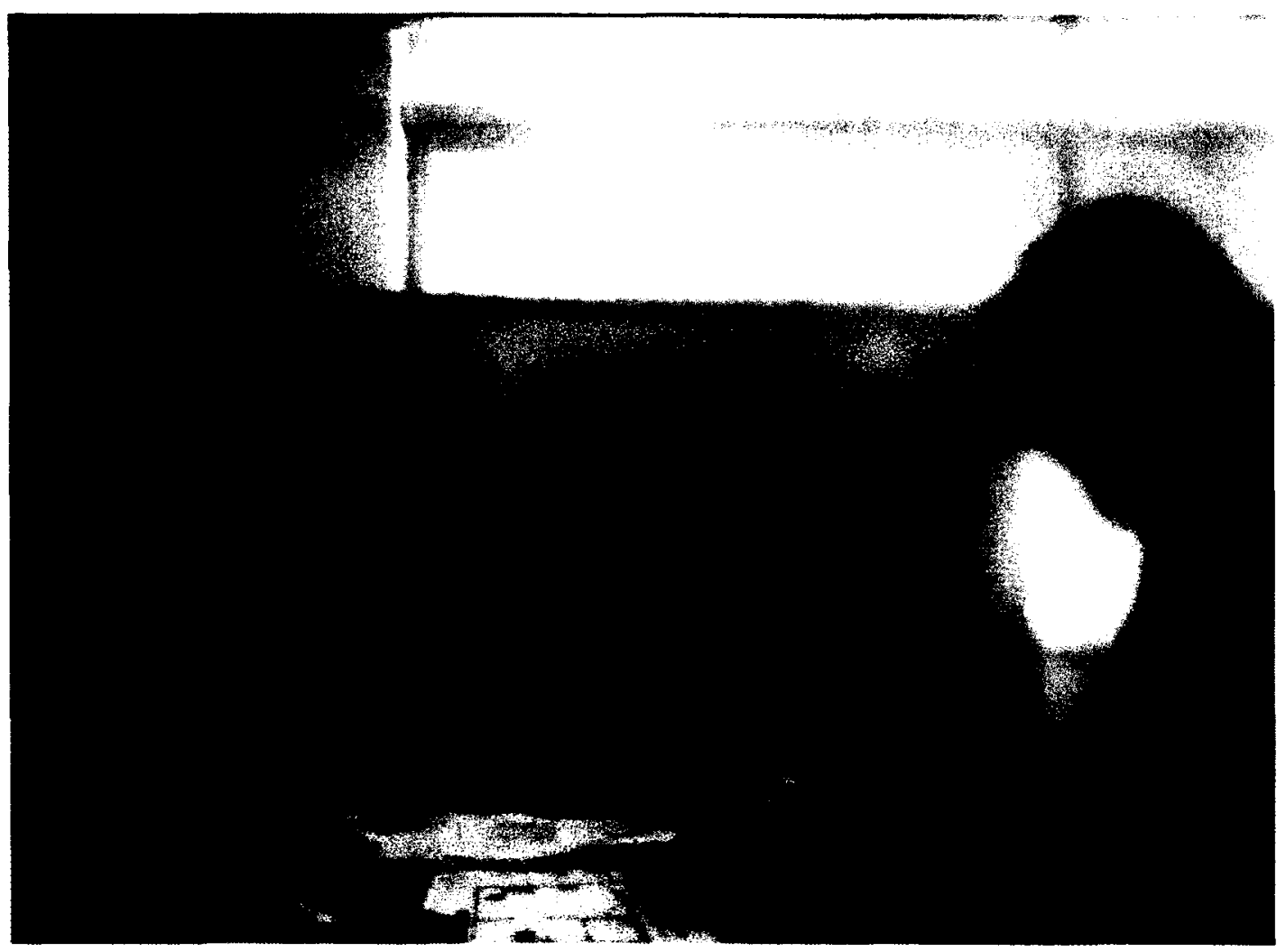

Figure 9. Design group 1 setting.

Table 9. Results for design group 1

\begin{tabular}{|c|c|c|}
\hline NIF ISI RI UIETIS & ATIICT & $1(110)$ \\
\hline Emergence of conflictual events & $\begin{array}{c}\text { Disagreements } \\
\text { Frustration } \\
\text { Interruptions } \\
\text { Boredom } \\
\text { Excitement }\end{array}$ & Verbal discussion \\
\hline
\end{tabular}


VIIASI REVIISIS

ISPIC

$1(110)$

\section{Paper}

Notepads

Map plan

Documents

Objects
Writing

Sketching

Handling

Verbalizing

\begin{tabular}{|c|c|c|}
\hline Alternation of roles & $\begin{array}{l}\text { Leading: Initiation, Disruptions } \\
\text { Following: Listening, Agreements }\end{array}$ & $\begin{array}{c}\text { Speaking } \\
\text { Sketching } \\
\text { Storytelling } \\
\text { Contradicting } \\
\text { Eye contact, nod }\end{array}$ \\
\hline
\end{tabular}

Process of evaluation

Probation

Elaboration

Confirmation
Suggestion

Questions

Compliment

Emergence of conflictual events. Interruptions represented the main source of conflict in Group

1. They were often expressed by verbalizations during the discussion such as "Yeah, but...", as shown in Table 10.

Table 10. Example of interruption in group dialogue
B - What about this situation...?
A - Yeah, but in this case, I think we should...
B - (Interrupts) No, no, no... I meant to make that more related to...
A - Yeah, but we need to stick on this (the house plan). What we should...?
B - I think we should focus on...
C - (Interrupts) Yeah, yeah! I agree (with B). The focus should be on...
B - Yeah!

Inevitably, these interruptions created some disagreements, which raised some frustrations. A

member showed frustration when after an argument he or she was unable to make a point (Table

11).

Table 11. Example of tension and frustration in group dialogue.

C. Ok, ok, but...but, I respect you (B), but that's what you want.

B. (Tense laugh) Well, I was just thinking that...

C. Ok, but this is what you want...

B. (Smile) Well, it is a valid point...

C. Yeah, yeah, it is indeed, but that's what you want. 
Use of collaborative components. Papers, notepads, a map of a senior's apartment, documents and objects were used by Group 1 . They produced writings that organized some thoughts, a few sketches on the map, manipulated personal objects (glasses, cup of coffee, and car alarm control), and used project documents for some references.

Alternation of roles. Talking was the main action equally performed by the three participants, who led the discussions by speaking out ideas, telling stories related to the project, and interrupting one another's line of thought by firstly agreeing and then contrasting the discussion with a different opinion. Besides agreeing, followers listened by keeping eye contact and nodding.

Process of evaluation. Group 1 probed and elaborated ideas mostly by suggesting and questioning individual offers to the performance. Confirmation was reached when mutual agreement was marked by compliments to the generated ideas. Table 12 showcases a dialogue between participants when manipulating an object and approving an idea.

Table 12. Example of confirmation in the dialogue between members

A - (Holding the controller) I have this car alarm controller, and things like that could work as a device to monitor...

$B$ - Well, this is the situation when...

C-Yeah!

B - (Holding the controller) What if we created a...

A - (Taking notes)That is actually brilliant! So, we would be creating...

$\mathrm{C}$ - (Nodding and holding the controller) Cool!

\subsubsection{Design Group 2}

$D, E, F$, and $G$ made part of Group 2 . The four participants sat around a table where they distributed their belongings (Figure 10). They also designed a system device that could monitor 
seniors' activities in their living space. As it follows, Table 13 exhibits the results of this exploratory analysis.

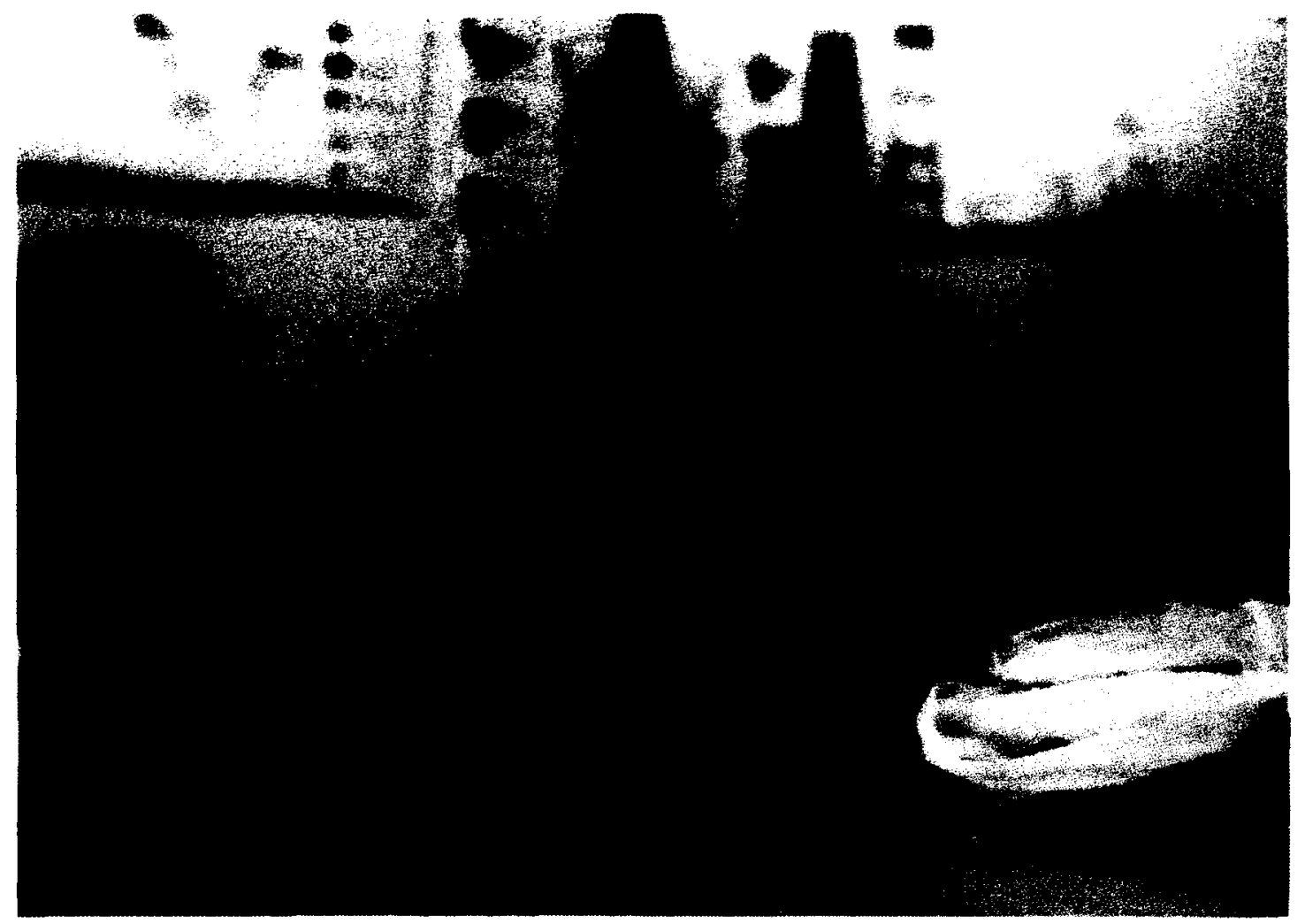

Figure 10. Design group 2 setting

Table 13. Results for design group 2

\begin{tabular}{|c|c|c|}
\hline Emergence of conflictual events & $\begin{array}{c}\text { Lack of engagement } \\
\text { Frustration } \\
\text { Uncertainty } \\
\text { Disagreements } \\
\text { Excitement }\end{array}$ & $\begin{array}{c}\text { Individual work } \\
\text { Absence of reaction } \\
\text { Verbal Discussion } \\
\text { Laughs }\end{array}$ \\
\hline Use of collaborative components & $\begin{array}{l}\text { Computers } \\
\text { Craft materials } \\
\text { Furniture }\end{array}$ & $\begin{array}{l}\text { Watching videos and browsing on the } \\
\text { internet } \\
3 D \text { modeling }\end{array}$ \\
\hline Alternation of roles & $\begin{array}{l}\text { Leading: addition } \\
\text { Following: listening }\end{array}$ & $\begin{array}{l}\text { Suggestions } \\
\text { Questions } \\
\text { Storytelling } \\
\text { Eye contact }\end{array}$ \\
\hline
\end{tabular}




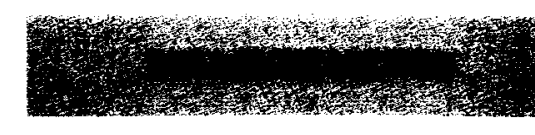

Process of evaluation
Probation

Elaboration
Errors

Questions

Emergence of conflictual events. The absence of a reaction to individual group members' work provided lack of engagement that precipitated some frustration and an uncertain atmosphere in Group 2. Some discussions ended up generating a few strong disagreements. At moments, some members would laugh in a critical way at some ideas generated.

Use of collaborative components. The group mostly used computers to find references to the project. They watched videos and searched for some websites. D and $\mathrm{E}$ also built two prototypes each with available materials and used the furniture in the room to play with the models. Alternation of roles. Leading attitudes involved storytelling to make a point, as well as the suggestion of ideas followed by questions. Following was characterized by listening which was evidenced most clearly by eye contact and nods.

Process of evaluation. Group 2 spent most of the time probing ideas with prototypes, and making enquiries about the discussion.

\subsubsection{Design Group 3}

Group 3 was formed by $\mathrm{H}, \mathrm{I}$, and J. The three participants sat at a table with their computers (Figure 11). 
Figure 11. Design group 3 setting

Table 14 showcases the result for Group 3 improvisational interaction.

Table 14. Results for design group 3

\begin{tabular}{|c|c|c|}
\hline 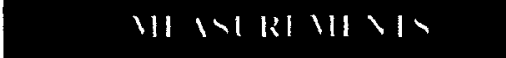 & $|V| 1 \mid 1$ & $1(111)$ \\
\hline Emergence of conflictual events & $\begin{array}{c}\text { Stuck ideas } \\
\text { Misunderstandings } \\
\text { Uncertainty } \\
\text { Absence }\end{array}$ & $\begin{array}{c}\text { Verbalizations } \\
\text { Questions } \\
\text { Contradiction of ideas }\end{array}$ \\
\hline Use of collaborative components & $\begin{array}{l}\text { Computers } \\
\text { Notepads }\end{array}$ & $\begin{array}{l}\text { Browse internet } \\
\text { Watch videas } \\
\text { Writing notes }\end{array}$ \\
\hline Alternation of roles & $\begin{array}{l}\text { Leading: Addition, disruption } \\
\text { Following: Agreement, listening }\end{array}$ & $\begin{array}{l}\text { Suggestions } \\
\text { Eye contact, nod }\end{array}$ \\
\hline Process of evaluation & Probation & $\begin{array}{c}\text { Questions } \\
\text { Individual job }\end{array}$ \\
\hline
\end{tabular}


Emergence of conflictual events. Stuck ideas, misunderstandings and uncertainty were the main conflictive issues in the middle of contradicted discussions and queries about the project problem (Table 15). From time to time, members would stop working collectively and remove themselves from the group performance, remaining isolated with their computers.

Table 15. Example of stuck idea in group dialogue

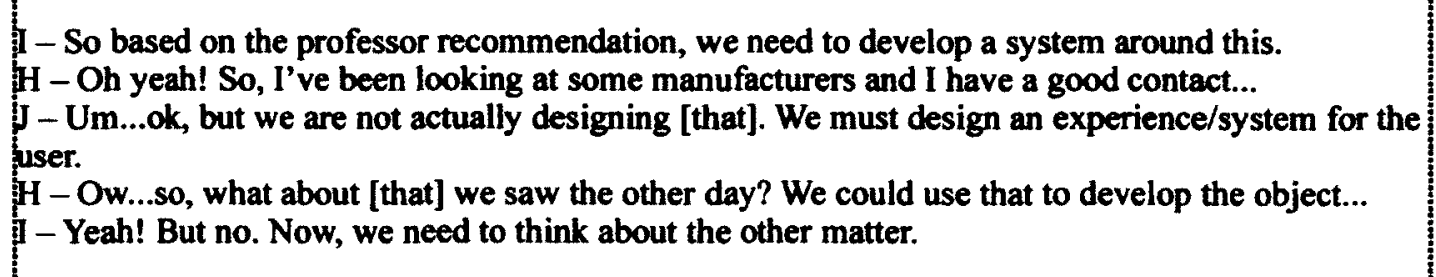

Use of collaborative components. Computer and notepads were the main simple structures used in this performance. With them, Group 3 could stream some videos that supported their conversation and note some ideas on paper.

Alternation of roles. Additions and disruptions occurred frequently within the group during idea discussion, while signs of agreement and listening were characterized by eye contact, approving sounds and nods in their conversation.

Process of evaluation. Probation was replete with queries among participants, who were often secluded in their individual activities, browsing on the internet.

\subsection{Summary of study results}

In the improvisatory jam session, the ensemble evaluated the group performance by probing musical ideas offered in the songs that sometimes sounded awkward, elaborating on and fixing ideas by accepting different reactions, refining and embellishing the song with different 
solos and disruptive movements, and confirming them by repeating musical structures that sounded original to the band. Negative conflict took place when the band started to discuss a song idea. The act of verbalizing created too much overhead that could only be reduced when musicians played musical ideas with their respective instruments.

In the interviews, the musicians' opinions were oriented to their individual style of playing songs. In this sense, their relationship with fellow musicians, external practices, and musical instruments dictated most of the behaviour in the ensemble. Conflicts were negotiated musically by the way each musician played and contributed to the improvisatory dialogue.

The design groups also suffered from some negative friction linked to verbalization. As a consequence, they spent too much time trying to reduce friction, thereby retarding the confirmation of ideas. The fact that the groups used different visual representations such as found objects and 3D models established a more dynamic and engaging process. Still, prototypes and sketches indicated a more advanced and specific task being often performed individually rather than collectively.

Next, the researcher proposes a discussion on the main aspects surfaced in the results. 


\section{CHAPTER 5}

\section{DISCUSSION}

Based on the results obtained from the data analysis, three main issues can be enumerated. Verbal communication, task definition and validation of individual performance were relevant outcomes related to different conflictual events and collaborative occasions in both improvisational interactions. Taking music improvisation as a successful model of collaborative performance, these three main issues provide a useful comparison between the musical ensemble and the design groups. It is suggested that verbalizations, task definition and validation of performance are issues particularly related to the playful characteristic of the groups, which is based on simple structures of performance such as musical instruments, found objects, tools and materials.

Table 16. Comparable information from the observations and interview.

\begin{tabular}{|c|c|c|}
\hline \multirow{3}{*}{ Verbalizations } & \multirow{3}{*}{$\begin{array}{l}\text { Rarely performed. When existing, } \\
\text { talking was followed by the } \\
\text { performance of individual } \\
\text { instruments. }\end{array}$} & $\begin{array}{l}\text { Group 1: Frequent. Participants } \\
\text { often recurred to verbal discussions } \\
\text { to convey an idea. Verbalizations } \\
\text { were sometimes supported by } \\
\text { individual notes or sketches, and } \\
\text { manipulation of objects. }\end{array}$ \\
\hline & & $\begin{array}{l}\text { Group 2: Occasional. This group } \\
\text { performed more individualistic } \\
\text { tasks. While an individual was } \\
\text { prototyping, the other was doing } \\
\text { research on the internet. Sometimes, } \\
\text { one would make a comment about } \\
\text { something, but few discussions } \\
\text { were generated. }\end{array}$ \\
\hline & & $\begin{array}{l}\text { Group 3: Frequent. Talking was } \\
\text { often supported by diverse } \\
\text { information from participants' } \\
\text { computers. }\end{array}$ \\
\hline
\end{tabular}


Task definition
The task of improvising a song was in accordance with the instruments played in performance. Besides the technical ability of each musician, their style and external factors were equally important to the generation of song ideas. There is a definition of sub-groups in the musical ensemble. In these sub-groups the musical dialogue is constant, whereas the dialogue between the sub-groups can be more frictional.

Group 1: No previous or clear taskdefinition. Focus on problem solving. Although all groups had a variety of individual expertise, all participants seemed preoccupied with solving the design goal. Sometimes, participants would tell a story to contextualize an idea.

Group 2: Different tasks. Half of participants worked on different prototypes. The remaining participants worked mostly on their computers looking for references to help solving the design problem.

Group 3: No clear task-definition. Everyone talked. Just one took notes. When not talking, participants were navigating on the internet.

Group 1: Validation occurred at the end of the footage when participants were holding a car alarm controller and telling different stories related to the object.

From the observation and conversation with musicians there was an endeavour to quickly find a song structure and make every idea valuable. Personal expression has to be validated in musical improvisation. Individual style is a very respected issue in musicians' jam session.

\section{Validation of individual performance}

object.

Group 2: At the end of the footage one participant started to play with the prototypes he/she had made, proposing to the rest of the group to assume different roles to explain the idea. Validation was perceived when everybody was involved and enjoying the activity.

Group 3: No clear validation of individual ideas. During the footage, the ideas offered were not exactly refined or elaborated. Participants spent a long time analyzing videos and defining what to do. 


\subsection{Verbal communication}

Verbalization was as essential as it was problematic to the design groups. Talking was not necessarily a cause of negative conflict, but, to a certain extent, it was linked to conflictual events in performance. In the musical session, the conversation was based on the performance of musical instruments. Even on the occasion when musicians stopped playing to discuss a song idea, they played musical instruments to make sense of the verbalized comments. Presumably, because of the nature of music, improvisational negotiation should take place through musical instruments. In the same vein, the nature of design activity includes verbal communication.

The comparison of improvisatory modes of dialogue within music and design settings provides useful insights within this analysis. In the musical setting, dialogue resulted from the interaction of the different musical instruments, backgrounds, and musical personalities of the performers. In the design groups, verbalization is one of the communicative channels in interaction. As seen in the footage, the use of videos, personal objects, notes, prototypes and sketches can provide different ways to convey an idea. The fusion of these different streams in improvisational performance creates a cross-functional interaction, which can help the group to innovate (Cho, 2010; Barrett, 2002).

The "channels" or "streams" in performance are connected to the way individuals offer an idea to the group. The channel of verbalization can carry stories, questions, or facts that shape the interaction. In the design groups, this channel was largely used by everyone in the groups as if a pipe was clogged with too much information (Figure 12). By using a different medium, such as objects or prototypes, the information was spread to the other visual streams (Figure 13). This 
idea reinforces the significance of the use of simple components in improvisational performance.

The diverse use of mediums simplifies the negotiation process between performers.

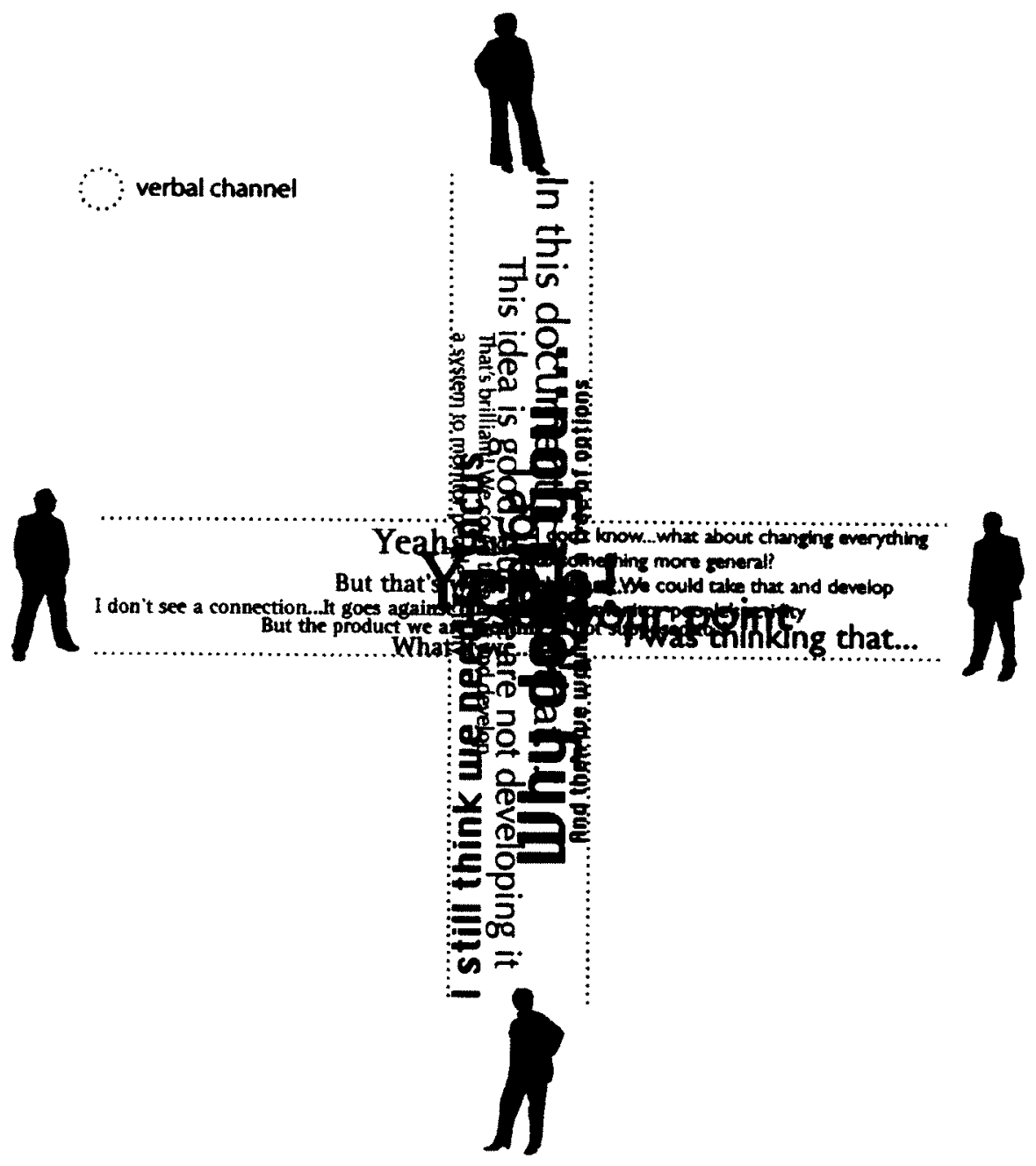

Figure 12. The communicative channel for verbalization in the design groups 


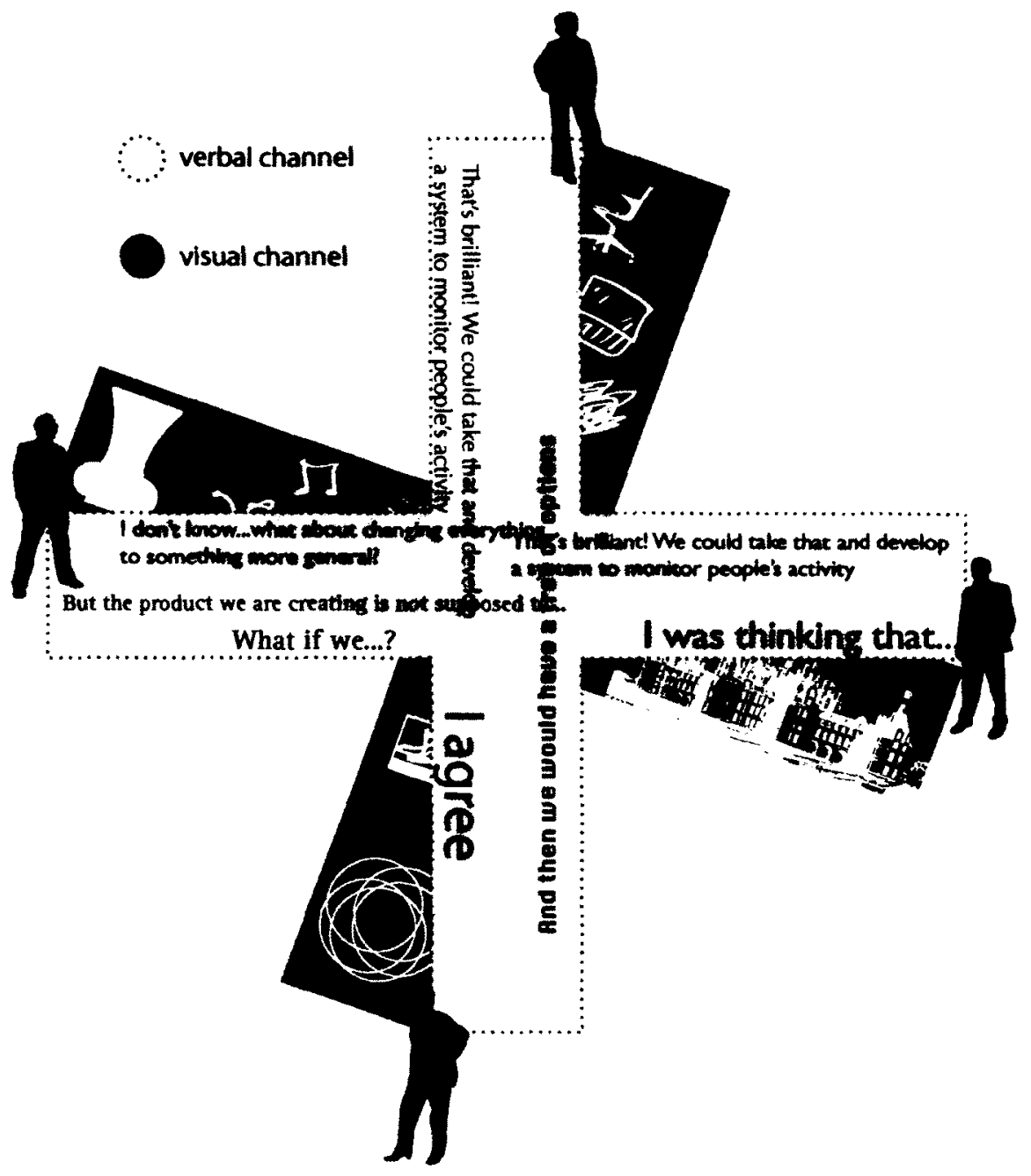

Figure 13. The communicative channels combined in the design groups.

It is thus very important to diversify the activity being performed. Depending on one way alone to offer an idea can generate too much friction in the group. However, the context of the design groups posed different challenges from those of the musical ensemble. While musicians are constantly playing different instruments, the design participants seemed quite comfortable in verbalizing ideas instead of building prototypes or sketching solutions. A way to diversify

85 
communication within the design groups may be to look at the roles participants are able to play in design performance. Next, the importance of task roles in improvisation is elucidated.

\subsection{Task definition}

It is important to take into account task definition in performance, that is, the role that each individual is supposed to perform in idea generation. In music, each performer plays a specific instrument that has specific characteristics. The drummer provided rhythmic support; the bassist provided both rhythmic and harmonic support. But they also added musical disruptions to the improvised musical dialogue in the form of fills and solos. In similar fashion, the guitarists and the vocalist, who were responsible for most of the melodic dimensions of the music, eventually followed each others' ideas.

In the design groups, the definition and distribution of tasks were not clear. As the main source of idea generation took place through verbalizations, following actions were limited to listening. On the other hand, musicians followed by not only listening but also by developing a harmonic phrase, or a rhythmic motif to mark the tempo, and led by not only soloing or disrupting, but by listening as well. This balance between task-roles in design was rare because designers were performing the same task, rather than fulfilling their main roles which could have provided something new to the group performance.

On that note, it is imperative to define the roles performers play in design as the main channels of idea communication. Task definition in this sense can be a form of division of labour, creating a zone of individual action that balances performers' attitudes. As an example, if a drummer interrupts a guitar solo by playing an extended drum fill, he is entering the guitarist's 
zone. This "invasion" cannot overwhelm the guitarist's action, or else it might precipitate the interaction in intensive musical confusion, detracting from the group's accomplishment. The drummer is allowed to disrupt, but he has to guarantee that the rhythmic section remains active in fulfilling its primary role.

Task definition meaning goes beyond the individual capability of playing music or designing solutions. Task here can be related to the personal experiences each individual has had within and outside group settings. As heard from the musicians, their musical style and their relationship with other musicians influence how they play. According to them, those variables are what make the improvisational process so effective. In the same way they need to respect one another's expectations, they need to fulfil their own musical desires to be satisfied. In contrast, in the design groups, personal experiences were seldom shared in interaction. Perhaps the group concern in reaching a design goal could have stifled or retarded the possibility of individual expression.

In some cases, some participants in the design groups told stories about different experiences. In Group 1, when the members were discussing an idea, one participant grabbed his car alarm controller to tell the experience of locking a car and turn on the alarm. By holding the object in his hand, the other participants were constrained to developed an idea on the object or on the experience related to this object. Following the insights gleaned from the observation of the musical ensemble, it can be argued that the use of found objects or tangible mediums, which provide or enact individual expression, such as the car alarm controller, creates effectiveness in group collaboration. The instrument (lower level component) an individual plays, being that a musical instrument or a found object, represents a set of skills and experiences when performed 
in collaboration. In the groups, effectiveness was present when participants could contribute or express ideas through different means. Not only did the use of lower level components define tasks and foster individual expression, but also contributed to the validation of individual performance.

\subsection{Validation of individual performance}

In the footage, the process of evaluation of ideas- probation, elaboration, refinement, and confirmation - is related to validation of individual performance. Every idea offered in the improvised performance is thoroughly negotiated until it is validated. Validation is more of a cyclical process in which every new attempt is filtered to its best. In this validative process of ideas, an individual is constrained by a collective evaluation, critiques or judgment. In this sense, the group validates individual ideas in improvisation creating a self-organized performance. To validate is to reward individual efforts within the group through the iteration of different ideas. For instance, every time a musician offered a musical idea to the group, partiipants could accept it or not. When accepted, one idea was repeated by the group. This iteration at the same time rewarded and validated individual performance, providing a sense of satisfaction within the ensemble.

Probation is the first phase of validation. This took place when musicians produced mistakes in the footage, creating some tension and awkward moments in performance, which, instead of being discarded, were embraced and refined until all members felt satisfied with the new idea. By producing errors, musicians generated conflict that was resolved by the second phase, that is, the phase of elaboration and refinement of ideas. At this point, musicians started 
repeating some passages and more solos were performed. Embellishing, polishing, and developing are possible terms to describe the second phase of validation. The third and last phase is the approval, authentication or rewarding stage. There, musicians could enter a zone of satisfaction, which involved musicians making different expressions of approval for a guitar solo or a rhythmic turn on the drums, or a flawless line on the bass. Compliments, nods, smiles were the most common reactions at this phase of validation.

In the design groups, the validative aspect was quite similar to the musical ensemble, except for the time spent on each phase of the process of evaluation. Probation was the major way to evaluate individual ideas taking a great portion of time of the groups' performances. By looking at the results, it can be said that the constant use of verbal communication might have confused participants to develop ideas. Elaboration, refinement and approval of individual offers could be validated with the manipulation of objects, which limited verbal conversation, enhancing the design dialogue (see the case of the use of a car alarm controller in Group 1, Chapter 4, Page 74). That is what happened with the musicians when they discussed a new idea for a song. When a musician interpreted a verbalized idea by playing his instrument, the others could finally validate that idea saying "Yeah! That's what I was talking about!" or "Wow! This is nice! Let's use this riff." When the discussion started to become confused with everybody talking at the same time, one member said, "Hey, play that last part and let's see how it works."

The musicians' creative process always called for a musical conversation. They had to play their musical instruments to trigger a proper and productive song ideation. As an influential process, improvisation involves moulding different ideas, testing, evaluating, correcting, fixing, re-testing, refining, and embellishing a song idea. 
A similar situation occurred in the design groups. To generate and develop ideas, participants needed a means to communicate. The use of materials/tools/objects helped the fast development of design solutions as musical instruments helped the band to rapidly validate musical ideas. Musical instruments constrained individual actions, while at the same time liberating the ensemble to fuse different genres of music.

The importance of the group's validation of individual ideas is likely to be the affirmation and differentiation of tasks in group improvisation. This contribution is possible through a clear definition of roles; that is, what each member is responsible for and capable of doing for the group. If everyone in the group is doing the same thing, as it happened for a long period in the design groups when talking ideas, there might be a clash of opinions caused by a certain degree of competition among members. Competition can be detrimental to group performance (Barrett, 2002). In the case of the design teams, a lot of thoughts were conveyed in the same channel of communication, whereas in the musical ensemble, ideas came from diverse streams represented by the different instruments played by musicians (Figure 14). 


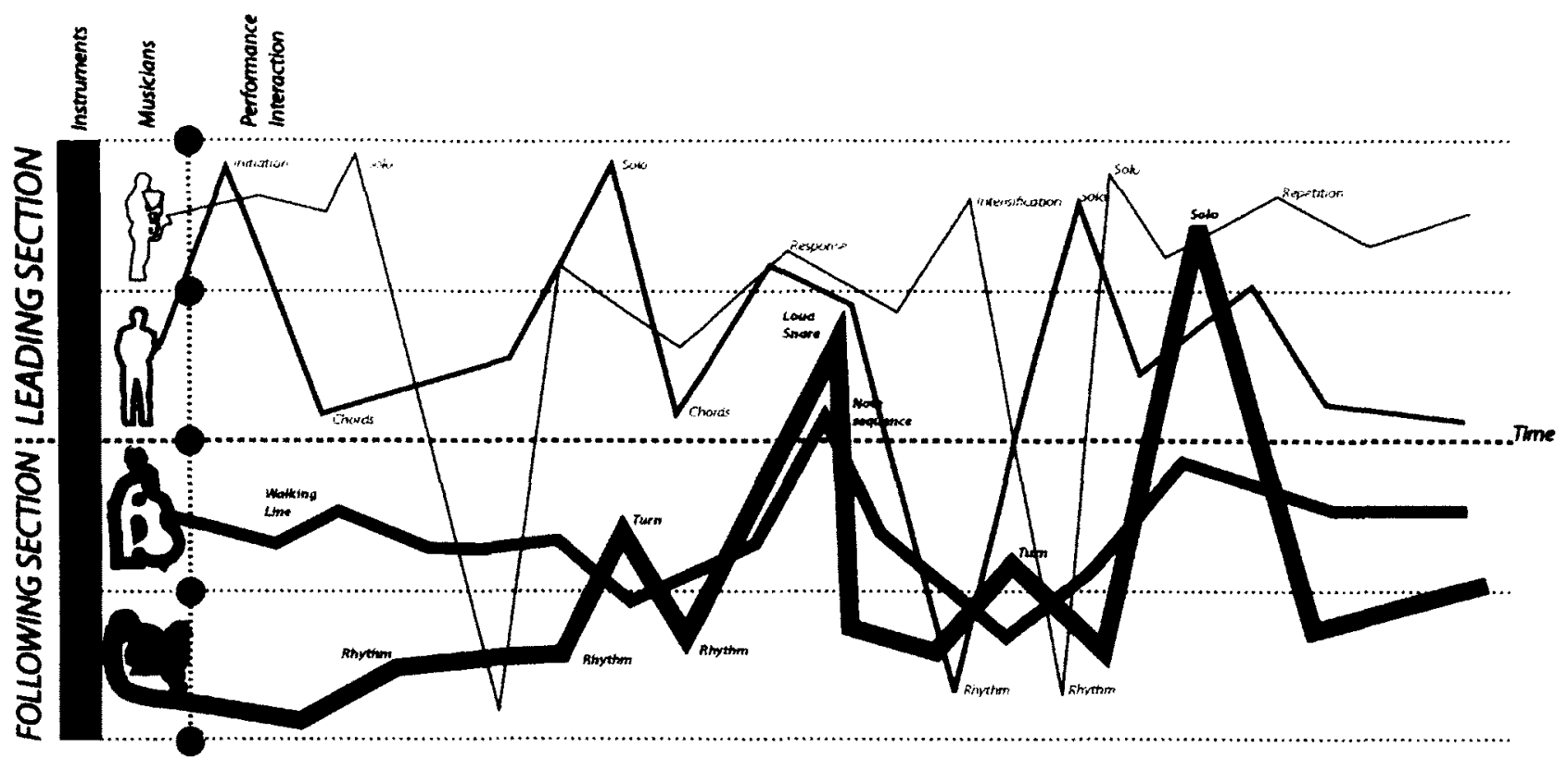

Figure 14. Instruments/roles/channels of communication in musical groups

Validating clears confusion from improvisational performance through iterative passages. For instance, the bassist starts following the guitarist and slips a note. The guitarist sees the mistake as an interesting increment to the song and begins to repeat the new idea. The iteration in this case is generating an agreement between the musicians (agreement that was originated by a dissonance which lately rewarded the bassist's action). Similarly, when playing with a found object, A was rewarded by the rest of Group 1 which iterated ideas through a process of evaluation, refinement and embellishment characterized by stories, notes and sketches created according to the interaction with the found object..

In this scope, as observed in the video, errors are fixed, tension is softened, and uncertainty is eliminated by a process that constrains individual's actions and liberates the group's judgement. Validation creates the possibility of a rewarding system guaranteeing that everyone in the ensemble is satisfied with their performance. As Blum (1998) suggests, this 
improvisational rewarding method is what keeps negotiation healthy and stable between performers.

\subsection{Summary of research discussion}

Individuality was an important aspect in the analysis of both music and design improvisation. Individual experiences, personality, style, and opinions were recurrent variables in the way improvisation took place in both interactions. The results showed that verbalization, task definition and validation were three main findings related to the emergence of conflictual events in collaborative settings. Even though connected to some conflictual issues in the observed performances, verbalization functioned as a sort of communicative channel. In music, the channels for communication were represented by the musicians' roles in the ensemble and their respective instruments. This definition of tasks in the design teams was at times unclear since participants could not constantly validate individual actions. Because they spent a long time discussing ideas, that is, communicating through only one channel of interaction, the design groups did not diversify their performance enough as much as the musical ensemble did. In the musical improvisation, the diversity of instruments played carried more than the technical ability of the musicians. It also bore musicians' personal experiences, which could be validated or legitimated in the service of creating something new. In the same vein, design groups could validate ideas when they used tangible mediums that elicited some sort of individual experience. Found objects stimulated participants to tell stories - personal or fictional - related to the design problem and to iterate ideas the group judged valid. By playing with objects, the design groups could work in a second channel; the channel for visualization. 


\section{CHAPTER 6}

\section{CONCLUSIONS}

This research explored and compared two different collaborative and creative activities. Much can be said about the similarities and differences of music and design activities, but improvisation represents both a similarity and a difference in this case. The similarity lies in the fact that music and design are improvisational involving performers making extemporaneous decisions, performing and composing at the same time, planning and implementing contemporaneously. Music improvisation involves years of practice and a very sophisticated organization. To designers, this practice is rather episodic, and it has only recently acquired more formal attention by the design community. In this research, jazz improvisation represents, besides a musical genre and a cultural discourse, a social phenomenon involving the interaction, conflict and behaviours of individuals on the bandstand. The metaphor of a musical ensemble was used to analyze improvisation in design group and then provide an improvisational model for design teams towards effective collaboration.

\subsection{Researchable questions}

This research aimed to understand how improvisation can help design groups to enhance collaboration in interaction. In order to understand the conflictual aspects of improvisational organization, other two main related questions permeated this study. Why have organizations, including design groups, been employing collaborative work when individual work has often shown more positive results? And what does make jazz, among other performing art practices, so 
effective in collaborative settings? Improvisational practice can tell us much about the driving social and cultural forces behind collaboration, as well as the sorts of behaviours and practices that bolster their efficacy (Fortier, 2008). The sorts of behaviours and practices of improvisation served as objects of study for this research to understand why and how musicians function in unexpected situations and how their improvisational methods can serve as a model to collaborative design groups.

\subsection{Context}

Effective team collaboration often faces the emergence of conflictual events. To many, conflict is seen as a negative occasion that blocks a group's creativity and efficacy. In contrast, jazz ensembles often use conflict as a productive element that can enable successful improvisation. This model of collaborative management is what non-performing art organizations have striven to find in attempting to solve the perennial problems that impede group efficiency and innovation.

Music improvisation is an unceasing struggle to collectively develop a structure that all musicians can rely on and add new ideas to. The persistent dichotomies of improvisation performing and composing, rigidity and flexibility, freedom and constraint, leading and following - are the driving forces of jazz musicians' practice. Indeed, what makes improv practices so effective among musicians is the balance between those forces. This balance is established by a negotiation process, in which musicians offer and learn different musical ideas. Musical improvisation is like a language formed with a grammar structure and vocabulary learned through years of practice. The musician's job within this idiomatic frame is to articulate 
and develop a dialogic process of give and take, hopefully finding "the groove" in the process. In this musical/social interaction, the groove is the optimal moment in improvisation, which can provide group effectiveness and individual satisfaction. In order to achieve this momentum, some behavioural aspects are essential considering musicians' reactions to different stimuli during a jam session.

In collaborative studies, improvised dialogue has two main characteristics. First, this dialogue is an evaluative and cyclical process of elaboration and refinement of ideas according to a collective mind-set. Second, this process has to proceed from the use of lower-level structures to higher-level structures. That means that musicians, to perform a song with different musical elements, need to consider the use of musical instruments, the musical setting, as well as the specific musical statements of their co-performers. Alternation between leading and following roles, provocative competence, rule of agreement, and embracing errors are among the most important rules of improvisation to boost collaboration and manage conflict in interaction.

Following the musical metaphor, in creative design processes participants invent ideas through sketches, 3D models, and storytelling, just like musicians improvise a song by playing their musical instruments. 


\subsection{Recommendation}

The groups were compared according to the emergence of conflictual events, the use of collaborative components, the alternation of roles, and the process of evaluation. As a result, three main issues were highlighted from the observation and interview with musicians: verbalization, task definition and validation are interrelated in both musical and design improvisation. Group efficiency is related to the level of individual expression in performance. The musical ensemble made it clear that the exchange of ideas should be made through diverse streams. If there is only one channel of communication, such as verbalization, friction can become a significant problem in collaboration. In order to diversify the channels of communication within a collaborative team, it is important to define individual tasks and roles within a group, creating multiple overlapping performance zones that enable each group member to contribute effectively to the whole.

If design is a practice of creating new user experiences, design teams should be constantly making use of mediums that can provide or simulate those experiences. A source of interpersonal conflict might be the lack of opportunities for individual expression and the overreliance on design outcomes, which tend to emphasize group goals instead of the agency of individuals within the group. In much the same way that the musicians in an effective musical ensemble have different instrumental roles, the members of an interdisciplinary design team must play different roles, including such activities as prototyping and sketching. However, these activities demand considerable preparation and domain knowledge to be performed in crossfunctional groups. Hence, discussion, storytelling and written documents become essential parts of a cross-functional process. Still, from an improvisational point of view, design retains a 
vernacular language of practice that is not primarily related to written documents. It is a process of storytelling in which narratives are constructed and elucidated through the representation of ideas through diagrams and the manipulation of objects/models.

In the design teams, there was a visible strain in group dialogue due to the fact that the groups' main strategy for idea generation was verbalization. As a result, participants spent an extended time probing ideas, which could only be elaborated and refined with the use of mediums or instruments, such as models and personal objects. However, sketches, notes, and 3D models became more individualistic activities rather than collaborative. Personal objects were effective in creating a focused discussion because they offered group members a means to express their personal experiences as they related to the design problem. In the musical ensemble, musical instruments were the main vehicles for self-expression, conveying different experiences, styles, and attitudes (aspects that enriched the improvisational performance).

Of course, verbalization was inevitable, particularly in the analyzed design teams in which individual tasks were not well clarified in advance and the majority of the group did not have the necessary training or tools to sketch or prototype. Verbal discussion is possibly the easiest way to develop and expose an idea, yet for the rest of the group it creates a certain barrier to creative communication. In this sense, talking should be mediated by tangible mediums in an attempt to rapidly validate performance. When using computers, car controllers, glasses and a cup of coffee, for example, the participants created stories related to these objects, which helped to elucidate the particular design problems that the group was grappling with. Storytelling, an activity widely performed by all members of the design groups, created new possibilities, refined 
ideas, and managed emergent conflicts that could have been harmful to the design performance.

Brown summarizes the importance of storytelling to the design process as follows:

At the heart of any good story is central narrative about the way an idea satisfies a need in some powerful way. (...) As it unfolds, the story will give every character represented in it a sense of purpose and will unfold in a way that involves every participant in the action. It will be convincing but not overwhelm us with unnecessary detail. It will include plenty of detail to ground it to some plausible reality.

(Brown, 2009:137).

Storytelling helps to visualize an idea as it unfolds over time, particularly when the narrative elements are supported by non-verbal visual elements (Brown, 2009).

Design ideas require a skilful representation and manipulation of reality. This is similar to the performing arts, such as music, theatre, painting, and cinema, which also depend vitally on domain-specific knowledge and skills, creative problem-solving abilities, and craftsmanship. Improvisation can teach us about the quest for a form of design artistry, in which thinking and crafting have to be in tune. In this sense, verbal communication in design must be balanced with experimentation. Design experimentation, in this scope, does not necessarily need to be restricted to prototyping and sketching, but can be also manifested through the playful and metaphoric use of different objects.

In jazz improvisation, performing and composing on the spur of the moment requires a retrospective method of action; musicians cannot predict the future, so they must rely on past experiences to produce innovative musical statements. Improvisational design artistry requires a "library" of favourite products, objects, books, designers, just like musicians have favourite albums and artists. This library symbolizes the improviser's knowledge, capability, commitment and inspirations; it prepares her/him to tackle a variety of unpredictable problems. In design, problems should be resolved by tapping into each performer's library. In the design groups, participants seemed to be overly concerned with finding a design solution right away, 
overlooking the ability of individual group members to provide fresh, diversified and inventive ideas that could have lead to even more innovative design solutions.

Musical improvisation provides a useful model for the management of conflict and collaboration in design teams because of the way musicians use previous preparation and ongoing practice to balance performance and composition, constraint and freedom, leading and following, chaos and coordination. Thus, conflict can be managed and collaboration can be enhanced in interdisciplinary design groups by:

- Defining a basic task for each team-mate based on their past experience knowledge. Task definition provides an individual zone of interaction and controls the overlap of different actions by dosing the degree of friction in performance;

- Using each individual's particular strengths to develop design solutions;

- Fostering the utilization of objects that are familiar to performers. Familiarity creates stories that validate an individual's idea. It creates structure and builds trust among members;

- Validation means recognition of the fellow's action. Functioning as a rewarding system, improvisation presents constant iteration of valid ideas. The iteration of ideas will eventually be related to individual's satisfaction and performance structure in group interaction;

- Creating discussions based on various objects played, which can provide iteration. The use of diverse objects channels the discussion of the design idea creating enough friction that can advance the performance. 


\subsection{Contributions}

It is important to note that all design teams analyzed in this research delivered successful and satisfactory project outcomes at the end of the semester. Innovation was achieved according to the agenda and the students fulfilled the expectations of the stakeholders. Therefore, it is valid to state that this research explored conflict and collaboration within a short-time frame compared to the amount of work the students developed. Still, the results presented here are significant since they provide valuable insights that can be evaluated in further studies. By applying improvisational theories to design practices and research, this research offers a model of empowerment for individuals working within a group setting.

\subsection{Direction for further studies}

This research provides a conceptual foundation of improvisation for design teams towards the optimization of conflicts, effective collaboration and product innovation. The idea of an improvisatory form for team collaboration raises new questions for further analysis. In order to provide a concise model, it is necessary to pursue future exploratory analyzes with jazz bands or theatre troupes, which are able to provide different insights from their practice.

In design groups, a focus on different narratives elucidated through found objects or experiences may offer new opportunity for study. Storytelling provided opportunities for the design groups to define comfort zones of task performance. As an improvisatory technique, storytelling can spark creativity and inventiveness based on past or imagined experiences. A possible method to foster storytelling in design groups is the utilization of ordinary objects which can serve as creative metaphors for design solutions. 
Verbal communication is integral to the design process but it can also be a source of tension. Further studies in this area might be able to expose different types of verbal communication that exist in the design process and why they are often connected to conflict. This research presents an initial contribution to the design field. The conceptual foundation of improvisation learned from musical performance creates new possibilities for further studies on the improvement of design creative methods and tools, team management, collaboration and creativity studies, and product innovation. As a group activity, improvisation can promote the empowerment of those involved in creative processes, increasing group capacity to rapidly innovate through authentic and legitimate individual experiences. 


\section{BIBLIOGRAPHY}

Akgün, A. and Lynn, G. (2002). New product development team improvisation and speed-tomarket: an extended model. European Journal of Innovation Management 5(3): 117-129.

Bailey, D. (1980). Improvisation: its Nature and Practice in Music. Ashborune: Moorland Pub.

Barrett, F. (2002). Creativity and improvisation in jazz and organizations: implications for organizational learning. In Organizational Improvisation, edited by K. Kamoche, M. Cunha and J. Cunha (pp. 135-162). New York: Routledge.

Bastien, D. and Hostager, T. (2002). Jazz as a process of organizational innovation. In Organizational Improvisation, edited by K. Kamoche, M. Cunha and J. Cunha (pp. 13-26). New York: Routledge.

Berliner, P. (1994). Thinking in Jazz. Chicago: University of Chicago Press.

Blum, S. (1998). Recognizing improvisation. In In the Course of Performance: Studies in the World of Musical Improvisation, edited by B. Nettl and M. Russell (pp. 27-46). Chicago: The University of Chicago Press.

Brown, S. and Eisenhardt, K. (2002). The art of continuous change: linking complexity theory and time-paced evolution in relentlessly shifting organizations. In Organizational Improvisation, edited by K. Kamoche, M. Cunha and J. Cunha (pp. 225-256). New York: Routledge.

Brown, T. (2009). Change by Design: How Design Thinking Transforms Organizations and Inspires Innovation. New York: HarperCollins.

Cho, A. (2010). The Jazz Process: Collaboration, Innovation, and Agility. Boston: Pearson Education, Inc.

Chung, W. (2009). Theoretical background of an early prototype use in cross-functional collaborative design context. Paper presented at the International Association of Societies of Design Research (IASDR).

Coker, J. (1964). Improvising Jazz. Englewood Cliffs: Prentice-Hall, Inc.

Coutu, D. (May 2009). Why teams don't work. Harvard Business Review, 99-105.

Creswell, J. (2003). Research design: qualitative, quantitative, and mixed method approaches (2nd Edition). Thousand Oaks: Sage Publications. 
Cross, N. \& Cross, A. (1995). Observations of teamwork and social processes in design. Design Studies 16(2):143-170.

Cross, N. (1996). Creativity in design: not leaping but bridging. Creativity and Cognition 1996: proceeding of the Second International Symposium. Loughborough: LUTCHI.

Crossan, M. and Sorrenti, M. (2002). Making sense of improvisation. In Organizational Improvisation, edited by K. Kamoche, M. Cunha and J. Cunha (pp. 27-48). New York: Routledge.

Ciborra, C (2002). The Labyrinths of Information: Challenging the Wisdom of Systems, Oxford: Oxford University Press.

Dane, E. and Pratt, M. (2007). Exploring intuition and its role in managerial decision making. Academy of Management Review, 32(1), 33-54.

Danzico, L. (2010a). From Davis to David: lessons from improvisation. Interactions, 20-23. doi: $10.1145 / 1699775.1699780$

Danzico, L. (2010b). The design of serendipity is not by chance. Interactions, 16-18. doi: $10.1145 / 1836216.1836220$

Davis, M. (1989). Miles: The Autobiography (1st ed.). New York: Touchstone.

Dean, R. (1992). New Structures in Jazz and Improvised Music since 1960. Philadelphia: Open University Press.

De Dreu, C. \& Weingart, L. (2003). Task versus relationship conflict, team performance, and team member satisfaction: a meta-analysis. Journal of Applied Psychology, 88(4), 741-749.

Faulkner, R. \& Becker, H. (2009). "Do you know...?" The Jazz Repertoire in Action. Chicago: The University of Chicago Press.

Fischlin, D. \& Heble, A. (2004). The Other Side of Nowhere: Jazz, Improvisation, and Communities in Dialogue. In The Other Side of Nowhere: Jazz, Improvisation, and Communities in Dialogue, edited by D. Fischlin \& A. Heble (pp. 1-42). Middletown: Wesleyan University Press.

Fortier, B. (2008). Long Form Improvisation: Creating Spontaneous Communities Through Collaborative Comedic Performance (Master's thesis). Retrieved from ProQuest Dissertations and These database. (UMI No. 1476647) 
Frankel, L. and Tsuji, B. (2005). Cross-Functional Design Leadership: Learning from the Future that Was. Paper presented at the IDSA National Education Conference. Retrieved September 1, 2009, from http://new.idsa.org/webmodules/articles/anmviewer.asp?a $+2084 \& z=131$

Gasson, S. (2009). "Design as a trajectory of goal-definitions." Accessed September 20, 2010. http://blog.improv-design.com, 2009

Gasson, S. (2010). "Design as bricolage." Accessed September 20, 2010. http://blog.improvdesign.com, 2009

Gerber, E. (2007). Improvisation Principles and Techniques for Design. CHI 2007 Proceedings: Learning \& Education, 1069 - 1072.

Gerber, E. (2009). Using Improvisation to Enhance the Effectiveness of Brainstorming. CHI 2009 Proceedings: Expertise/People Finding, 97 - 104.

Gioia, T. (1988). The Imperfect Art. New York: Oxford University Press.

Gladwell, M. (2005). Blink: the Power of Thinking without Thinking. New York: Little, Brown and Company.

Hansen, M. (2009). Collaboration: How Leaders Avid the Traps, Create Unity, and Reap Big Results. Boston: Harvard Business Press.

Heble, A. (2000). Landing on the Wrong Note: Jazz, Dissonance, and Critical Practice. New York and London: Routledge.

Hodson, R. (2007). Interaction, Improvisation, and Interplay in Jazz, New York: Routledge.

Hough, K. (2011). The Improvisation Edge: Secrets to Building Trust and Radical Collaboration at Work. San Francisco: Barrett-Koehler Publishers, Inc.

Jehn, K. (1995). A multimethod examination of the benefits and detriments of intragroup conflict. Administrative Science Quarterly, 40(2), 256-282.

Jehn, K. \& Mannix, E. (2001). The dynamic nature of conflict: a longitudinal study of intragroup conflict and group performance. The Academy of Management Journal, 44(2), 238-251.

Kelley, T. (2001). The Art of Innovation: Lessons in Creativity from IDEO, America's Leading Design Firm. New York: Doubleday 
Kamoche, K. and Cunha, M. (2001). Minimal structures: from jazz improvisation to product innovation. Organization Studies, 22(5):733-764. Available at: http://oss.sagepub.com/ cgi/doi/10.1177/0170840601225001 [Accessed February 7, 2011].

Kamoche, K., Cunha, M. \& Cunha, J. (2002). Introduction and Overview. In Organizational Improvisation, edited by K. Kamoche, M. Cunha and J. Cunha (pp. 1-12). New York: Routledge.

Lawrence, D. and Thomas, J (1988). Social Dynamics of Storytelling: Implications for StoryBase Design. Discourse. 1988-1991.

Lawson, B. (1997). How Designers Think: The Design Process Demystified (3rd ed.). Oxford: Architectural Press.

Lewis, G. (2004). Improvised Music after 1950: Afrological and Eurological Perspectives. In The Other Side of Nowhere: Jazz, Improvisation, and Communities in Dialogue, edited by D. Fischlin \& A. Heble (pp. 131-162). Middletown: Wesleyan University Press.

Magni, M., Proserpioa, L., Hoeglb, M. and Provera, B. (2008). The Role of Team Behavioural Integration and Cohesion in Shaping Individual Improvisation. Research Policy 38(6): 1044 - 1053.

Martinez, A. (2010, December 14). The Improvisational Brain. Seedmagazine.com, Retrieved May 27, 2011 from http://seedmagazine.com/content/print/the_improvisational_brain/

Miner, A., Bassoff, P. and Moorman, C (2010). Organizational and Improvisation Learning: A Field Study. Science, 46(2):304-337.

Monson, I. (1996). Saying Something: Jazz Improvisation and Interaction. Chicago and London: The University of Chicago Press.

Moorman, C. and Miner, A. (2002). The Convergence of Planning and Execution: Improvisation in New Product Development. In Organizational Improvisation, edited by K. Kamoche, M. Cunha and J. Cunha (pp. 257-290). New York: Routledge.

Morris, M., Nadler, J., Kurtzberg, T. and Thompson, L. (2002). Schmooze or Lose: Social Friction and Lubrication in E-mail Negotiations. Group Dynamics, Theory, Research \& Practice 6(1), 89-100.

Oliveros, P. (2004). Harmonic anatomy: Women in improvisation. In The Other Side of Nowhere: Jazz, Improvisation, and Communities in Dialogue, edited by D. Fischlin \& A. Heble (pp. 87-130). Middletown: Wesleyan University Press. 
Pollack, S. (2005). Sketches of Frank Gehry. United States: Sony Pictures.

Sadie, S. (1988). The Grove Concise Dictionary of Music. London: Macmillan Press.

Sanders, E. and Stappers, P. J. (2008). Co-creation and the new landscapes of design. CoDesign, 4(1):5-18.

Santi, M. and Illetterati, L. (2010). Improvisation between performance art and lifeworld. In Improvisation: Between Technique and Spontaneity, edited by M. Santi (pp. 1-6). Newcastle: Cambridge Scholars Publishing.

Sawyer, K. (1997). Pretend Play as Improvisation: Conversation in the Preschool Classroom. New Jersey: Lawrence Erlbaum Associates.

Sawyer, K. (2003a). Improvised Dialogues: Emergence and Creativity in Conversation. Westport: Ablex Publishing.

Sawyer, K. (2003b). Group Creativity: Music, Theatre, Collaboration. Mahwah: Laurence Erlbaum Associates.

Sawyer, K. (2007). Group Genius: The Creative Power of Collaboration. New York: Basic Books.

Schwartz, P., \& Kelley, K. (1996, August 4). The Relentless Contrarian. Wired 116(4.08), 1-5.

Sonnenwald, D. (1996). Communication roles that support collaboration during the design process. Design Studies 17(3): 277 - 301.

Soules, M. (2004). Improvising character: jazz, the actor, and the protocols of improvisation. In The Other Side of Nowhere: Jazz, Improvisation, and Communities in Dialogue, edited by D. Fischlin \& A. Heble (pp. 268-297). Middletown: Wesleyan University Press.

Vrooman, R. (1997). Group Process Tools: Teams and Quality. Alexandria: The American Society for Training \& Development.

Walser, R. (1993). Out of Notes: Signification, Interpretation, and the Problem of Miles Davis. Musical Quarterly, 77(2): 343-365. doi:10.1093/mq/77.2.343

Weick, K. (2002). Managing as Improvisation: Lessons from the World of Jazz. In Organizational Improvisation, edited by K. Kamoche, M. Cunha and J. Cunha (pp. 49-69). New York: Routledge.

Yudkin, J. (2008). Miles Davis, Miles Smiles, and Invention of the Post Bop. Bloomington: Indiana UniversityPress. 


\section{GLOSSARY}

Bars

Blues

Chord

Chordal Progression

Chorus

Chromaticism

Ethnomusicology

Harmony

Lead Sheets

Note (Music Notation)
Bars are vertical lines used to delimit metrical units in written music. They have been especially recurrent to soloists since the XVII century (Sadie, 1988).

Blues is a 20th century African American music, which has affinities with jazz. The word describes a melancholic mood characterized by harmonic progressions in 8 , 12 and 32 bars. The most common is 12 bars (Sadie, 1988).

A simultaneous sound of two or more musical notes (Sadie, 1988).

A succession of chords, or similar musical structures, which keep a harmonic coherence (Sadie, 1988).

A part of a song that is repeated after each verse, typically by more than one singer (Sadie, 1988).

The use of notes that do not make part of the tonal scale of a composition (Sadie, 1988).

A branch of the Musicology, which emphasizes music in its cultural context; the anthropology of music (Sadie, 1988).

The combination of notes vibrating simultaneously to produce chords or chordal progressions (Sadie, 1988).

A lead sheet is a type of music notation which summarizes the content of a song. The usual elements are the melody, chords, tempo, time signature, style and the lyrics, if any (Sadie, 1988).

A visual equivalent to the musical sound, which serves as a register of the heard sound to interpreters (Sadie, 1988). 
Phonographic Recording

Syncopation
In 1877, Thomas Edison made the first sound recording that could be played in his "phonograph," a machine with a metalic cylinder engraved by blade according to sonic vibrations. Attached to it, an acoustic tube reproduced the engraved vibrations (Sadie, 1988).

A shift in the song time in a cadenced pattern always in the same value behind or ahead of its regular position in the bars (Sadie, 1988). 
APPENDIX A LitScape 


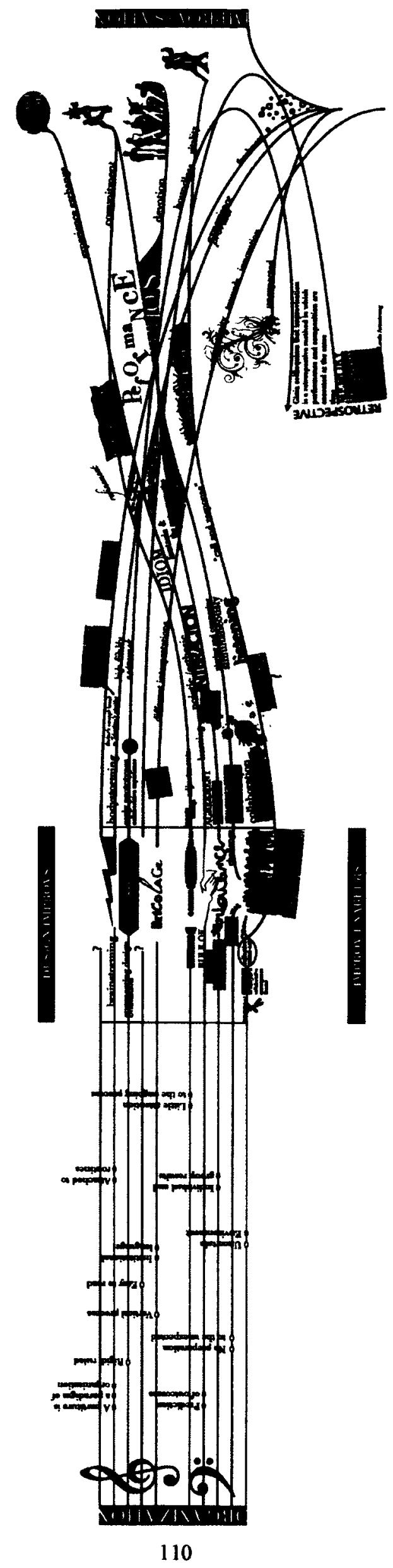


APPENDIX B Creative Methods 
B1. Brainstorming Rules (Vrooman, 1997)

1. State the issue or problem.

2. Instruct team members to generate as many ideas or solutions as possible.

3. Review the four ground rules of brainstorming: No criticism of an idea is allowed.

Strive for the longest list possible-go for quantity. Strive for creativity - "wild and crazy" ideas are encouraged. Build on the ideas of others - "hitchhike" and "piggyback."

4. After an allotted time (no more than $\mathbf{4 5}$ minutes is suggested), share ideas one at a time.

5. Write all the ideas on a flipchart or whiteboard.

6. Review the list and select the best ideas for further consideration. This is done by the team or a representative task force.

Developed in the 1930 s by Alex Osborn. 


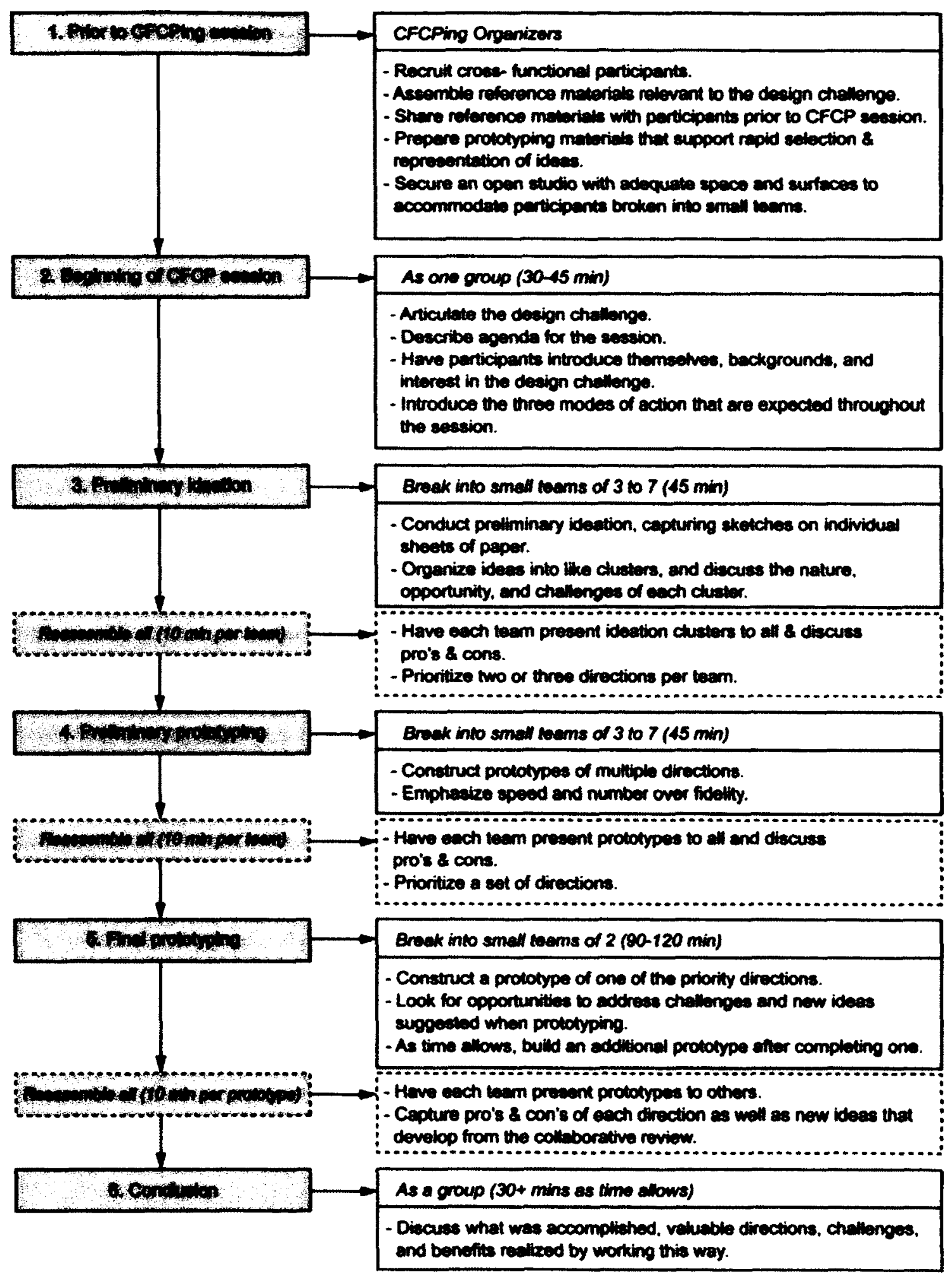




\section{APPENDIX C Ethics Documentation}




\section{- Carleton}

Cenada's Capitel Univeraty

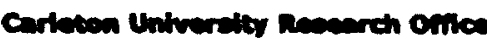

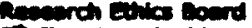

5' Foor Tory buldere 1125 colon bon

Otrme, ow k1s ses conad

Th: $613-520-2517$

Fax: 613-520-252

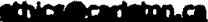

\section{Ethics Clearance form}

This is to certify that the Carleton Untversity Research Ethics Board has examined the epplication for ethical clearance. The REB found the research project to meet appropriate ethical standards as outlined in the Tri-Coundl Policy Statement: Ethical Conduct for Research Involwing Humans and, the Carteton University Pallctes and Procedures for the Ethical Conduct of Reseanch.

a Now charence

$X$ Renewal of orloinal chearence Origlanal date of cleurance: 25 June 2010

Date of renewal Reasarcher

Status

Supervisor

Funding extus

Project number

Tite of project
32 May 2012

Lucen Lncenda

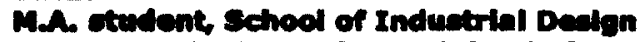

Profecoor Wonjoon Chung, Sehool of Inductutal Dealen

nem-tunded

12-1408

Embancing collaboration in creathie dealgp procwes: Lewcone from mesle buproviawion towarde efiectwe group integration

Ethics approval expires on: 31 May 2012

All recearchers are governed by the following condrilowa:

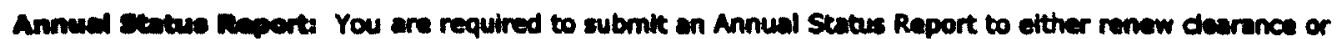
clowe the file. Fillure to eubmit the Annual Status Report will reault in the Immediate suspenaton of the project. Funded projects will have sccounts suepended unth the report ts exbmitted and approved.

Changes to the eroject: Any changes to the project must be subrnitted to the Carteton Univerally Research Ethics bound for epproval. All changes must be approvad prior to the continuence of the research.

Adveres crentas Should any pertidipant suffer adversely from their particlpation in the project you are required to report the mutter to the Carleton Universiky Recearch Echica Bourd. You must submit a wilten

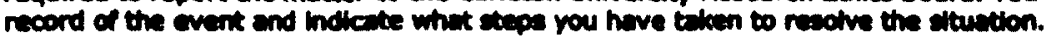

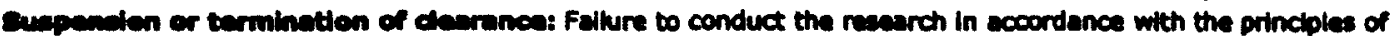

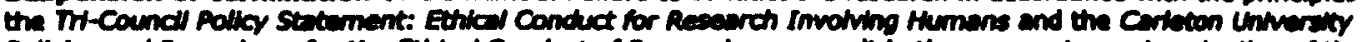

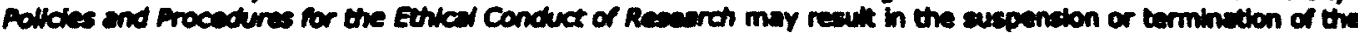
research project.

$$
\text { Antaio R. Gualtioni }
$$

Antonio R. Gualtier, Chalr

Carktion University Resoarch Ethics Board 
I, voluntarily agree to

participate in a research project conducted by Lucas Lacerda who is taking IDES 5099 in the Winter session 2011, and supervised by Professor Wonjoon Chung, School of Industrial Design, Carleton University.

Purpose: The study is a required experiment that will be used in thesis research and publication. The objective of the study is to understand improvisational interaction in music practice, and its applicability in collaborative design process.

Tasks and duration: You are asked to take part in an observation process that will take maximum 1 hour. If necessary, some questions will be posed in order to clarify any doubts related to the process. Right to withdraw: You may withdraw from participation any time without prejudice and you may omit answering any specific question if you choose.

Permission to video record the procedure: We request your permission to video record the session. The recorded material is going to be deleted after the completion of the study.

Potential of risk or discomfort: There are not known risks, physical or emotional, to participation in this study.

Anonymity/confidentiality: "I understand that my identity will be kept anonymous, that the data collected from this observation will be stored and analyzed collectively and used only for the stated research purpose. The data will be accessible only to the researcher named above and to his supervisor. All recorded data will be destroyed upon completion of the data analysis."

"I have read the above description of this research project. I acknowledge that I have received a personal copy of this form. I agree to participate in this research and I understand that I may withdraw at any time."

If you have any concerns regarding how this study was conducted please contact Lucas Lacerda (Graduate Student, School of Industrial Design, Carleton University, llacerda@carleton.connect.ca, (819) 923-9903), or WonJoon Chung (Assistant Professor, School of Industrial Design, Carleton University, wonjoon_chung@carleton.ca, (613) 520-6606).

Participant's Signature: Date: Date: 


\section{Debriefing}

Thank you for participating in this study that aims to investigate improvisational interaction in jazz music practice. The research is carried out as a thesis study in IDES 5009, which is conducted by Professor Wonjoon Chung whose details are provided below.

Your anonymity is assured; no individual will be recognizable, and no one other than the student researcher and his supervisor will have access to the data.

The findings of this study will be part of a work for a thesis research.

Your time and efforts are greatly appreciated! If you have any further questions or comments about this study, you may contact:

Lucas Lacerda at llacerda@connect.carleton.ca and on 8199239903.

Professor Wonjoon Chung at wonjoon_chung@carleton.ca and on 613 520-6606.

For any other concerns, contact Valerie Daley, (Administrative Assistant, School of Industrial Design, Carleton University, (613) 520-5672). 


\section{APPENDIX D Music Analysis}




\section{D1 Scans of Musicians' Behaviours}

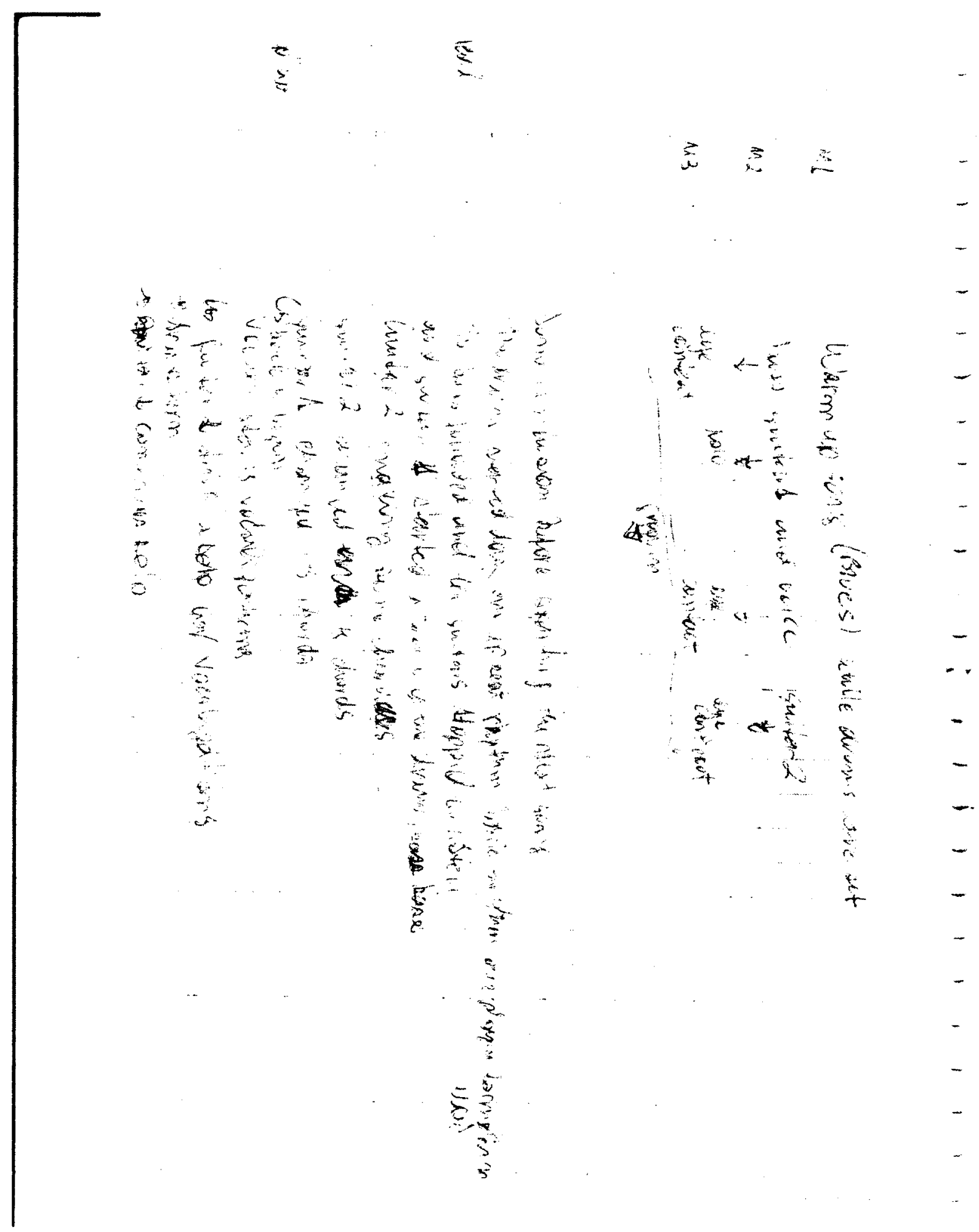




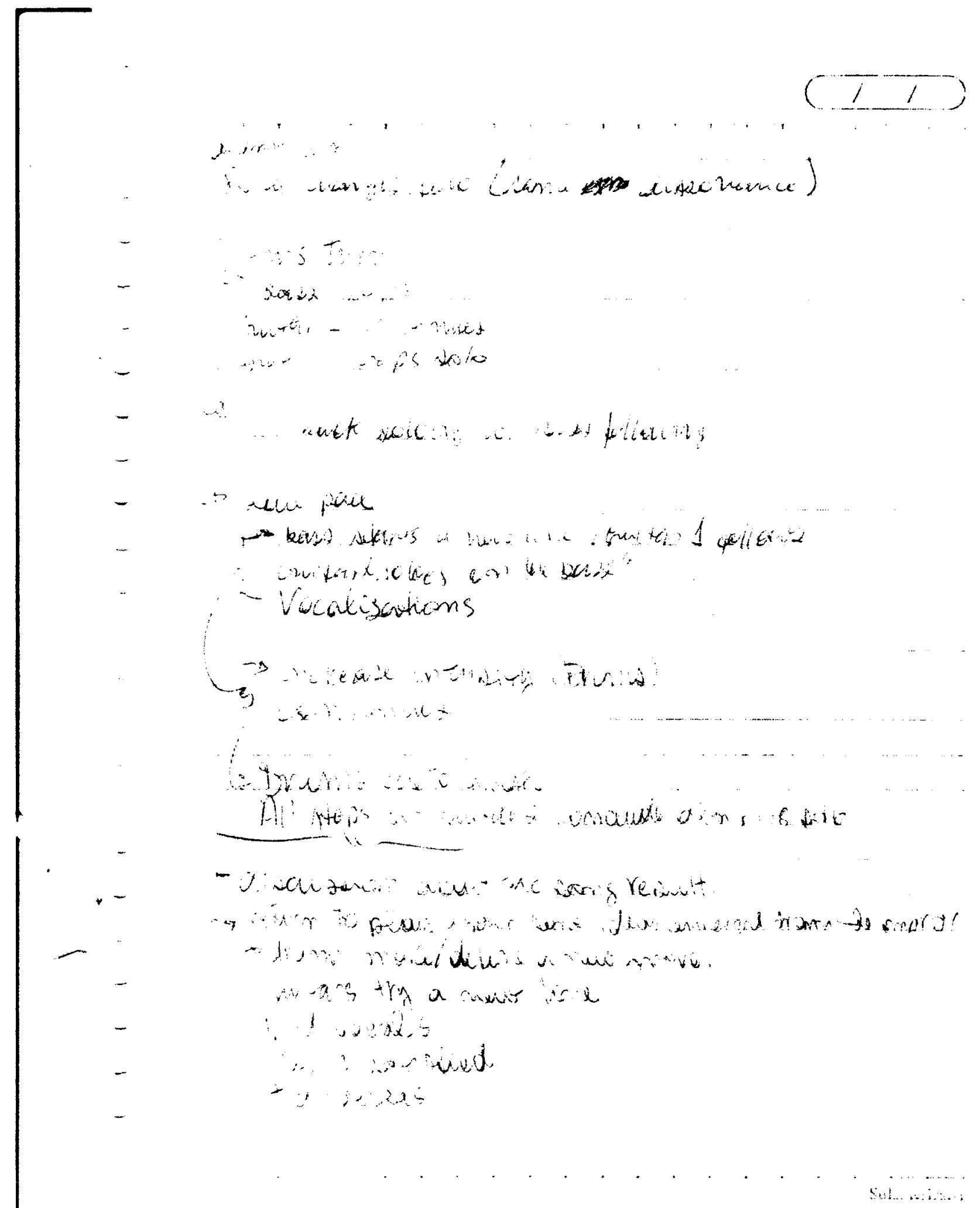

120 


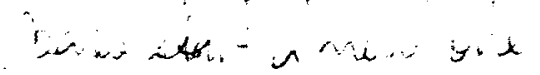

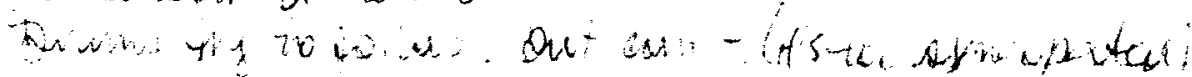

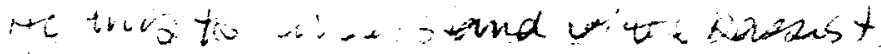

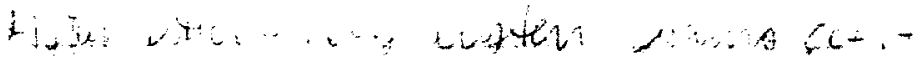

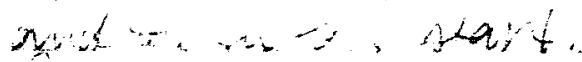$$
-\gamma \text {. } \cdots \ldots \ldots+\cdots
$$

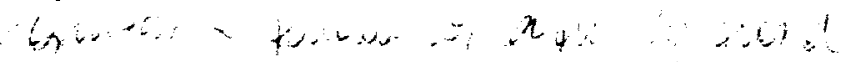

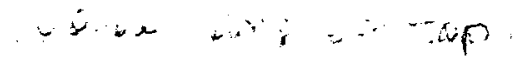

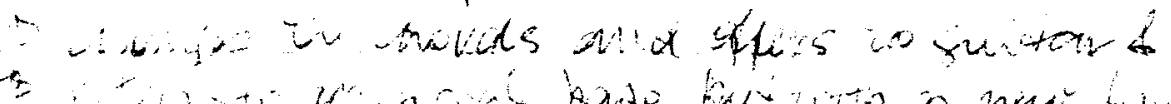

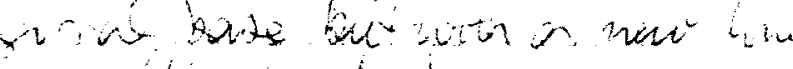

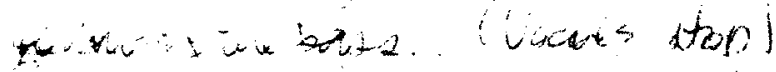

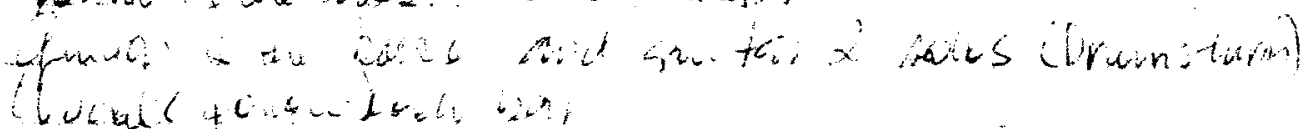

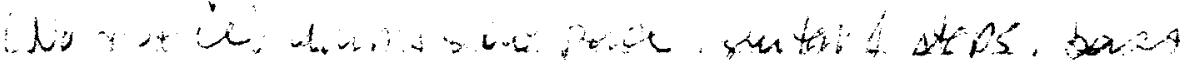

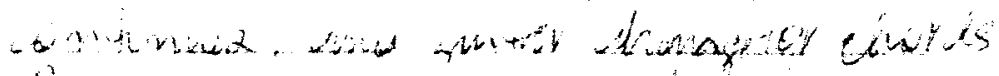

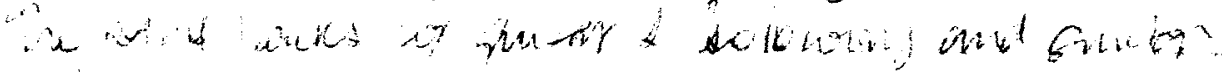$$
24060
$$

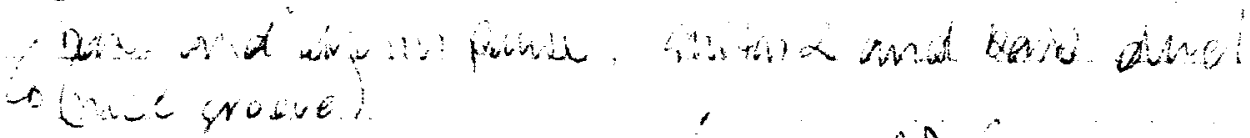

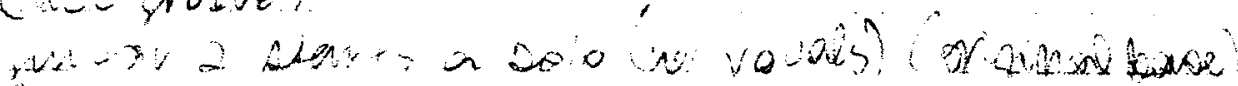

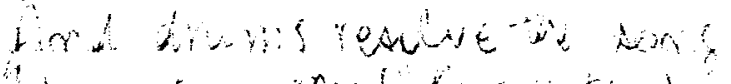

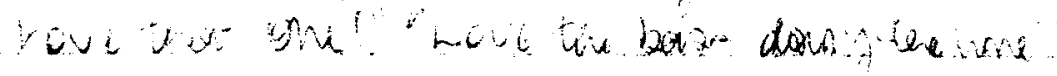

121 


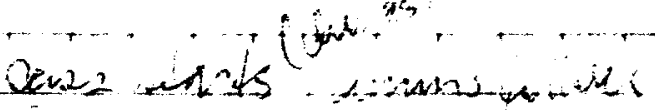

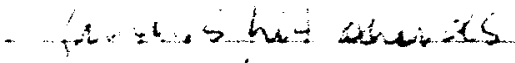

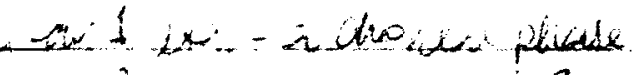

$(1,1)$

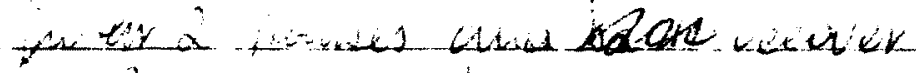

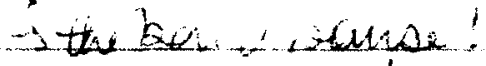

unvicin stivt

- tar raciover

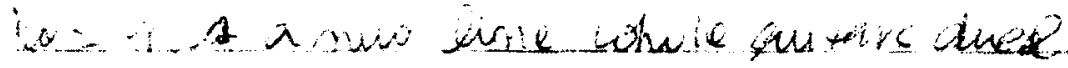

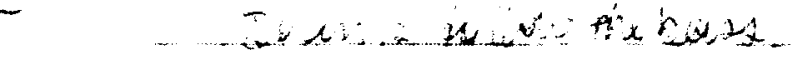

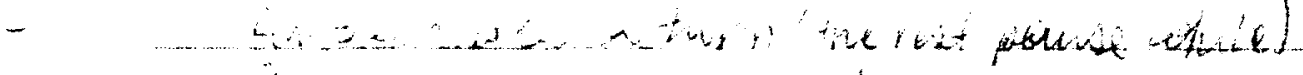

- Janca ine

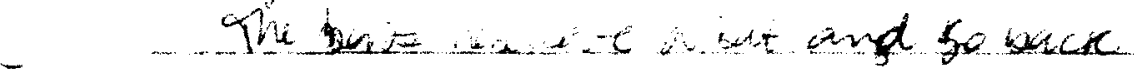

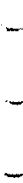

-

$-$ 


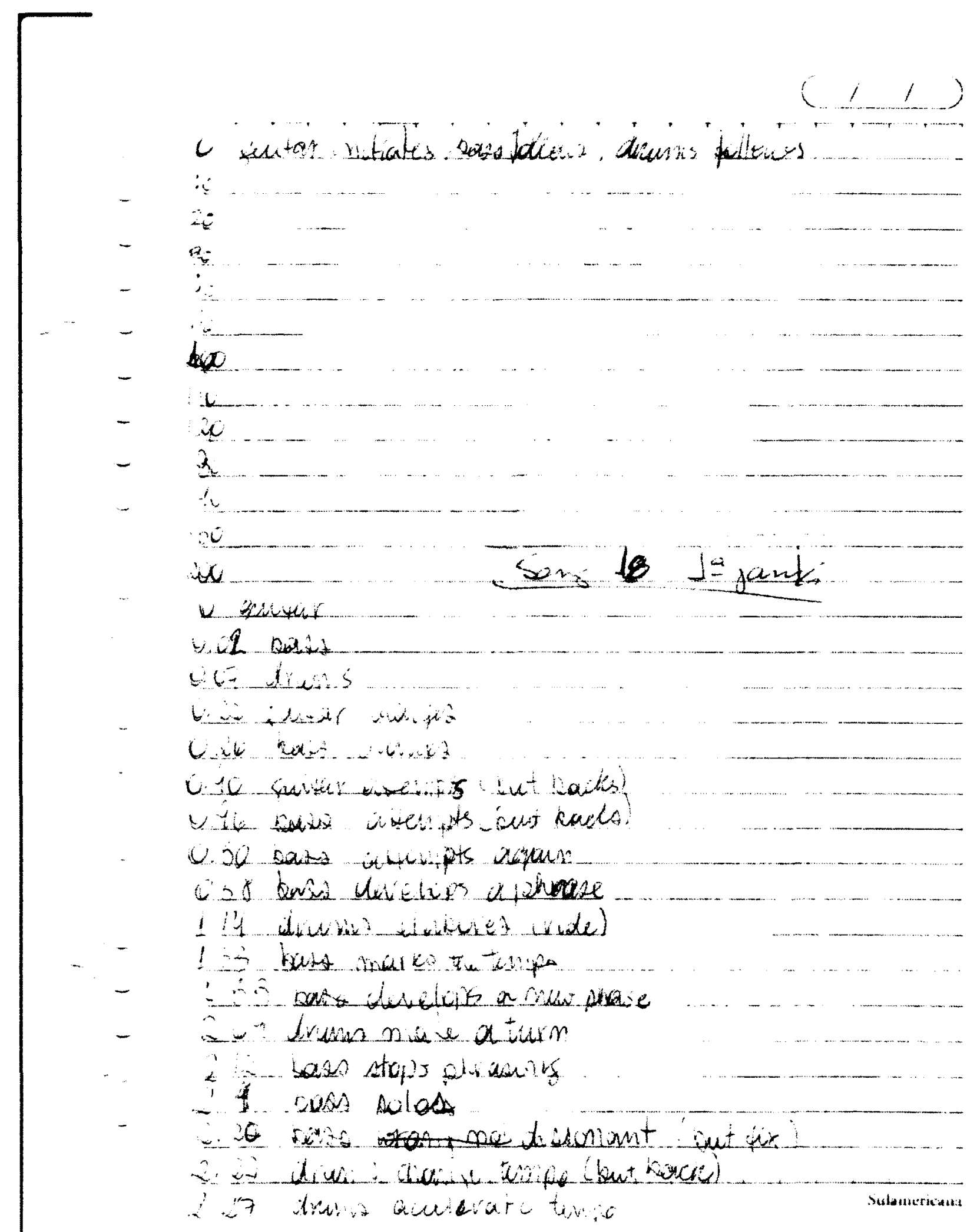

123 


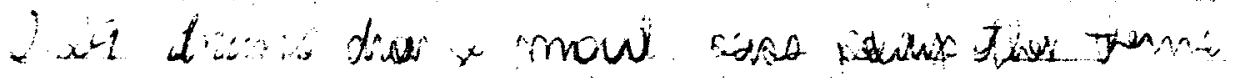

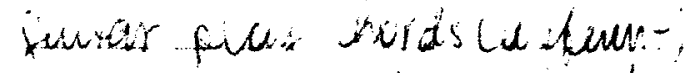

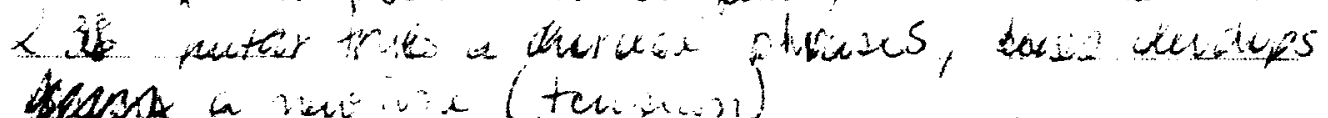

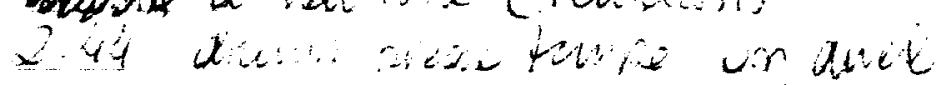

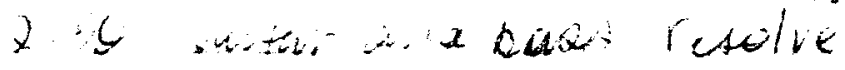

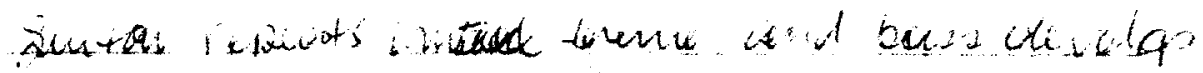

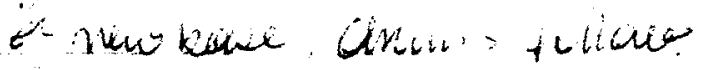

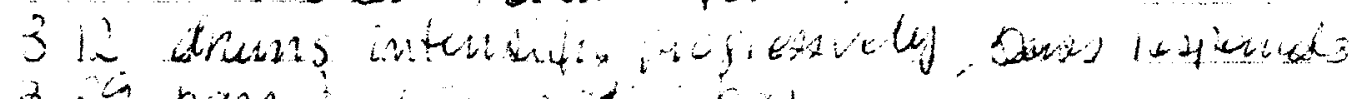

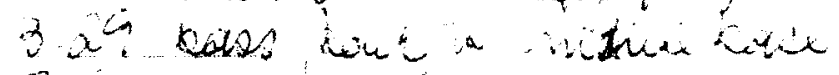

3 . 3 juntar suin

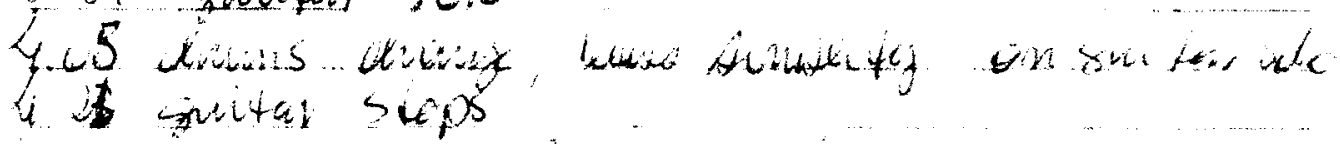

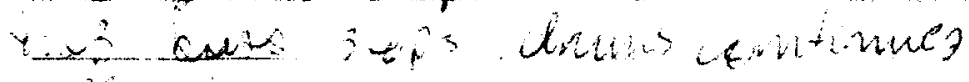

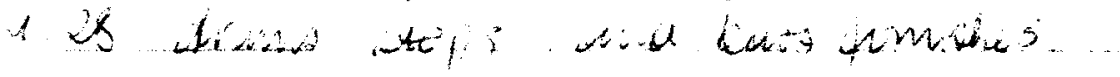

4 jomer

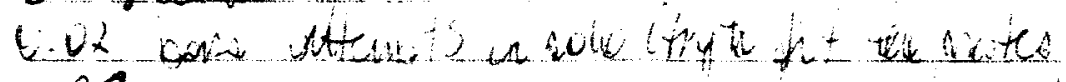

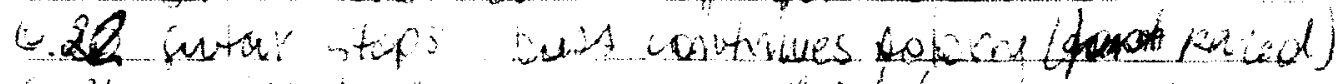

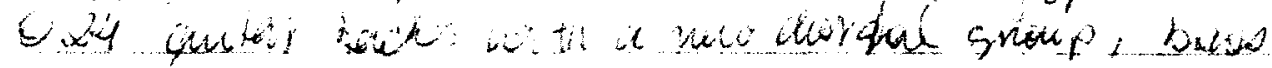

contimuat trofos

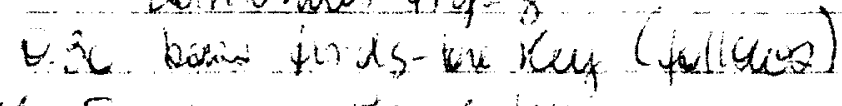

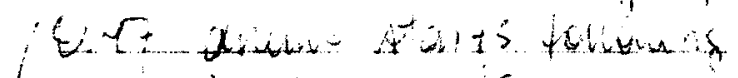

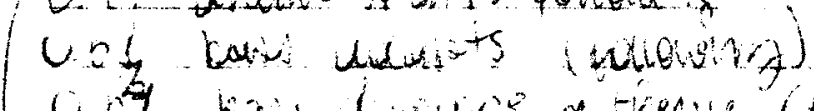

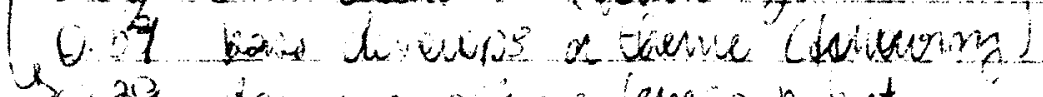

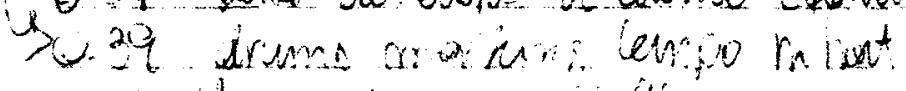

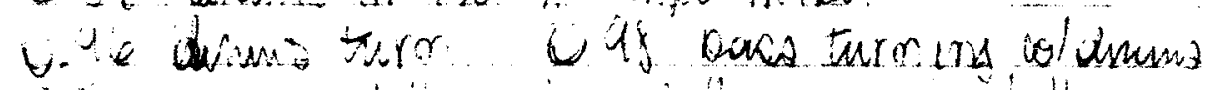

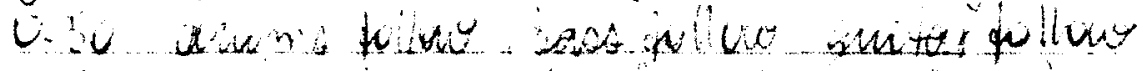

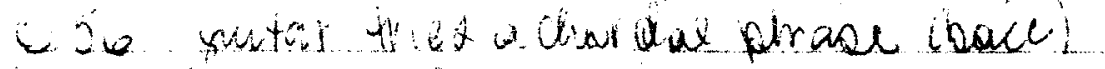

"L bajo divelars wivo.

124 

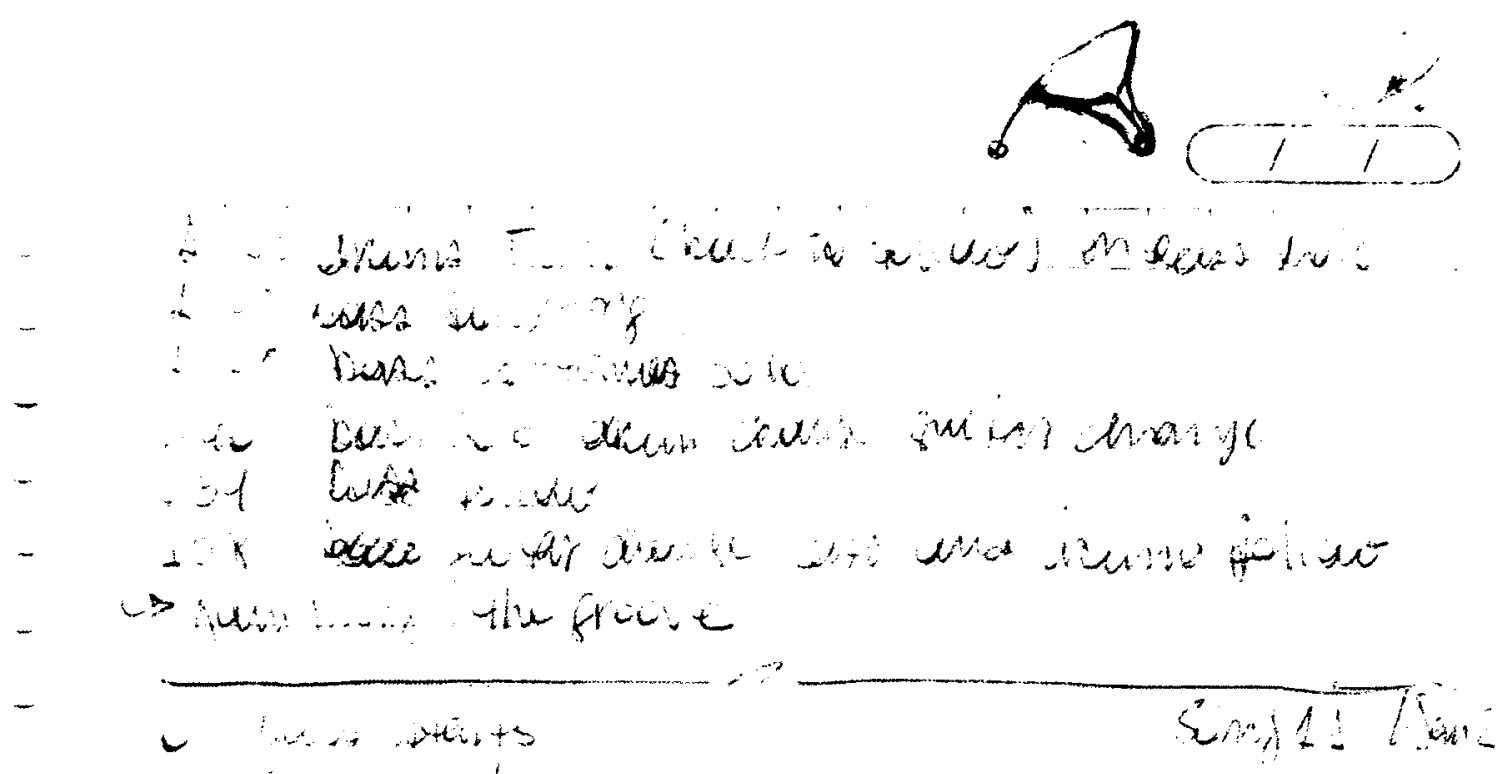

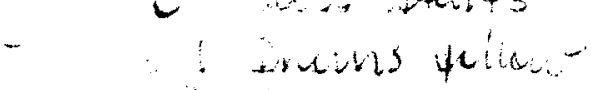

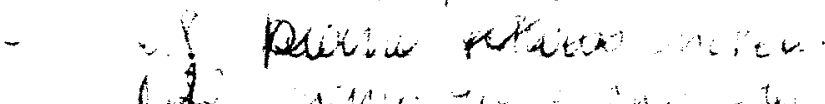

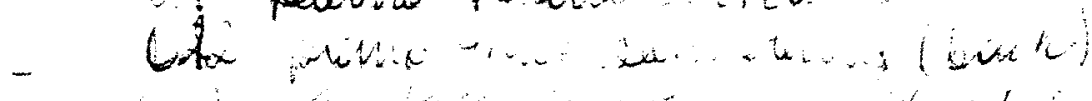

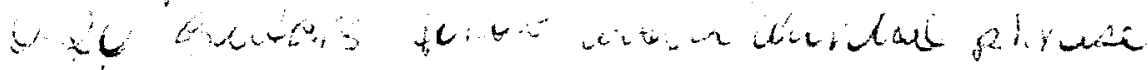

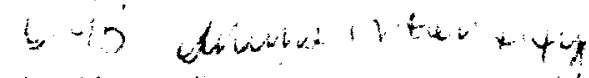

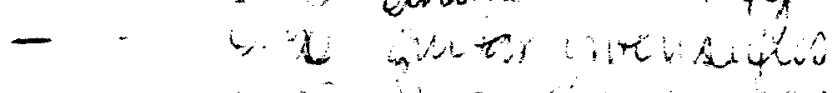

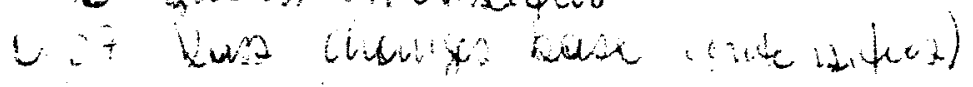

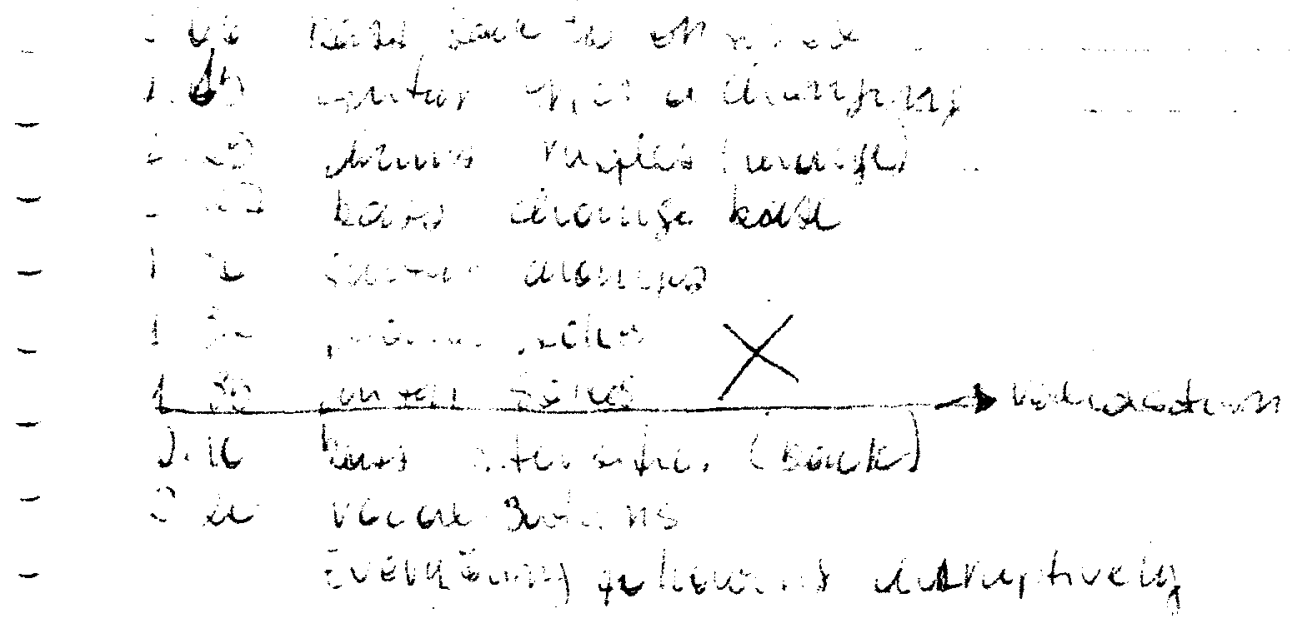

125 
D2 Graphic of Improvisational Interaction

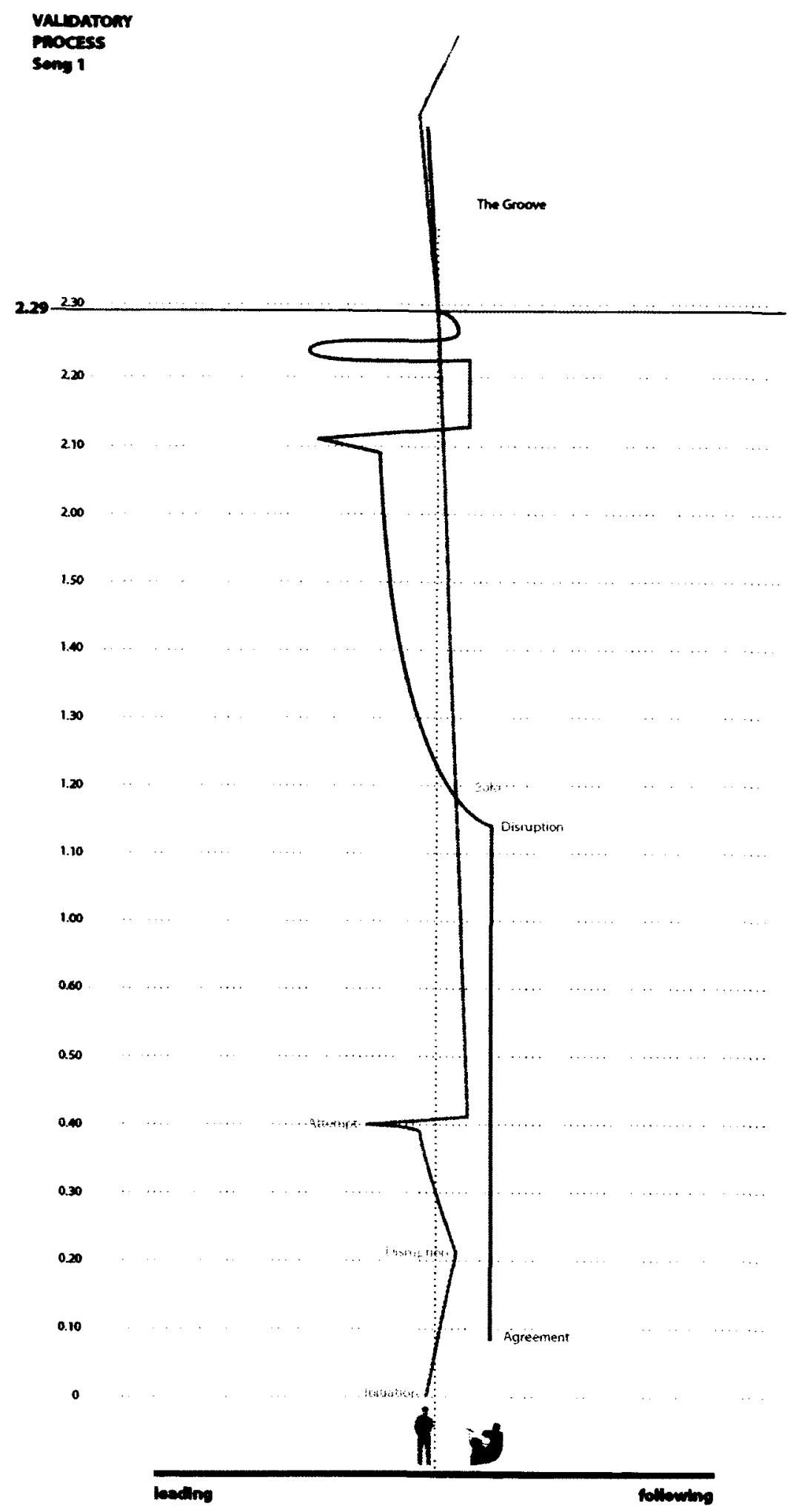


APPENDIX E Design Analysis 


\section{E1. Scans of Participants'Alternation of Roles}

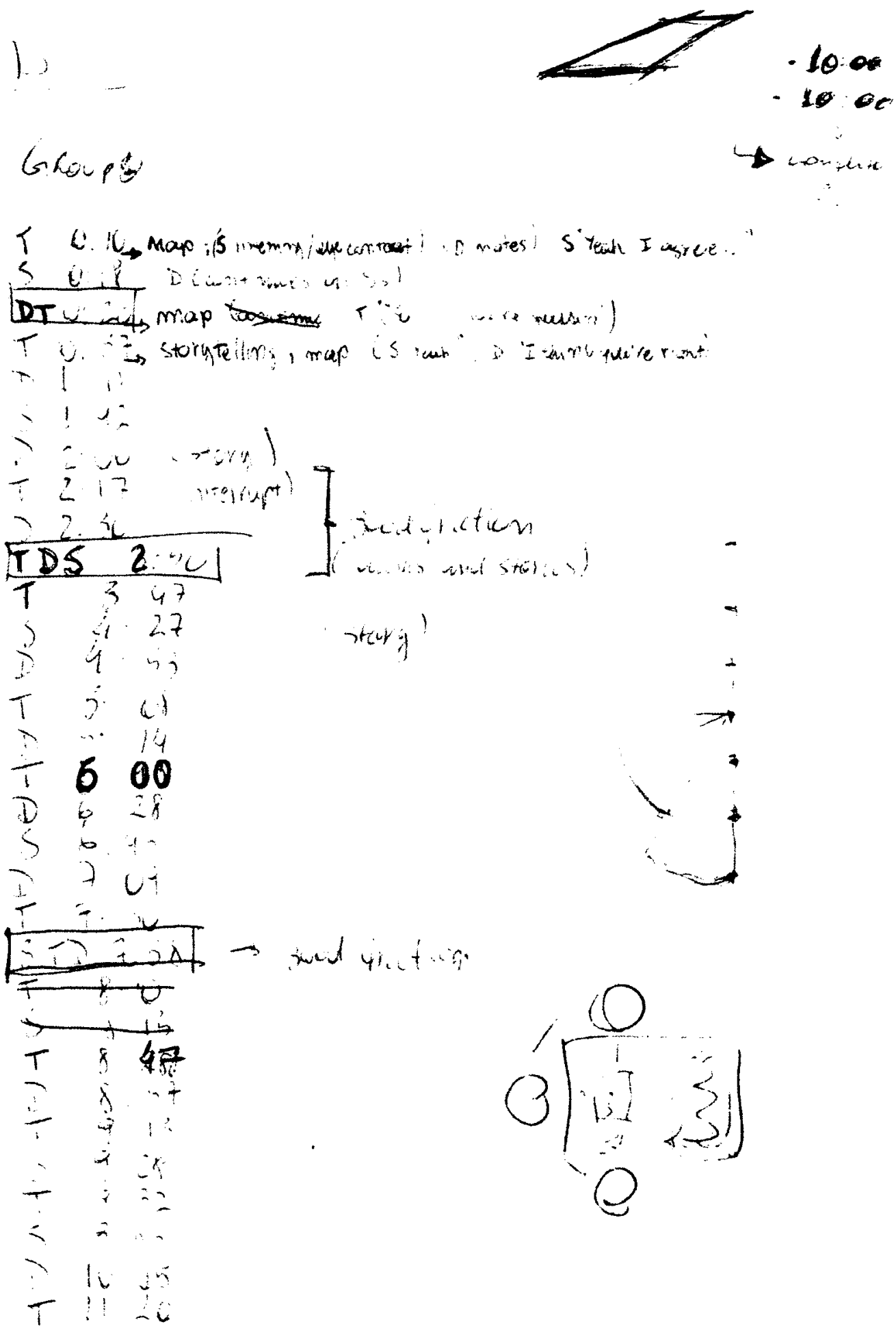




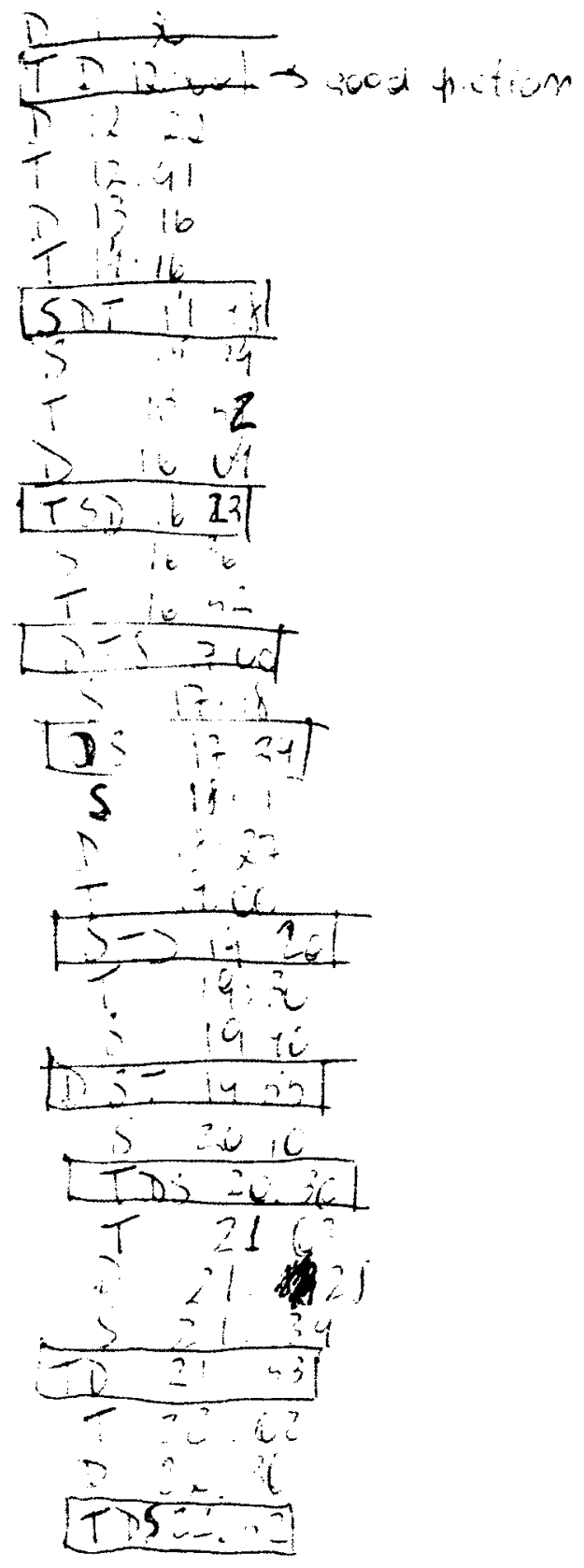




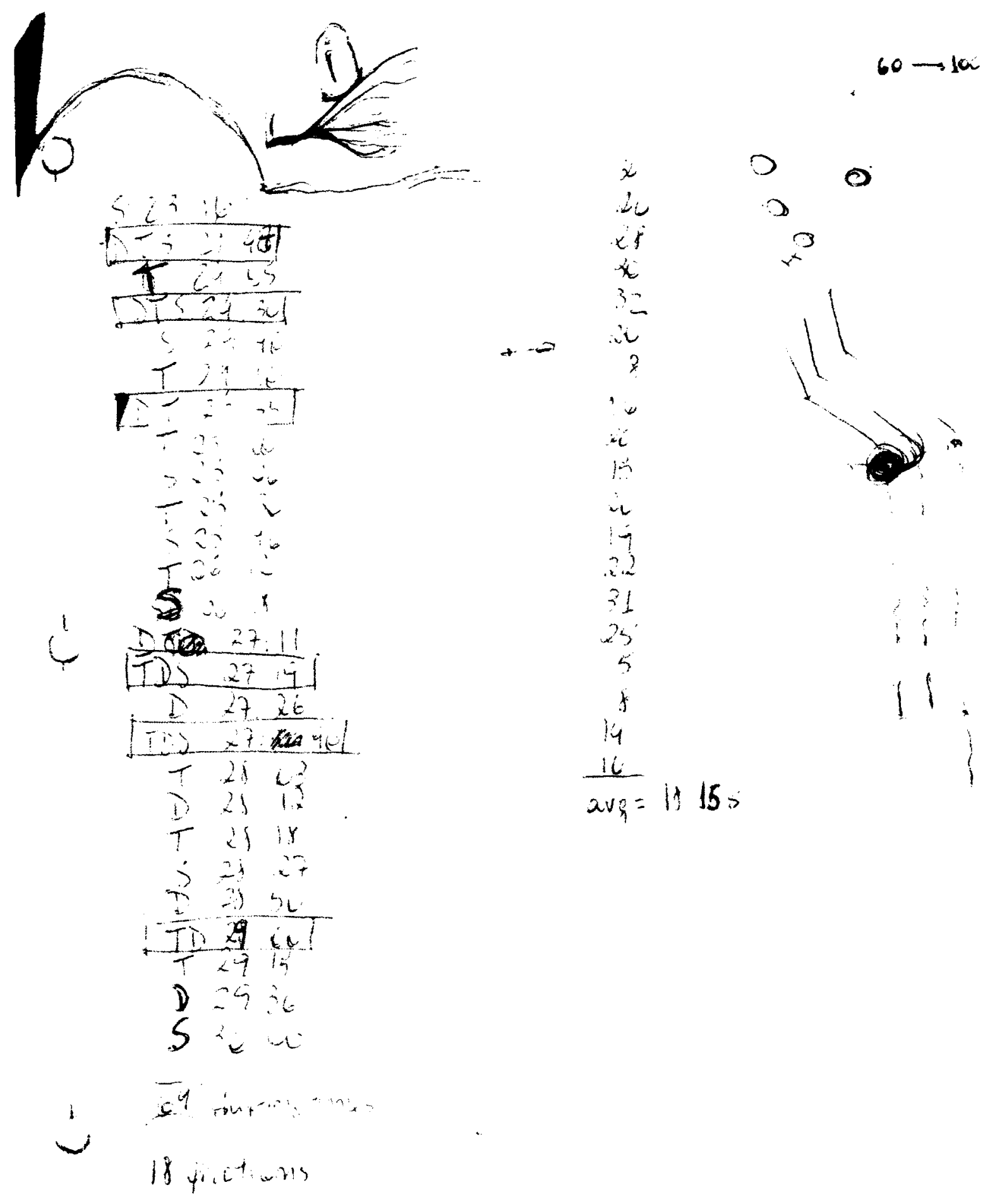




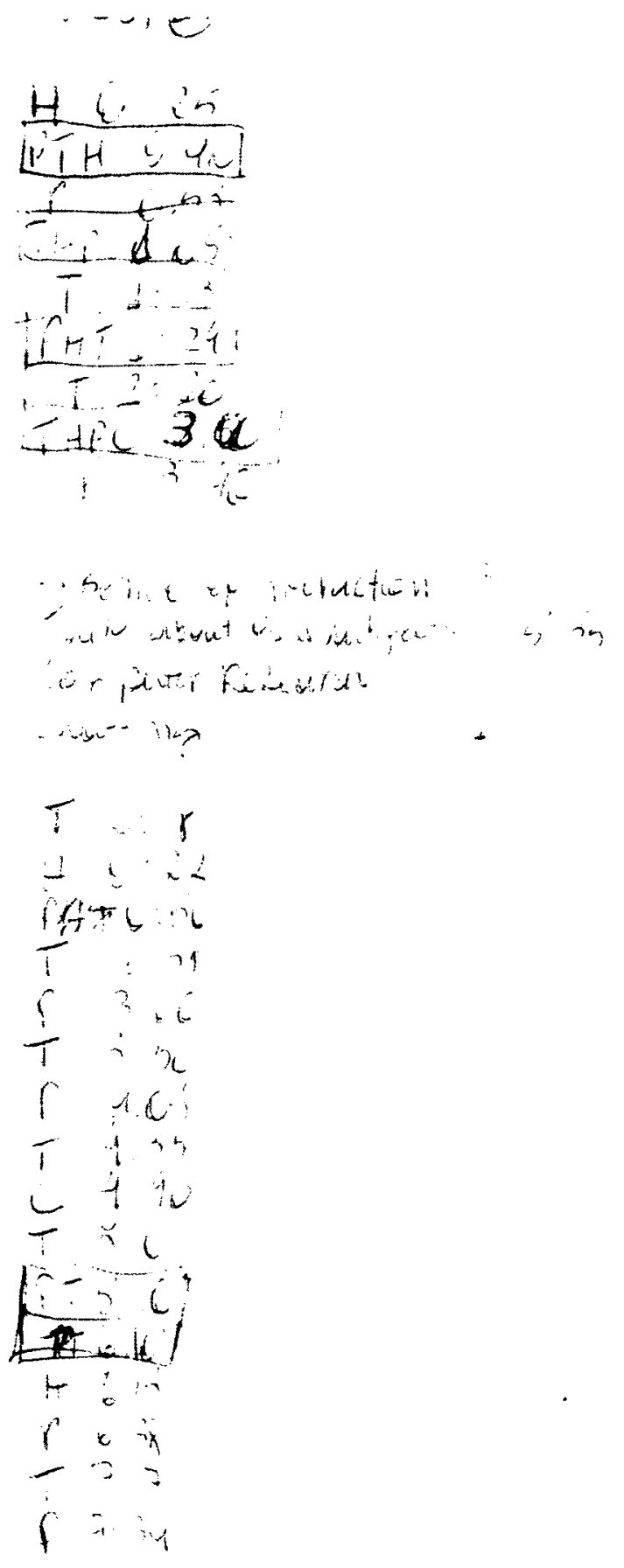




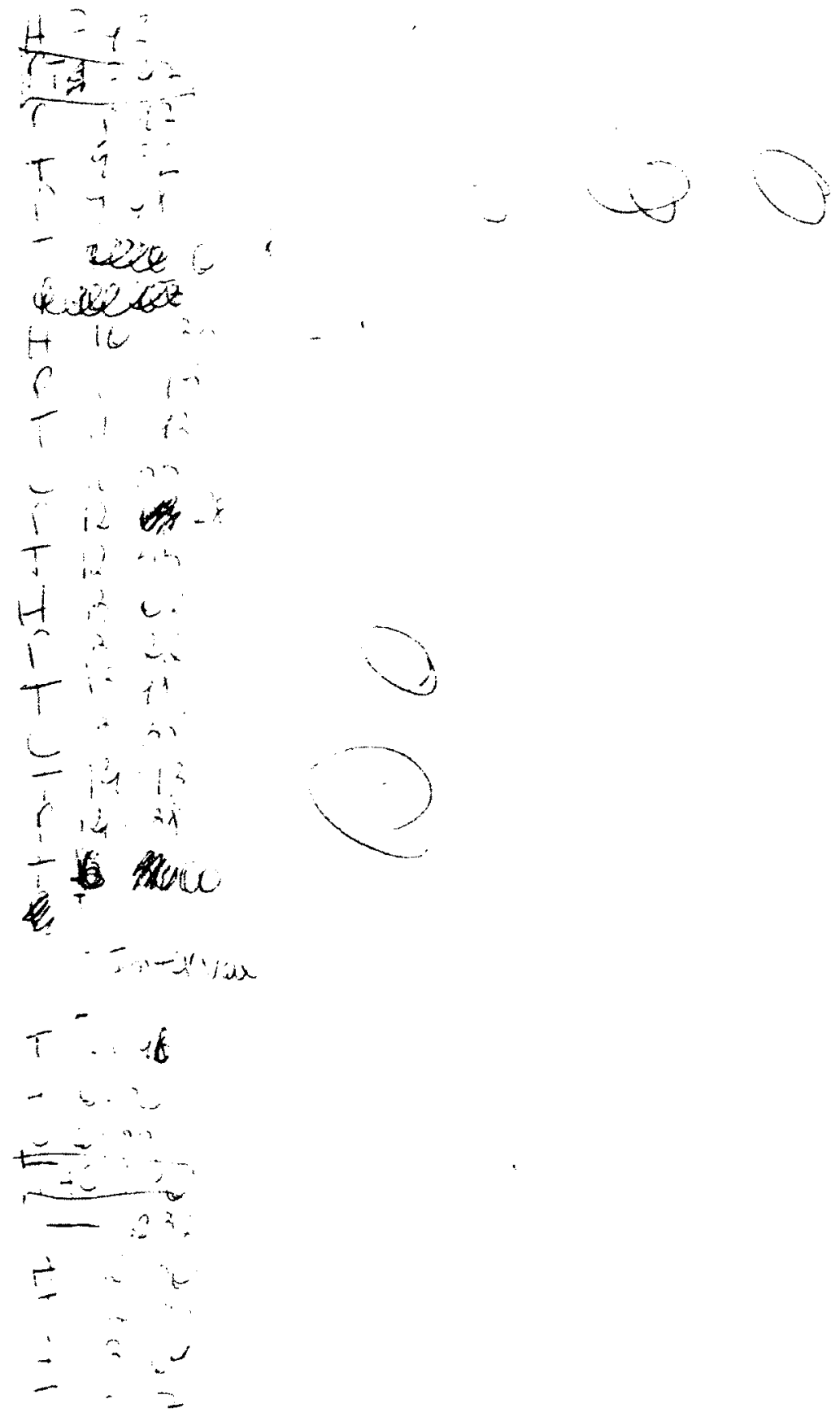




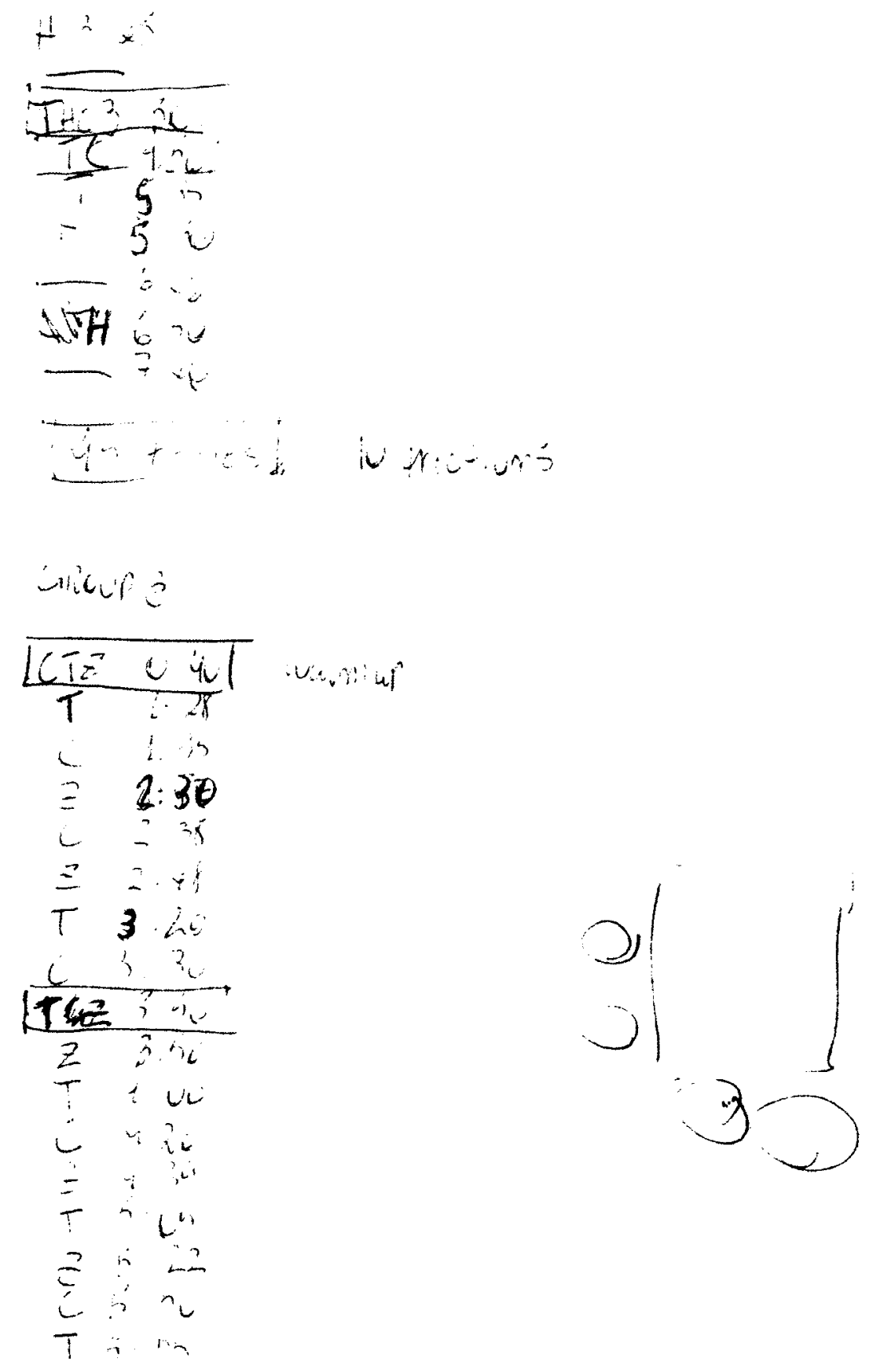




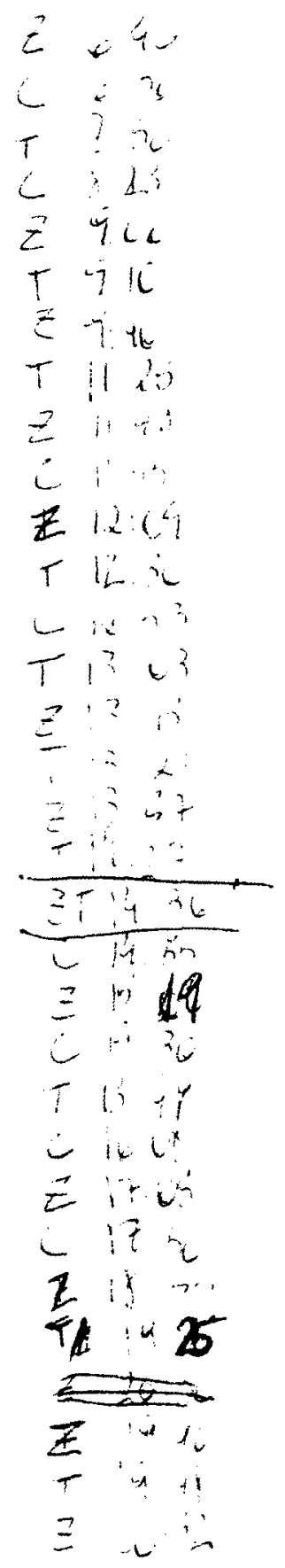




$$
\begin{aligned}
& T 2 u \\
& \text { ב } \\
& T: 4 \\
& =\ldots u \\
& \text { L - } 34 \\
& \text { C is } 08 \\
& \text { C. } 643
\end{aligned}
$$

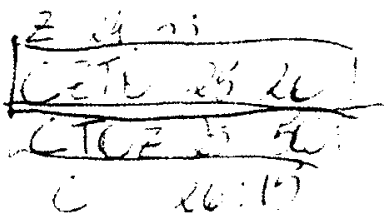

$$
\begin{aligned}
& =\quad 26.23 \\
& T \quad i j \cdot 4 i \\
& \text { L } \quad 2 d \\
& =27 \times 3 \\
& \text { T } 27 \text { ic } \\
& \text { i }-14 \\
& \frac{15 x+4 x}{2+140} \\
& \text { coi in } \\
& c \text { ic }
\end{aligned}
$$

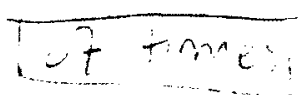

$$
\begin{aligned}
& \because+y+\text { ins }
\end{aligned}
$$

